\title{
Assessing the Influence of Coronary Heart Disease Knowledge, Perception of Personal Risk, and Delay Discounting of Future Health on Diet and Physical Activity
}

Kimberly Bosworth Blake

West Virginia University

Follow this and additional works at: https://researchrepository.wvu.edu/etd

\section{Recommended Citation}

Blake, Kimberly Bosworth, "Assessing the Influence of Coronary Heart Disease Knowledge, Perception of Personal Risk, and Delay Discounting of Future Health on Diet and Physical Activity" (2010). Graduate Theses, Dissertations, and Problem Reports. 4564.

https://researchrepository.wvu.edu/etd/4564

This Dissertation is protected by copyright and/or related rights. It has been brought to you by the The Research Repository @ WVU with permission from the rights-holder(s). You are free to use this Dissertation in any way that is permitted by the copyright and related rights legislation that applies to your use. For other uses you must obtain permission from the rights-holder(s) directly, unless additional rights are indicated by a Creative Commons license in the record and/ or on the work itself. This Dissertation has been accepted for inclusion in WVU Graduate Theses, Dissertations, and Problem Reports collection by an authorized administrator of The Research Repository @ WVU.

For more information, please contact researchrepository@mail.wvu.edu. 
Assessing the Influence of Coronary Heart Disease Knowledge, Perception of Personal Risk, and Delay Discounting of Future Health on Diet and Physical Activity

Kimberly Bosworth Blake

\author{
Dissertation Submitted to the School of Pharmacy \\ at West Virginia University
}

in partial fulfillment of the requirements for the degree of

Doctor of Philosophy

in

Pharmaceutical \& Pharmacological Sciences

Carole V. Harris, PhD, Chair

S. Suresh Madhavan, MBA, PhD

Cindy Tworek, PhD, MPH

Anoop Shankar, MD, PhD

Laura Davisson, MD

Department of Pharmaceutical Systems and Policy

\author{
Morgantown, West Virginia \\ 2010
}

Keywords: Diet, physical activity, perceived risk, and delay discounting Copyright 2010 Kimberly Bosworth Blake 


\begin{abstract}
Assessing the Influence of Coronary Heart Disease Knowledge, Perception of Personal Risk, and Delay Discounting of Future Health on Diet and Physical Activity
\end{abstract}

Kimberly Bosworth Blake

Although modifiable risk factors for coronary heart disease (CHD) can be favorably impacted by healthful diet and physical activity, health care providers face a population that generally exhibits unhealthy eating habits and sedentary lifestyles. Identifying strategies to improve the effectiveness of health care provider guidance is urgently needed to reduce CHD risk. The objective of this series of studies was to determine the association between CHD knowledge, perceived risk, and delay discounting and diet and physical activity (PA) levels in adults. The research design was cross-sectional and the methods included an online survey to obtain information regarding CHD knowledge, perceived risk, and preventive behaviors and a binary choice discounting procedure to elicit degree of discounting for hypothetical monetary and health rewards in an Appalachian population. The specific aims of the studies were: (1) To determine the association between knowledge and perceived risk of $\mathrm{CHD}$ and diet and PA in Appalachians, and (2) To evaluate the association between the degree of discounting of future health and diet and PA. In the first two studies, overall knowledge of CHD was positively correlated with both healthfulness of diet and PA levels, but these associations were no longer significant after controlling for demographic factors and other components of the HBM, including perceived risk of CHD, perceived severity of $\mathrm{CHD}$, perceived benefits and barriers to preventive behaviors, self-efficacy, and cue to action. Contrary to the direction of association predicted by the HBM, perceived risk was negatively associated with diet and PA behaviors. Age, perceived barriers, selfefficacy and physician recommendations for lifestyle changes may also play a role based on their significance as predictors of dietary or PA behaviors. In the third study, degree of delay discounting was not associated with CHD preventive behaviors, specifically diet and PA. Perceived risk was negatively associated with preventive behaviors, but no association with degree of discounting was shown. When associations between value of the future and preventive behaviors were explored by BMI category, a positive correlation was demonstrated between value of the future and dietary behavior in underweight/healthy participants, but no association was found in overweight/obese participants. 


\section{DEDICATION}

I dedicate this dissertation to my mom, Gwen, my dad, Johnny, and my brother, Rick, who have made me who I am today, and to my best friend, Jake, without whom this would not have been possible. 


\section{ACKNOWLEDGEMENTS}

There are several individuals I would like to acknowledge for their contributions to this project. First, I want to thank my major advisor and chair, Dr. Carole Harris, for the training, guidance and friendship she has provided over the past two years. Her confidence in my abilities allowed me to step outside my comfort zone and explore an emerging area of research, and for that I am truly grateful.

I also want to thank my committee members, Drs. Suresh Madhavan, Cindy Tworek, Anoop Shankar and Laura Davisson. Dr. Madhavan always encouraged me to strive for excellence in my education and career. Dr. Tworek provided wonderful guidance as both a faculty mentor and friend. Dr. Shankar's analytical input and Dr. Davisson's clinical expertise were invaluable.

I would also like to acknowledge Mark Bolding, who provided programming support for the delay discounting procedure, and Angie Frame, who helped me keep track of the funds. I would like to express my sincere appreciation for my graduate school family - Dr. Ginger Scott, my fellow PSP graduate students, and faculty, staff

and students in the Health Research Center, all of whom provided their friendship and support over the past four years.

And finally, I want to thank God, who has shown me the path to take and provided the strength I needed to follow it. 


\section{TABLE OF CONTENTS}

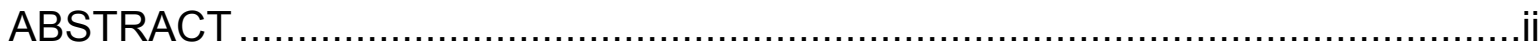

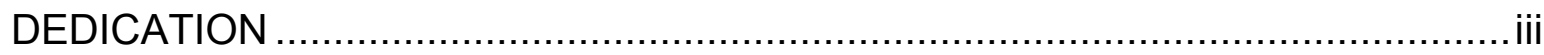

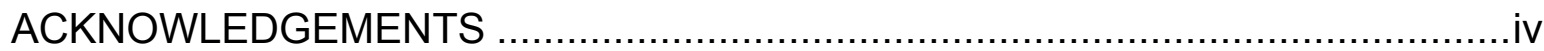

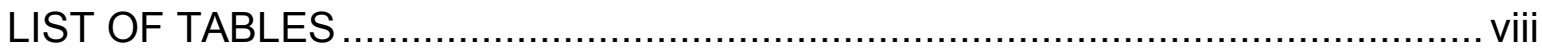

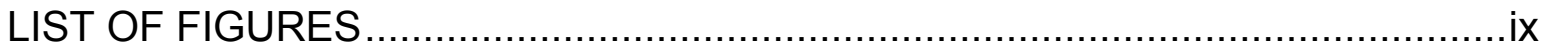

CHAPTER I: BACKGROUND AND SIGNIFICANCE $\ldots \ldots \ldots \ldots \ldots \ldots \ldots \ldots \ldots \ldots \ldots \ldots .2$

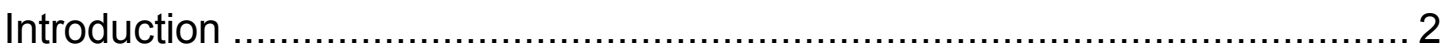

Modifiable Risk Factors for Coronary Heart Disease ............................ 3

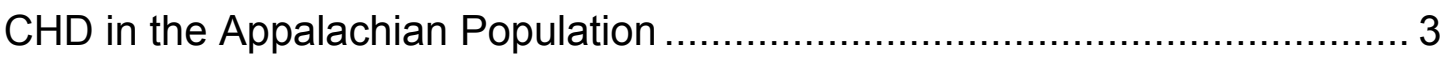

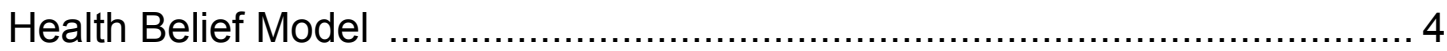

History of the Model ................................................................. 4

Components of the Model ........................................................ 4

Association between CHD Knowledge and Preventive Behaviors.... 5

Association between Perceived Risk of CHD and Preventive

Behaviors ............................................................................. 6

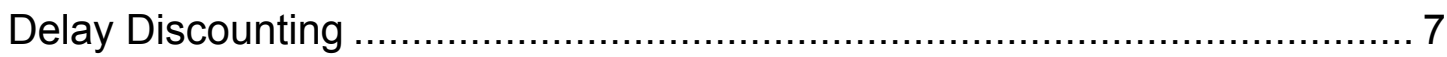

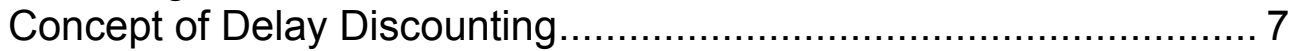

Biases in Delay Discounting .............................................. 8

Delay Discounting in Addictive Behaviors ................................ 9

Delay Discounting in Preventive Health Behaviors ...................... 9

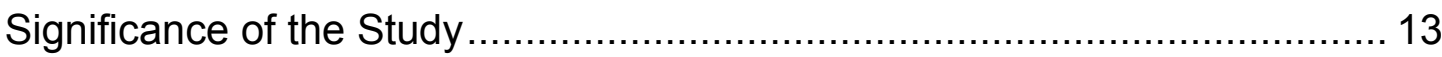

Methods to Incorporate Time Preference into Patient Education ..... 13

Methods to Incorporate Time Preference into Health Policy and

Environmental Change .................................................... 14

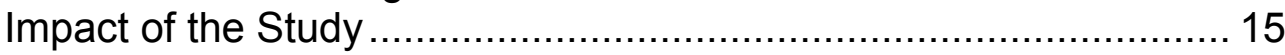

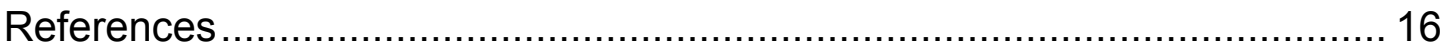

CHAPTER 2: ASSOCIATION AMONG CORONARY HEART DISEASE KNOWLEDGE, PERCEIVED RISK OF CORONARY HEART DISEASE AND DIETARY BEHAVIOR 


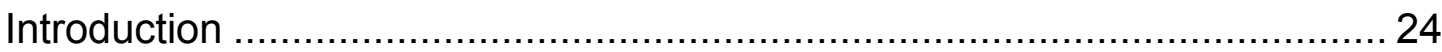

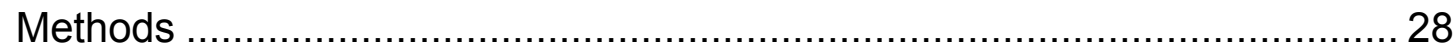

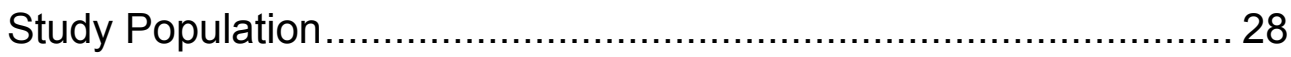

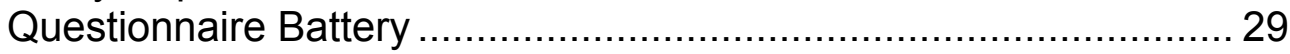

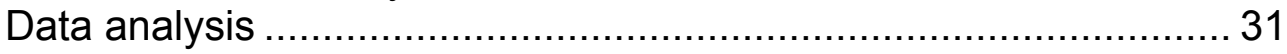

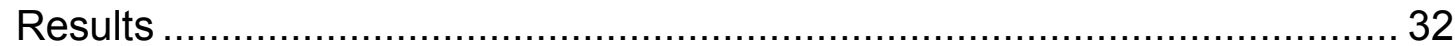

Demographics of the Sample ................................................. 32

Dietary Behavior and HBM Component Scales ............................... 33

Examination for Outliers and Normality of Distributions...................... 34

Correlations and Mean Comparisons ........................................... 34

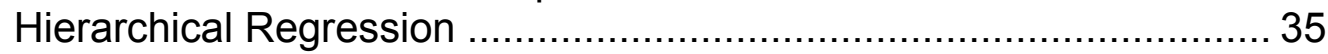

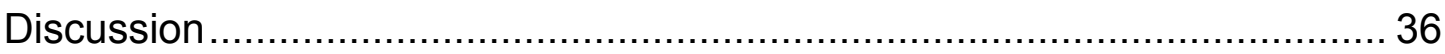

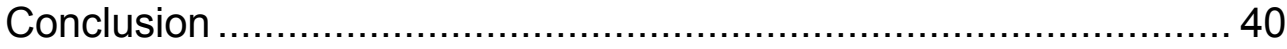

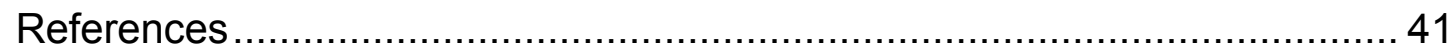

CHAPTER 3: USE OF THE HEALTH BELIEF MODEL TO EXPLAIN PHYSICAL ACTIVITY BEHAVIOR: WHAT IS THE ASSOCIATION WITH CORONARY HEART DISEASE KNOWLEDGE AND PERCEIVED PERSONAL RISK? ...51

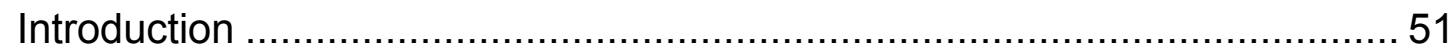

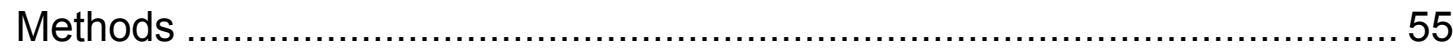

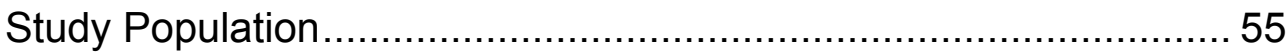

Questionnaire Battery ........................................................ 56

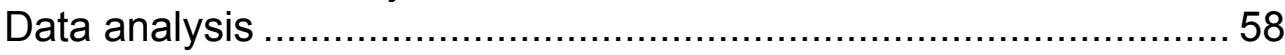

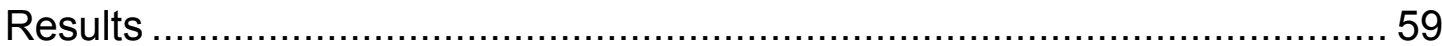

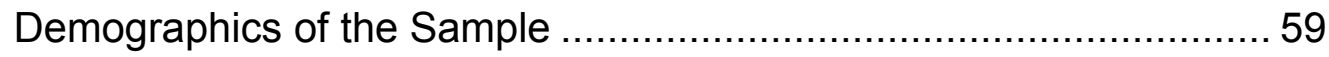

Physical Activity and HBM Component Scales................................ 59

Examination for Outliers and Normality of Distributions.....................6 60

Correlations and Mean Comparisons ............................................ 61

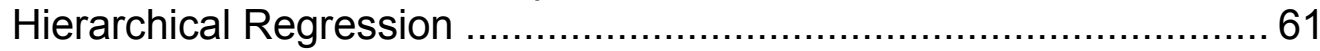

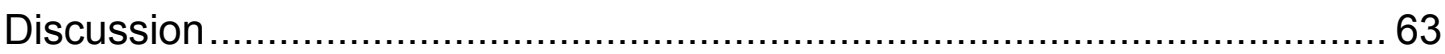

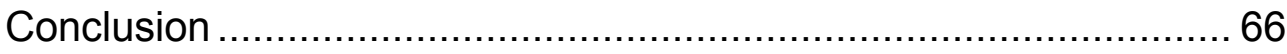

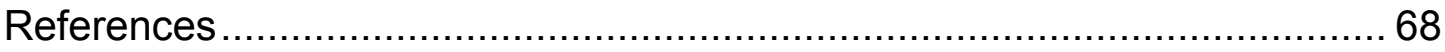

CHAPTER 4: ASSOCIATION BETWEEN DELAY DISCOUNTING AND DIETARY AND PHYSICAL ACTIVITY BEHAVIORS ............................................ 79

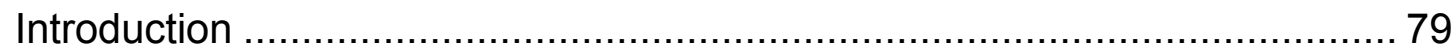




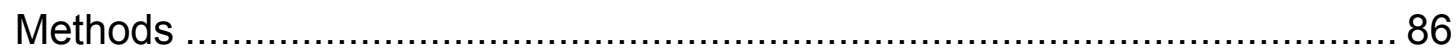

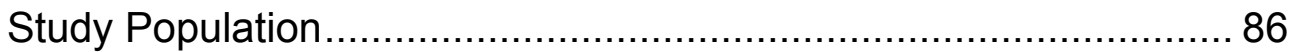

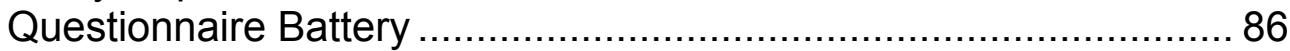

Delay Discounting Procedure ............................................... 88

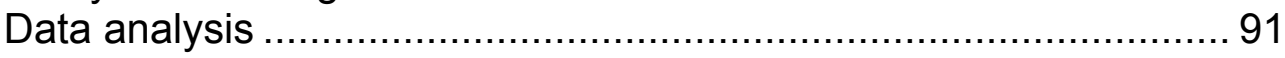

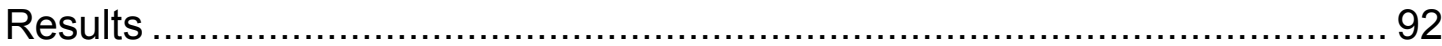

Demographics of the Sample .................................................... 92

Examination for Outliers and Normality of Distributions..................... 92

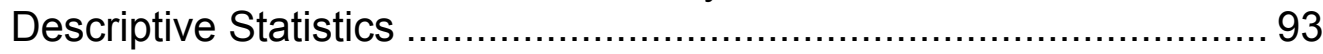

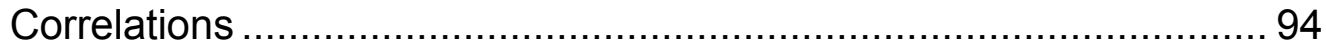

Hierarchical Regressions - Diet .............................................. 95

Hierarchical Regressions - Physical Activity ................................. 96

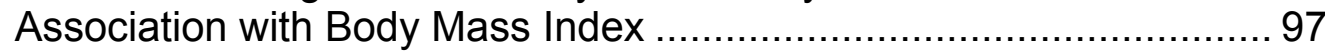

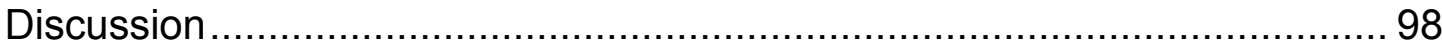

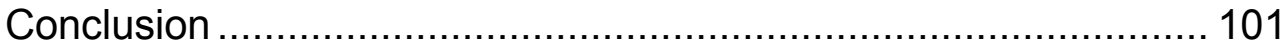

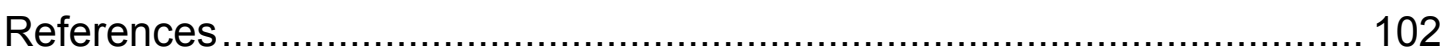

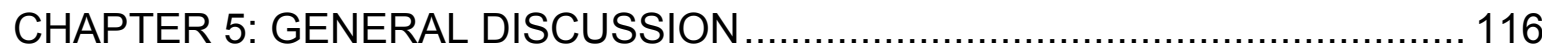

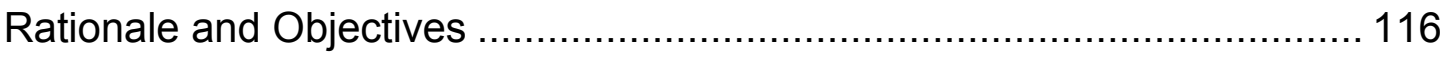

Summary of Findings ................................................................... 117

CHD Knowledge, Perceived Risk of CHD, and Diet and Physical

Activity (PA) Behaviors ........................................................ 117

Degree of Delay Discounting and Diet and PA Behaviors ............. 118

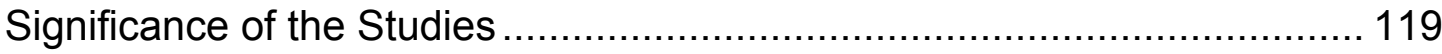

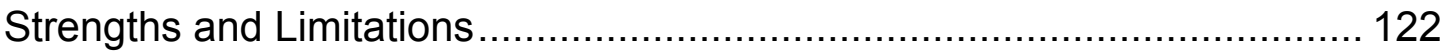

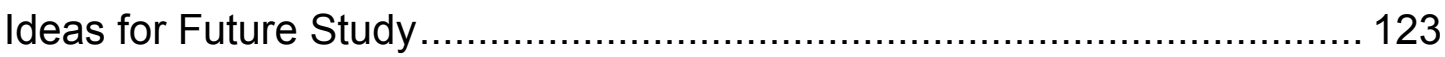

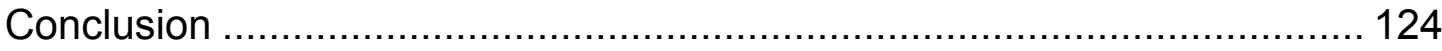

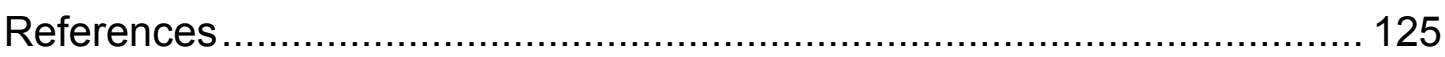

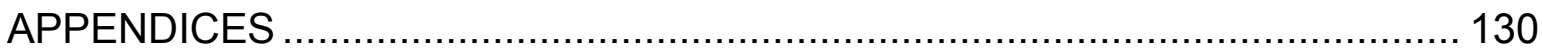

Appendix A. Online Questionnaire Conducted using Survey Monkey ......... 131

Appendix B. Delay Discounting Procedure Part 1 - Monetary Rewards ..... 158

Appendix C. Delay Discounting Procedure Part 2 - Health Rewards ......... 164 


\section{LIST OF TABLES}

Table 2.1. Descriptive Characteristics of the Sample 46

Table 2.2. Components of the Health Belief Model and Instruments used for Measurement

Table 2.3. Pearson Correlations 48

Table 2.4. Hierarchical Regression - Food Behavior Checklist Score as Dependent Variable 49

Table 3.1. Descriptive Characteristics of the Sample. 74

Table 3.2. Components of the Health Belief Model and Instruments used for Measurement

Table 3.3. Pearson Correlations

Table 3.4. Hierarchical Regression - Square Root of Physical Activity Score as Dependent Variable ........................................................... 77

Table 4.1. Descriptive Characteristics of the Sample. 108

Table 4.2. Components of the Health Belief Model and Instruments used for Measurement. 109

Table 4.3. Pearson Correlations 110

Table 4.4. Hierarchical Regression - Association between Discounting of Monetary Rewards and Diet Score $(n=168)$.

Table 4.5. Hierarchical Regression - Association between Discounting of Health Rewards and Diet Score $(n=168)$

Table 4.6. Hierarchical Regression - Association between Discounting of Monetary Rewards and Physical Activity Score $(n=163)$

Table 4.7. Hierarchical Regression - Association between Discounting of Health Rewards and Physical Activity Score $(n=163)$ 


\section{LIST OF FIGURES}

Figure 2.1. The Health Belief Model (adapted from Rosenstock, 1974) .............. 45

Figure 3.1. The Health Belief Model (adapted from Rosenstock, 1974) ...............73 
CHAPTER 1 


\section{CHAPTER 1:}

\section{BACKGROUND AND SIGNIFICANCE}

\section{Introduction}

In February of 2010, the American Heart Association (AHA) published its Strategic Impact Goal for 2020, which is to improve the cardiovascular health of all Americans by $20 \%$ while reducing deaths from cardiovascular diseases (CVD) and stroke by $20 \%{ }^{1}$ CVD includes coronary heart disease (CHD) as well as congenital heart disease and venous thromboembolic disease. Cardiovascular health is defined by the AHA as absence of clinical CVD, combined with simultaneous presence of 4 favorable health factors and 4 favorable health behaviors. The health factors considered in this definition include abstinence from smoking in the past 12 months, total cholesterol $<200 \mathrm{mg} / \mathrm{dL}$, blood pressure $<120 /<80 \mathrm{~mm} \mathrm{Hg}$, and fasting blood glucose $<100 \mathrm{mg} / \mathrm{dL}$. It is important to note that the definition does not include those who achieve ideal levels of these health factors through drug therapy, recognizing the benefit of having maintained or achieved ideal levels of these health factors throughout the individual's lifetime. The specific health behaviors considered in the definition of cardiovascular health include abstinence from smoking in the past 12 months, ideal body mass index $\left(<25 \mathrm{~kg} / \mathrm{m}^{2}\right)$, physical activity (PA) levels at goal (at least 150 minutes of moderate intensity or 75 minutes of vigorous intensity PA per week), and a dietary pattern that promotes cardiovascular health. Abstinence from smoking is considered both as a health behavior and a health factor due to its importance as a significant contributor to cardiovascular health. 


\section{Modifiable Risk Factors for Coronary Heart Disease}

As the leading cause of death in both men and women in industrialized nations, coronary heart disease (CHD) carries with it substantial negative clinical, economic, and

humanistic consequences. ${ }^{2-4}$ Fortunately, many risk factors for $\mathrm{CHD}$ are modifiable with lifestyle changes and drug therapy. Modifiable risk factors have been shown to account for over $90 \%$ of the risk of initial acute myocardial infarction. ${ }^{5}$ Lowering the prevalence of these modifiable risk factors would lead to a substantial decrease in morbidity and mortality from coronary heart disease. ${ }^{1}$ Behavioral risk factors are often the target of individual interventions (patient counseling delivered by health care providers and other health educators), as well as population-level interventions (through policy implementation or environmental change) with the purpose of producing changes in behavior necessary to reduce risk of CHD. Despite these efforts, lifestyle modifications can be difficult to adopt and even more difficult to maintain. A report by the Centers for Disease Control and Prevention states that maintenance of recommended lifestyle changes, including smoking cessation, medication adherence, diet, and exercise, was only $25-40 \%$ six months after initiation. ${ }^{6}$

\section{CHD in the Appalachian Population}

The Appalachian region of the United States has been associated with a history of underdevelopment, leading to rurality, lower levels of socioeconomic status and education, and greatly increased rates of premature death. ${ }^{7}$ Although economic 
conditions have improved over the last several decades, the Appalachian region still fares worse than other regions of the United States in health outcomes related to coronary heart disease.$^{8}$ A culture of unhealthy lifestyle, including poor diet and sedentary behavior, are contributors to this trend. ${ }^{9,10}$

\section{Health Belief Model}

History of the Model

Individual behavior change theories, such as the Health Belief Model (HBM), propose that factors such as individual perceptions of disease and costs vs. benefits of adopting health promoting behaviors together influence the likelihood an individual will make the desired behavior change. ${ }^{11}$ The HBM was first described in the 1950 s by Hochbaum, Rosenstock, Leventhal and Kegeles, researchers for the United States Public Health Service, and was expanded in 1974 by Marshall Becker of Johns Hopkins University. ${ }^{12}$

Components of the Model

There are 6 main components to the model: perceived severity is the degree to which an individual believes the consequences of the health problem in question will be severe if left unchecked; perceived susceptibility (or perceived risk) is the degree to which an individual believes he or she is personally at risk for having the health problem; perceived benefits are the positive outcomes an individual expects will result 
from taking the proposed action; perceived barriers are both the negative outcomes an individual believes may result from the action (costs), and any roadblocks he or she may face when attempting to adopt the behavior; cues to action are any external events or messages that motivate an individual to take preventive action; and self-efficacy is an individual's confidence in his or her ability to adopt the proposed behavior. According to a review of HBM research by Janz and Becker, ${ }^{13}$ the most important components of the model in explaining health behavior are, in order of importance, perceived barriers, perceived risk, perceived benefits, and perceived severity. Factors demonstrated to modify the influence of these components on health behaviors include demographic (age, gender, ethnicity), sociopsychological (personality, social class, peer groups), and structural factors (knowledge about the health problem and prior experience). ${ }^{11}$

\section{Association between CHD Knowledge and Preventive Behaviors}

According to the HBM, an individual's knowledge of CHD (risk factors, clinical consequences, and positive effects of lifestyle changes) can improve the likelihood of adopting preventive behaviors by modifying perceptions of susceptibility, severity, benefits and barriers. ${ }^{11}$ Studies assessing the relation between knowledge of $\mathrm{CHD}$ and preventive behaviors have demonstrated a positive association. Two studies in women with no prior history of CHD demonstrated a significant association between $\mathrm{CHD}$ knowledge and health promoting behaviors, including diet and PA. ${ }^{14,15}$ Another study in rural African-American men and women showed a significant association between knowledge of dietary risk factors of heart disease and healthy dietary practices. ${ }^{16}$ 
However, an association between CHD knowledge and preventive behavior was not demonstrated in a study in women with a current diagnosis of CHD, suggesting a possible lack of influence of knowledge once an individual has been diagnosed. ${ }^{17}$ In addition, no association between reported levels of physical activity and knowledge of the relevance of physical activity to the development of heart disease was found in a study of college students. ${ }^{18}$ The relative youth of the study population (ages ranged from 17 to 30 years) may help explain the lack of association. These studies demonstrate a potential association between CHD knowledge, diet and physical activity, but more research is needed to fully elucidate the relative strength of these associations and the factors which modify the relationships.

Association between Perceived Risk of CHD and Preventive Behaviors

The HBM also states that perception of personal risk of CHD is influential in the adoption of risk-reducing behaviors. The association between perceived personal risk of CHD and health promoting behavior has not been extensively studied, and the few existing studies show conflicting results. A significant correlation between perceived susceptibility and preventive behavior was demonstrated in women without prior history of heart disease, with perceived susceptibility alone accounting for more than half of the variance in preventive behavior. ${ }^{15}$ In contrast, another study showed an increased likelihood of visiting a health care provider in the past year in women who perceived themselves at high risk for heart disease, but no association between high perceived risk and actions to improve diet or physical activity. ${ }^{19}$ A study in women with CHD 
demonstrated similar findings, with no significant correlation between perceived risk and diet, PA, and other risk-reducing behaviors. ${ }^{17}$ No significant association was demonstrated between perceived risk of $\mathrm{CHD}$ and session attendance in a $\mathrm{CHD}$ exercise program. ${ }^{20}$ In a prospective study assessing readiness for exercise adoption, a significant negative correlation was demonstrated between perceived heart disease risk and exercise adoption in men between the ages of 20 and 40, but no significant correlation in men over $40 .{ }^{21}$ Perceived risk of CHD was assessed among college students and was shown to be significantly positively correlated with diet regulation in students identified as having Type B personality, whereas no significant correlation was found in students identified as having Type A personality. ${ }^{22}$ These studies suggest that other factors, such as prior diagnosis of CHD and age, modify the influence of perceived risk on health promoting behaviors in individuals.

\section{Delay Discounting}

Concept of Delay Discounting

Delay discounting refers to the idea that individuals will discount the future to varying degrees depending on how far into the future rewards are received. This phenomenon is also known as time preference. A high rate of discounting indicates an individual's preference toward more immediate rewards and a lower value placed on the future. Traditional Discounted Utility Theory states that individuals discount the future at a constant rate per unit of delay (exponential discounting function). ${ }^{23}$ With exponential discounting, relative preference for future outcomes will not change as the timing of the 
choice of outcome moves in closer proximity to the receipt of the outcome. Contrary to this theory, research has demonstrated that actual behavior follows a more hyperbolic discounting function, where rewards are discounted more steeply in the near future, leveling off as delay to reward increases. ${ }^{24}$ The implication of this discrepancy is that a preference reversal can occur, in which an individual changes his or her preference from the smaller, sooner reward (SSR) to the larger later reward (LLR) as delay to the SSR increases.

\section{Biases in Delay Discounting}

Several biases related to how people discount health and money have been identified based on an accumulated body of literature incorporating both real and hypothetical rewards, and should be considered when applying delay discounting to health behaviors. Chapman and Elstein highlight four such biases: magnitude effect refers to the finding that individuals tend to discount small rewards to a greater degree than large rewards; sign effect refers to the tendency for individuals to discount gains more than losses; sequence effect describes the tendency for discount rates to be lower when outcomes are framed as a series of sequential outcomes, rather than a single outcome; and lastly, domain effect indicates that individuals tend to discount health to a greater degree than money. ${ }^{25}$ 


\section{Delay Discounting in Addictive Behaviors}

Degree of delay discounting has been examined in regard to several negative health behaviors, and has been found to be greater in smokers, ${ }^{26}$ alcohol abusers, ${ }^{27}$ and illicit drug users ${ }^{28}$ compared to controls. For example, one study demonstrated that current smokers have a significantly higher rate of discounting of monetary rewards compared to ex- and never-smokers. ${ }^{26}$ Neuroimaging studies have investigated the association between delay discounting and activation of specific portions of the brain involved in impulsive choice. A study in abstinent alcoholics and non-substance abusing controls demonstrated a significant positive correlation between impulsive choice and activity in particular portions of the brain (the dorsal prefrontal cortex, the posterior parietal cortex, and the anterior parahippocampal gyrus), suggesting a possible biological mechanism for this behavior. ${ }^{29}$ In addition to these effects in addictive disorders, discount rates have also been shown to be greater in children with Attention Deficit/Hyperactivity Disorder compared to controls. ${ }^{30}$

\section{Delay Discounting in Preventive Health Behaviors}

Despite a growing body of literature on delay discounting in addictive behaviors, there have been relatively few studies of delay discounting in preventive health behaviors. In an early exploratory study by Fuchs, rate of delay discounting was not found to be associated with seat belt use, exercise frequency, being overweight, or frequency of dental visits. ${ }^{31}$ However, the author suggested that the method used to 
elicit discount rates in this study was flawed, leading to inconsistent results and the suggestion to refine survey methods, specifically, increasing the number of binary choices in future research. A more recent investigation by Chapman with 60 community-members in Chicago found a significant association between exercise frequency and discount rate, but in the counter-predicted direction. ${ }^{32}$ In this research, participants completed discounting procedures for both health and monetary rewards, and were asked how many times per week they exercised, and how long they exercised during each session. Approximately half of the participants were recruited from an exercise class, possibly biasing the sample. Chapman suggested that the discrepancy in significance of association between discount rate and addictive behaviors compared to other health behaviors may be explained by the effect of addiction on time preferences, rather than vice versa. ${ }^{33}$ In other words, an addictive substance itself may increase tendency to make impulsive choices (and thus produce a higher discount rate), due to biological effects on the brain. This idea is reinforced by research that has shown a decrease in discount rate with prolonged abstinence from addictive substances. $^{34}$

In a large, nationally-representative sample of adults, degree of time preference explained more of the variance in diet quality than market or socio-cultural factors and was found to be a significant predictor of healthfulness of diet. ${ }^{35}$ However, time preference was not measured directly, but assessed using proxy variables, including education, smoking, exercise, nutrition knowledge, and regular use of nutrition labels. Selection of these variables was based on their theoretical association with time 
preference, and the authors suggest that studies utilizing more direct measures of future discounting are needed.

A pilot study of patients with hypertension revealed a significant association between discount rate and likelihood of altering diet and exercise behaviors. ${ }^{36}$ In this study, implicit discount rates were inferred using five binary choice questions and imputed using interval regression. Individuals with an imputed discount rate in the highest quintile were compared to those with rates in the four lowest quintiles. However, likelihood of diet- and exercise-related behavior change was assessed indirectly using a single item that asked whether the individual would rather eat, drink, and live life the way they want and have poorer health in 5 years, or would rather forgo these habits and enjoy better health in 5 years. A more recently published study, conducted in a sample of adults 50 years of age or older and their spouses or partners, utilized a similar method to assess discount rates and demonstrated a significant association between high discount rate and lower rates of healthy behaviors, including weekly vigorous physical activity. ${ }^{37}$ Health maintenance behaviors were assessed using data from the Health and Retirement Survey, and included mammograms, breast examinations, Pap smears, prostate examinations, dental visits, cholesterol testing, flu shots, and non-smoking status, in addition to physical activity. Higher discount rates were associated with significantly lower rates of all healthy behaviors, except for breast examination and Pap smears in women.

Several studies have also demonstrated a significant association between time preference and obesity. ${ }^{38-41}$ Other studies have not found a significant association between time preference and obesity. ${ }^{42,43}$ While these studies may suggest that delay 
discounting is associated with diet and physical activity behaviors, they did not look specifically at these behaviors. More research is needed to better understand the influence of delay discounting on preventive behaviors and obesity.

Axon, Bradford, and Egan suggest that degree to which individuals value the future relative to the present is an important attitudinal factor that should be incorporated into frameworks for health promotion. ${ }^{36}$ Health behavior models, such as the HBM and others, have been criticized because they do not incorporate the concept of time preference. ${ }^{33}$ Decisions regarding adoption of health behavior may involve a mental cost-benefit analysis. ${ }^{44}$ According to the concept of delay discounting, delay to receipt of benefit is a salient factor in decision-making. Behaviors to prevent $\mathrm{CHD}$ lend themselves well to the theory of delay discounting because benefits of the behavior are delayed (decreased risk of future heart disease) and the opportunity costs of adopting the behavior are immediate (deprivation of pleasurable foods, increased meal preparation time, less time for sedentary activities, discomfort from physical exertion, etc). Among the most critical lifestyle changes needed to reduce CHD risk are adoption of a healthful diet and regular physical activity, as indicated by the AHA's new definition of cardiovascular health. ${ }^{1}$ A better understanding by health care providers and health educators of the factors that influence likelihood to adhere to lifestyle change recommendations could positively impact health behavior, thereby decreasing the societal burden of CHD. 


\section{Significance of the Study}

Methods to Incorporate Time Preference into Patient Education

Demonstration of an association between degree of delay discounting and likelihood of participation in preventive health behaviors would suggest that patient education strategies to counteract preference for immediate rewards would result in more successful attempts at behavior change. Bradford suggests that health messages that focus on proximal rather than long-term benefits may be more effective at motivating behavior change in individuals who are less future-oriented. ${ }^{37}$ Ortendahl and Fries suggest that framing of risk can influence degree of discounting, thus improving adherence to lifestyle changes. ${ }^{45}$ These same authors recommend that framing future health outcomes as large or important (utilizing magnitude effect) and framing health decisions as losses rather than gains (utilizing sign effect) may result in the individual choosing the course of action that improves long-term health. ${ }^{46}$

Given the tendency for preference reversal, any action which increases temporal distance between decision-making and receipt of the SSR (e.g., ice cream sundae) will improve the likelihood that an individual will forgo the SSR in favor of the LLR - in this case, long-term health. For instance, encouraging patients to shop at the grocery store for food that will be consumed in the upcoming week will result in choosing their food items days prior to consumption. This will decrease the chance that a tempting, unhealthful food item will be chosen over a more healthful alternative if presented immediately prior to consumption. Another method to encourage adherence to healthy lifestyle changes is the use of precommitment devices. Ariely and Wertenbach suggest 
that precommitment strategies can assist individuals in adhering to intended lifestyle modifications rather than giving in to immediate gratification. ${ }^{47}$ Precommitment to a desired behavior lengthens the temporal distance from the time of decision to the receipt of the SSR. This leads to a preference reversal, resulting in an increased likelihood that the individual will choose the more self-controlled option, i.e., long-term health. Monterosso and Ainslie suggest such strategies as (1) removal of the opportunity to engage in unwanted behavior (e.g., avoiding fast food restaurants), (2) making the unwanted behavior less desirable (e.g., announcing a resolution to a friend, which, if broken, would lead to embarrassment), or (3) partial precommitment, such as directing attention away from activities that prompt the unwanted behavior (e.g., avoiding watching too much television, which encourages sedentary behavior and snacking). ${ }^{48}$

Methods to Incorporate Time Preference into Health Policy and Environmental Change

It has been suggested that knowledge of mean discount rates for a specific population may be useful to inform the most effective means of health promotion intervention for that particular population. ${ }^{36}$ Based on a potentially negative impact of delay discounting on health behavior, one-size-fits-all public health education messages that do not address differences in individual time preferences may not be effective in people with high rates of future discounting. Messages that focus more on short-term benefits or increase the salience of future benefits may be more effective at motivating behavior change. 
Policy change at the level of employer-sponsored health plans could also utilize the concept of delay discounting to promote healthy behaviors. Changing the structure of financial incentives may increase the likelihood of adherence to health programs. For example, providing incentives with regular, frequent payouts rather than a single payout at some future time point may utilize bias toward immediate gains to counteract the impulse to engage in unhealthy behaviors. This strategy has been adopted by companies such as General Electric as part of their smoking cessation program. ${ }^{49}$ Environmental changes that reduce immediate "costs" of healthy choices may also have a positive impact on health behavior. These might include increased affordability of fruits and vegetables, access to fitness centers in the workplace, or improved walkability in communities.

\section{Impact of the Study}

This project is significant because it will contribute to our understanding of the factors that influence preventive behaviors, such as healthful diet and physical activity. Determining the factors that influence the association between CHD knowledge, perceived risk, degree of discounting of future health and diet and physical activity will address the gap in knowledge in these areas. The impact of this study is the development of more effective patient education strategies that can be used by healthcare providers and health educators to motivate changes necessary to reduce future health risks, as well as implementation of health policy and environmental changes that encourage healthful diet and physical activity behaviors. 


\section{References}

1. Lloyd-Jones DM, Hong Y, Labarthe D, et al. Defining and setting national goals for cardiovascular health promotion and disease reduction: the American Heart Association's strategic Impact Goal through 2020 and beyond. Circulation. Feb 2 2010;121(4):586-613.

2. Stone NJ. The clinical and economic significance of atherosclerosis. Am J Med. Oct 8 1996;101(4A):4A6S-9S.

3. Trogdon JG, Finkelstein EA, Nwaise IA, Tangka FK, Orenstein D. The economic burden of chronic cardiovascular disease for major insurers. Health Promot Pract. Jul 2007;8(3):234-242.

4. van Jaarsveld $\mathrm{CH}$, Sanderman R, Miedema I, Ranchor AV, Kempen GI. Changes in health-related quality of life in older patients with acute myocardial infarction or congestive heart failure: a prospective study. J Am Geriatr Soc. Aug 2001;49(8):1052-1058.

5. Yusuf S, Hawken S, Ounpuu S, et al. Effect of potentially modifiable risk factors associated with myocardial infarction in 52 countries (the INTERHEART study): case-control study. Lancet. Sep 11-17 2004;364(9438):937-952.

6. United States Department of Health and Human Services CDC. Physical Activity and Health: A Report of the Surgeon General. Atlanta, GA: Author; 1996.

7. Barnett E, Elmes GA, Braham VE, Halverson JA, Lee JY, Loftus S. Heart Disease in Appalachia: An Atlas of County Economic Conditions, Mortality, and 
Medical Care Resources. Morgantown, WV: Prevention Research Center, West Virginia University; 1998.

8. Halverson J, Ma L, Harner EJ. An analysis of disparities in health status and access to care in the Appalachian region. Washington, D.C.: Appalachian Regional Commission; 2004.

9. Amarasinghe A, D'Souza G, Brown C, Oh H, Borisova T. The influence of socioeconomic and environmental determinants on health and obesity: a West Virginia case study. Int J Environ Res Public Health. Aug 2009;6(8):2271-2287.

10. Wewers ME, Katz M, Fickle D, Paskett ED. Risky behaviors among Ohio Appalachian adults. Prev Chronic Dis. Oct 2006;3(4):A127.

11. Rosenstock I. Historical Origins of the Health Belief Model. In: Becker MH, ed. The Health Belief Model and Personal Behavior. Thorofare, NJ: Slack, Inc.; 1974.

12. Edberg M. Individual Health Behavior. In: Riegelman R, ed. Essentials of Health Behavior. Sudbury, MA: Jones and Bartlett; 2007:35-49.

13. Janz NK, Becker MH. The Health Belief Model: a decade later. Health Educ Q. Spring 1984;11(1):1-47.

14. Thanavaro JL, Moore SM, Anthony M, Narsavage G, Delicath T. Predictors of health promotion behavior in women without prior history of coronary heart disease. Appl Nurs Res. Aug 2006;19(3):149-155. 
15. Ali NS. Prediction of coronary heart disease preventive behaviors in women: a test of the health belief model. Women Health. 2002;35(1):83-96.

16. Pace R, Dawkins N, Wang B, Person S, Shikany JM. Rural African Americans' dietary knowledge, perceptions, and behavior in relation to cardiovascular disease. Ethn Dis. Winter 2008;18(1):6-12.

17. Oliver-McNeil S, Artinian NT. Women's perceptions of personal cardiovascular risk and their risk-reducing behaviors. Am J Crit Care. May 2002;11(3):221-227.

18. Haase A, Steptoe A, Sallis JF, Wardle J. Leisure-time physical activity in university students from 23 countries: associations with health beliefs, risk awareness, and national economic development. Prev Med. Jul 2004;39(1):182190.

19. Mosca L, Mochari H, Christian A, et al. National study of women's awareness, preventive action, and barriers to cardiovascular health. Circulation. Jan 31 2006;113(4):525-534.

20. Mirotznik J, Feldman L, Stein R. The health belief model and adherence with a community center-based, supervised coronary heart disease exercise program. $J$ Community Health. Jun 1995;20(3):233-247.

21. Lindsay-Reid E, Osborn RW. Readiness for exercise adoption. Soc Sci Med Med Psychol Med Sociol. Mar 1980;14A(2):139-146. 
22. O'Brien WH, VanEgeren L. Perceived susceptibility to heart disease and preventive health behavior among Type A and Type B individuals. Behav Med. Winter 1991;17(4):159-165.

23. Loewenstein G, Prelec D. Anomalies in intertemporal choice: Evidence and an interpretation. Q J Econ. May 1992;107(2):573-597.

24. Ainslie G. Specious reward: a behavioral theory of impulsiveness and impulse control. Psychol Bull. Jul 1975;82(4):463-496.

25. Chapman GB, Elstein AS. Valuing the future: temporal discounting of health and money. Med Decis Making. Oct-Dec 1995;15(4):373-386.

26. Bickel WK, Odum AL, Madden GJ. Impulsivity and cigarette smoking: delay discounting in current, never, and ex-smokers. Psychopharmacology (Berl). Oct 1999;146(4):447-454.

27. Vuchinich RE, Simpson CA. Hyperbolic temporal discounting in social drinkers and problem drinkers. Exp Clin Psychopharmacol. Aug 1998;6(3):292-305.

28. Madden GJ, Petry NM, Badger GJ, Bickel WK. Impulsive and self-control choices in opioid-dependent patients and non-drug-using control participants: drug and monetary rewards. Exp Clin Psychopharmacol. Aug 1997;5(3):256-262.

29. Boettiger CA, Mitchell JM, Tavares VC, et al. Immediate reward bias in humans: fronto-parietal networks and a role for the catechol-O-methyltransferase 158(Val/Val) genotype. J Neurosci. Dec 26 2007;27(52):14383-14391. 
30. Barkley RA, Edwards G, Laneri M, Fletcher K, Metevia L. Executive functioning, temporal discounting, and sense of time in adolescents with attention deficit hyperactivity disorder (ADHD) and oppositional defiant disorder (ODD). J Abnorm Child Psychol. Dec 2001;29(6):541-556.

31. Fuchs VR. Time preference and health: An exploratory study. NBER Working Paper No. W0539. Cambridge, MA: National Bureau of Economic Research; August 1980.

32. Chapman GB. Sooner or Later: The Psychology of Intertemporal choice. In: Medin DL, ed. The Psychology of Learning and Motivation. Vol 38. New York, NY: Academic Press; 1998:83-113.

33. Chapman GB. Short-term cost for long-term benefit: time preference and cancer control. Health Psychol. Jul 2005;24(4 Suppl):S41-48.

34. Petry NM. Delay discounting of money and alcohol in actively using alcoholics, currently abstinent alcoholics, and controls. Psychopharmacology (Berl). Mar 2001;154(3):243-250.

35. Huston SJ, Finke MS. Diet choice and the role of time preference. J Consum Aff. 2003;37(1):143-160.

36. Axon RN, Bradford WD, Egan BM. The role of individual time preferences in health behaviors among hypertensive adults: a pilot study. J Am Soc Hypertens. Jan-Feb 2009;3(1):35-41. 
37. Bradford WD. The association between individual time preferences and health maintenance habits. Med Decis Making. Jan-Feb 2010;30(1):99-112.

38. Komlos J, Smith PK, Bogin B. Obesity and the rate of time preference: is there a connection? J Biosoc Sci. Mar 2004;36(2):209-219.

39. Smith PK, Bogin B, Bishai D. Are time preference and body mass index associated? Evidence from the National Longitudinal Survey of Youth. Econ Hum Biol. Jul 2005;3(2):259-270.

40. Zhang L, Rashad I. Obesity and time preference: the health consequences of discounting the future. J Biosoc Sci. Jan 2008;40(1):97-113.

41. Weller RE, Cook EW, 3rd, Avsar KB, Cox JE. Obese women show greater delay discounting than healthy-weight women. Appetite. Nov 2008;51(3):563-569.

42. Nederkoorn C, Smulders FT, Havermans RC, Roefs A, Jansen A. Impulsivity in obese women. Appetite. Sep 2006;47(2):253-256.

43. Borghans L, Golsteyn BH. Time discounting and the body mass index. Evidence from the Netherlands. Econ Hum Biol. Jan 2006;4(1):39-61.

44. Loewenstein GF, Weber EU, Hsee CK, Welch N. Risk as feelings. Psychol Bull. Mar 2001;127(2):267-286.

45. Ortendahl M, Fries JF. Discounting and risk characteristics in clinical decisionmaking. Med Sci Monit. Mar 2006;12(3):RA41-45. 
46. Ortendahl M, Fries JF. Framing health messages based on anomalies in time preference. Med Sci Monit. Aug 2005;11(8):RA253-256.

47. Ariely D, Wertenbroch K. Procrastination, deadlines, and performance: selfcontrol by precommitment. Psychol Sci. May 2002;13(3):219-224.

48. Monterosso J, Ainslie G. The behavioral economics of will in recovery from addiction. Drug Alcohol Depend. Sep 2007;90 Suppl 1:S100-111.

49. Fuhrmans V. Training the brain to choose wisely. Wall Street Journal. April 28, 2009: D1. 
CHAPTER 2 


\section{CHAPTER 2:}

\section{ASSOCIATION AMONG CORONARY HEART DISEASE KNOWLEDGE, PERCEIVED RISK OF CORONARY HEART DISEASE AND DIETARY BEHAVIOR}

\section{Introduction}

As the leading cause of death in both men and women in industrialized nations, coronary heart disease (CHD) carries with it substantial negative clinical, economic, and

humanistic consequences. ${ }^{1-3}$ Fortunately, many risk factors for $\mathrm{CHD}$ are modifiable with lifestyle changes and drug therapy. Modifiable risk factors have been shown to account for over $90 \%$ of the risk of initial acute myocardial infarction. ${ }^{4}$ Such risk factors include behavioral factors (smoking, sedentary lifestyle, low fruit and vegetable consumption), physiologic factors (abdominal obesity, hypercholesterolemia, hypertension, diabetes), and psychosocial factors (depression, locus of control, perceived stress, life events). Lowering the prevalence of these modifiable risk factors would lead to a substantial decrease in morbidity and mortality from coronary heart disease. ${ }^{5}$

The Appalachian region of the United States has been associated with a history of underdevelopment, leading to rurality, lower levels of socioeconomic status and education, and greatly increased rates of premature death. ${ }^{6}$ Although economic conditions have improved over the last several decades, the Appalachian region still fares worse than other regions of the United States in health outcomes related to coronary heart disease. ${ }^{7}$ A culture of unhealthy lifestyle, including poor diet and sedentary behavior, are contributors to this trend..$^{8,9}$ 
Behavioral risk factors are often the target of individual interventions (patient counseling delivered by health care providers and other health educators), as well as population-level interventions (through policy implementation or environmental modifications) with the purpose of producing changes in behavior necessary to reduce risk of $\mathrm{CHD}$. For example, modification of diet to include adequate amounts of fruits, vegetables, fish and whole grains and reduced amounts of saturated fat, sodium, and sugar-sweetened beverages is recommended by the American Heart Association to achieve cardiovascular health. ${ }^{5}$ An emphasis has been placed on the effects of the whole diet and the importance of overall diet quality, given the multiple dietary factors that influence CHD risk. ${ }^{10}$ Among these effects are weight status, lipid profile, blood pressure, and blood glucose levels. The primary goals of lifestyle change recommendations are to achieve energy balance and adequate nutrition, thus avoiding these deleterious effects that impact heart disease risk. Barriers to these goals include environmental factors that contribute to excess caloric intake, such as larger portion sizes, decreased access to healthy food options, and easy access to high-fat, highcalorie foods. This emphasizes the importance of both individual changes in dietary behaviors as well as environmental changes to maximize the impact on risk of CHD.

Despite efforts to improve behavioral risk factors for $\mathrm{CHD}$, lifestyle modifications can be difficult to adopt and even more difficult to maintain. A report by the Centers for Disease Control and Prevention states that maintenance of recommended lifestyle changes, including smoking cessation, medication adherence, diet, and exercise, was only $25-40 \%$ six months after initiation. ${ }^{11}$ Individual behavior change theories, such as the Health Belief Model (HBM), propose that factors such as individual perceptions of 
disease and costs vs. benefits of adopting health promoting behaviors together influence the likelihood an individual will make the desired behavior change. ${ }^{12}$ Components of the HBM include: perceived severity, perceived susceptibility, perceived benefits, perceived barriers, cues to action, and self-efficacy. Factors demonstrated to modify the influence of these components on health behaviors include demographic (age, gender, ethnicity), sociopsychological (personality, social class, peer groups), and structural factors (knowledge of the health problem and prior experience).${ }^{12}$ (Fig. 2.1) Research using the HBM has indicated associations between model components and dietary behaviors, and specifically that knowledge ${ }^{13-17}$ and perceived personal risk of $\mathrm{CHD}^{14}$ are positively correlated with these behaviors. These findings have not been consistent across populations, however, suggesting that other factors, such as age and health status, may influence the associations.

According to the HBM, an individual's knowledge of CHD (risk factors, clinical consequences, and positive effects of lifestyle changes) can improve the likelihood of adopting preventive behaviors by modifying perceptions of susceptibility, severity, benefits and barriers. ${ }^{12}$ Studies assessing the relation between knowledge of CHD and preventive behaviors have demonstrated a positive association. Two studies in women with no prior history of CHD demonstrated a significant association between $\mathrm{CHD}$ knowledge and health promoting behaviors, including diet and physical activity. ${ }^{13,14}$ Another study in rural African-American men and women showed a significant association between knowledge of dietary risk factors of heart disease and healthy dietary practices. ${ }^{15}$ A population-based study in Romania found a significant association between dietary preventive actions and nutrition knowledge (awareness of 
diet/disease relationships, principals of nutrition, and food nutrient density). ${ }^{16}$ A study in urban black men found that knowledge of fruit and vegetable recommendations was associated with greater consumption of fruits and vegetables, but level of awareness of recommendations was low. ${ }^{17}$ However, an association between CHD knowledge and preventive behavior, including healthy diet, was not found in a study in women with a current diagnosis of CHD, suggesting a possible lack of influence of knowledge once an individual has been diagnosed. ${ }^{18}$ These studies demonstrate a potential association between CHD knowledge and diet, but more research is needed to fully elucidate the relative strength of these associations and the factors which modify this relationship.

The HBM also states that perception of personal risk of CHD is influential in the adoption of risk-reducing behaviors. ${ }^{12}$ The association between perceived personal risk of $\mathrm{CHD}$ and health promoting behavior has not been extensively studied, and the few existing studies show conflicting results. A significant correlation between perceived susceptibility and preventive behaviors, including diet and physical activity, was demonstrated in women without prior history of heart disease, with perceived susceptibility alone accounting for more than half the variance in preventive behavior. ${ }^{14}$ In contrast, another study showed an increased likelihood of visiting a health care provider in the past year in women who perceived themselves at high risk for heart disease, but no association between high perceived risk and actions to improve diet or physical activity. ${ }^{19}$ A study in women with CHD demonstrated similar findings, with no significant correlation between perceived risk and diet, physical activity, and other riskreducing behaviors. ${ }^{18}$ Perceived risk of CHD was assessed among college students and was shown to be significantly positively correlated with diet regulation in students 
identified as having Type B personality, whereas no significant correlation was found in students identified as having Type A personality. ${ }^{20}$ These studies suggest that other factors, such as a diagnosis of CHD and age, modify the influence of perceived risk on health promoting behaviors in individuals.

The primary objective of this study was to determine the association between CHD knowledge, perceived risk of CHD and dietary behavior in an Appalachian population. The rationale for the study is to inform communication strategies for health care providers in order to improve patient adoption of recommended dietary modifications to reduce risk of $\mathrm{CHD}$. Our working hypothesis is that $\mathrm{CHD}$ knowledge and perceived risk of $\mathrm{CHD}$ will be associated with dietary behavior.

\section{Methods}

\section{Study Population}

The study population consisted of individuals who work or reside in a small college town within the Appalachian region, home to about 26,800 residents, $51 \%$ of whom are male and $90 \%$ are white. ${ }^{21}$ Median household income is $\$ 20,650$ and $69 \%$ have greater than high school education. Participants were recruited using electronic postings and listserves, newspaper advertisements, and postings on community bulletin boards. Surveys were administered online and completed either off-site or in the research center. Inclusion criteria were age $\geq 18$ years and ability to read and understand English. Individuals were excluded if they had a prior history of heart disease based on self-report (if they answered affirmatively to either of the following 
questions: (1) "Have you ever been told by your healthcare provider that you have coronary heart disease, angina or have suffered a heart attack?" or (2) "Have you ever had coronary bypass surgery, coronary stent placement, or angioplasty?") Approval was obtained from the university's Institutional Review Board.

Questionnaire Battery

The study design was cross-sectional and employed the use of an online questionnaire battery. The questionnaire battery contained items pertaining to demographic information, including gender, age, education, marital status, household income, height and weight, as well as instruments to measure each of the following constructs that comprise the HBM.

- The 16-item Food Behavior Checklist (FBC) was used to assess current dietary behaviors. ${ }^{22}$ It contains 15 items regarding diet quality in terms of fruit and vegetable, fat/cholesterol, milk/dairy and sugar-sweetened beverage consumption, and one item that measures self-rating of diet quality.

Published Cronbach's alpha coefficients for this measure are 0.8 for fruit and vegetable intake, 0.61 for diet quality, and Spearman's correlation was 0.47 for milk consumption (two items) ${ }^{23}$

- CHD knowledge was assessed by the 20-item modified Coronary Heart Disease Knowledge Test, which contains multiple-choice questions pertaining to CHD risk factors, diet, exercise, and stress. ${ }^{18,24}$ Published internal- 
consistency reliability for this scale is 0.84 for the original 40 -item measure, assessed using the Kuder-Richardson formula 20 (KR-20). ${ }^{24}$

- Perception of risk of CHD was assessed using the 20-item Perception of Risk of Heart Disease Scale. ${ }^{25}$ This measure consists of statements of risk, such as, "I feel sure I will get heart disease," rated by the respondent on a fourpoint Likert-type scale, where $1=$ strongly disagree and $4=$ strongly agree. Published Cronbach's alpha for this scale is $0.80 .^{25}$

- Perceived severity was assessed using five items from the Perceived Seriousness of Coronary Heart Disease Scale. ${ }^{26}$ It consists of statements such as, "The thought of coronary heart disease scares me," and is rated by the respondent on a five-point Likert-type scale, where 1=strongly disagree and 5=strongly agree. Published Cronbach's alphas for this scale are 0.71 to $0.73 .^{26}$

- Perceived benefits and barriers for CHD preventive behaviors, such as diet, exercise, and smoking cessation, were assessed by the 12-item Benefits Scale and 12-item Barriers Scale, respectively. ${ }^{27}$ The benefits measure consists of statements such as, "Lowering salt in my diet may lessen my chance of high blood pressure," and the barriers measure consists of statements such as, "I enjoy eating too much to change my diet." For both measures, statements are rated by respondents on a four-point Likert-type scale, where $1=$ strongly disagree and 4=strongly agree. Internal consistency reliability coefficients (Cronbach's alphas) for these measures are $0.72-0.79$ for the benefits scale and $0.72-0.76$ for the barriers scale. ${ }^{28}$ 
- Self-efficacy for healthful diet was assessed using the Eating and Exercise Confidence Scale, which contains 20 diet-related items. ${ }^{29}$ These measures include statements describing behavioral changes (e.g., "Eat smaller portions at dinner") and ask the respondent to rate his or her level of confidence in adopting and maintaining the behavior for at least six months, based on a five-point Likert-type scale where $1=\mid$ know I cannot and 5=I know I can. Published internal consistency reliability, assessed using Cronbach's alpha, ranges from $0.85-0.93$ for the five factors of the eating confidence scale. ${ }^{29}$

- Cue to action was assessed using the question, "Has your healthcare provider recommended that you change your diet to be healthier?"

Permission to use all instruments was obtained prior to the study.

\section{Data Analysis}

Body Mass Index (BMI) (weight in $\mathrm{kg} /$ height in $\mathrm{m}^{2}$ ) was calculated using selfreported height and weight, and used to categorize participants as underweight $(<18.5)$, healthy weight (18.5-24.5), overweight (25-29.5), or obese $(\geq 30)$. Scores for the instruments were calculated using standard scoring mechanisms, when available, such that higher scores indicated higher levels of the constructs (e.g., higher diet score $=$ healthier diet). These scores, along with gender, age (years), education ( $\leq$ high school, $>$ high school), total annual household income $(<\$ 70,000, \$ 70,000$ or more), marital status (single, married, widowed/divorced/separated) and cue to action (yes, no) were analyzed using hierarchical linear regression to determine the association between 
knowledge of $\mathrm{CHD}$, perceived CHD risk and dietary behavior. To examine effect on dietary behavior, the score for diet quality was utilized as the dependent variable, while scores for the remaining instruments related to diet were utilized as independent variables. Dummy variables for gender, income, education, marital status, and cue to action, and a continuous variable representing age were also entered as independent variables. Demographic variables were entered in the first step, followed by variables representing perceived seriousness, perceived benefits, perceived barriers, self-efficacy and cue to action in the second to determine the unique variance in dietary behavior explained by the model, after accounting for demographic factors. Perceived risk and CHD knowledge were entered in the third and fourth steps, respectively, to determine additional variance in behavior explained by each. Standardized beta coefficients were used to assess direction of association between each independent variable and behavior, holding other factors constant. PASW (version 18.0.0) was used for data analysis. ${ }^{30}$

\section{Results}

Demographics of the Sample

373 participants completed the online questionnaire. Demographic characteristics of the sample appear in Table 2.1. Of the respondents, the majority was female, currently married, had greater than high school education, and had a total household income $<\$ 70,000$. Mean age was 42 years \pm 12.77 . More than half $(55 \%)$ 
of participants were categorized as either overweight or obese based on self-reported height and weight.

\section{Dietary Behavior and HBM Component Scales}

Reliability and descriptive statistics for the measures appear in Table 2.2. Slightly more than one third $(35.7 \%)$ of participants met the national guidelines for fruit and vegetable consumption, reporting at least 2 servings of fruit and 3 servings of vegetables daily. A greater percentage of participants met the guidelines for fruit consumption than met the guidelines for vegetable consumption ( $64.3 \%$ vs. $43.4 \%)$. Internal consistency reliability for each of the HBM component scales was examined using Cronbach's alpha coefficients. Results indicated good reliability $(\alpha>0.7)$ for most scales, with the exception of Perceived Severity $(\alpha=0.621)$ and Knowledge $(\alpha=0.463)$. Average percent correct for the knowledge test was $68.8 \%$ (69.8\% for risk factor knowledge, $77.5 \%$ for diet knowledge, $68.8 \%$ for exercise knowledge, and $65.2 \%$ for stress knowledge.) On a scale of $20-80$, mean score for perceived risk was $54.7 \pm 6.05$, indicating a moderate perception of risk among participants. Mean score for perceived severity of CHD was $16.5 \pm 2.59$ on a scale of $5-25$. There was a much greater perception of benefits of preventive behavior among respondents compared to barriers, with mean scores of $41.8 \pm 4.40$ and $22.4 \pm 4.81$, respectively (on a scales of 12-48). Respondents also indicated a high degree of diet-related self-efficacy, with a mean score of $4.0 \pm 0.57$ on a scale of $1-5$. About a third (31.4\%) of participants reported having received a healthcare provider recommendation to improve their diet. Mean self- 
rating of diet quality was $6.3 \pm 1.95$ on a scale of 1 to 10 , with 10 being the highest quality rating.

Examination for Outliers and Normality of Distributions

Data were examined for outliers and to ensure normality of distribution for variables used in the model. Calculating $z$ scores and using $>3$ standard deviations from the mean as the criterion for exclusion, eight cases were excluded from the regression model. Final sample size for the regression, after removal of outliers and listwise deletion for missing values, was $n=359$. Skewness and kurtosis were in the acceptable range for all variables, except for perceived benefits and age, which had bimodal distributions, and knowledge, which was slightly negatively skewed.

\section{Correlations and Mean Comparisons}

Pearson product-moment bivariate correlation coefficients were calculated for all continuous variables in the model (Table 2.3). Knowledge, perceived benefits, selfefficacy for diet, and self-rating of diet quality were significantly positively correlated with healthfulness of diet (all ps<.01); and perceived risk ( $p<.001)$, perceived severity $(p=.04)$ and perceived barriers $(p<.001)$ were significantly negatively correlated with healthfulness of diet. Mean diet score was significantly lower for those respondents who reported receiving a recommendation to improve diet from their healthcare provider $(24.5 \pm 7.40)$ compared to those who did not $(28.5 \pm 7.28)[t(367)=4.77, p<.001]$. 
Mean diet score was significantly lower for participants identified as being overweight or obese $(25.7 \pm 7.48)$ compared to those categorized as underweight or at a healthy weight $(29.2 \pm 7.18)[t(360)=4.41, p<.001]$.

Hierarchical Regression

Results of the hierarchical regression are shown in Table 2.4. The final model explained $31.4 \%$ of the variance in dietary behaviors, using adjusted $R^{2}$. Demographic variables alone explained only $4 \%$ of the variance in dietary behaviors. There was a significant improvement over Step 1 with the addition of perceived severity, perceived benefits, perceived barriers, self-efficacy, and cue to action, which explained an additional $25.5 \%$ of the variance in dietary behavior. The $\mathrm{R}^{2}$ change for Step 3 was $.021(p=.001)$, indicating that perceived risk explained an additional $2 \%$ of variance over the model that contained other HBM components as well as demographic variables. Finally, when overall CHD knowledge was added (in Step 4) the additional variance explained was insignificant. In the final model, low perceived risk, low perceived barriers, high perceived self-efficacy and having received no cue to action from a healthcare provider were significant predictors of increased healthfulness of diet.

Durbin-Watson test statistic for the model was 1.997 , which is in the acceptable range of 1.5 to 2.5 , indicating there were no issues with autocorrelation in residuals. Variance inflation factor (VIF) and tolerance values for all variables in the model fell within the acceptable ranges of $<4$ and $>0.2$, respectively, indicating no concerns with multicollinearity. To test for heteroskedasticity, a histogram of standardized residuals 
was inspected for normality of distribution. Skewness and kurtosis were found to be acceptable, indicating no major issues with heterogeneity of variance.

Because overall score on the knowledge test was not a significant predictor of healthfulness of diet, the regression was repeated, using the domain-specific knowledge subscale score, diet knowledge. Greater knowledge pertaining to diet became a significant predictor of increased healthfulness of diet (Beta $=.173, p<.001)$. This model explained $33.4 \%$ of the variance in dietary behavior.

\section{Discussion}

In this sample of adults residing in an Appalachian community, healthfulness of diet was found to be associated with greater diet-specific CHD knowledge, lower perceived risk of CHD, lower perceived barriers to CHD-preventive behavior, higher self-efficacy for diet modification and not having been advised by a healthcare provider to improve diet.

As hypothesized, knowledge and perceived risk were correlated with dietary behavior, with knowledge demonstrating a weaker association than perceived risk. Although overall knowledge about CHD was not a significant predictor of healthfulness of diet after adjusting for demographic variables and other components of the HBM, diet-specific knowledge was significant, indicating that individuals with greater knowledge about benefits of dietary modifications to reduce risk of CHD are more likely to consume a healthier diet. This supports other studies that have found a significant association between $\mathrm{CHD}$ knowledge and preventive dietary behaviors. ${ }^{13-17} \mathrm{~A}$ 
qualitative study assessing determinants of fruit and vegetable consumption demonstrated that most participants were knowledgeable of the health benefits associated with consuming fruits and vegetables, but cited high cost and perceived lack of time as barriers to adhering to guidelines. ${ }^{31}$ While education alone is not sufficient to change behavior, it is important to provide individuals with proper education regarding the association between diet and CHD risk in order to lay a foundation for motivating behavior change.

As hypothesized, perceived risk of CHD was associated with healthfulness of diet, but in the counter-predicted direction, so that lower perceived risk was associated with increased healthfulness of diet. This may be due to the fact that individuals who practice healthy dietary habits accurately assess that they are at lower risk for CHD because of their behavior. This explanation is in agreement with the risk reappraisal hypothesis, which states that individuals who perceive themselves at high risk for disease may adopt preventive behavior, and subsequently reassess their risk as lower after adoption of the behavior. ${ }^{32}$ This hypothesis was tested and supported in a longitudinal study that assessed Lyme disease vaccination and risk perception. ${ }^{32}$ Individuals who perceived themselves to be at higher risk for Lyme disease at Time 1 were more likely to get vaccinated. Those who subsequently received the vaccine were found to have a lower perceived risk at Time 2 compared with Time 1. In addition, those who received the vaccine more accurately assessed their risk, having a lower perception of risk compared to those who did not receive the vaccine. Depending upon the time at which perceived risk and behavior are measured, results may demonstrate an association between perceived risk and preventive behavior in the direction opposite 
that predicted by the HBM, which holds that a higher perception of risk of disease leads to increased likelihood of participation in preventive behaviors. Unfortunately, this phenomenon cannot always be avoided in cross-sectional studies such as this one.

Cue to action (report that an individual had received advice from his or her health care provider to improve diet) was also significant in the counter-predicted direction, possibly indicating that individuals who already practice healthy dietary habits are less likely to be advised by their healthcare provider to improve their habits. This may also indicate that such advice does little to motivate those who practice unhealthy behaviors to improve. Further research that captures time course of recommendations and behavior change are needed to determine the true nature of this association.

As predicted by the HBM, lower perceived barriers and higher perceived selfefficacy were significant predictors of healthfulness of diet. This emphasizes the importance of improved access to healthy food options in order to reduce barriers to healthy eating. Self-efficacy has been included in several health promotion models to explain adoption of preventive behavior, and seems to be a key motivating factor. A study in college students demonstrated that self-efficacy directly impacts nutrition and physical activity preventive behavior in the positive direction when threat of disease is perceived as low. ${ }^{33}$ However, when perceived threat is high, perceived barriers moderated this relationship. The strong relationship between self-efficacy and preventive behavior suggests a need for patient counseling which assists individuals in developing confidence and skills to avoid temptation to indulge in unhealthy foods. 
The model predicted only about one-third of the variance in behavior, indicating that other factors, such as family history, may also play a role. We did not collect information on family history. Experiencing heart disease in a loved one could serve as a cue to action to motivate adoption of preventive behavior, especially given the influence of family history on actual risk of CHD. Incorporating family history of CHD in future studies could shed more light on its influence on preventive behavior.

As is true for cross-sectional survey research in general, these results must be interpreted with caution in light of several limitations. First, the cross-sectional nature of the study design does not allow for establishment of causation. Second, all measures were based on self-report, introducing the potential for recall or social desirability bias. Third, the sample tended to be highly educated and mostly female, limiting generalizability to other populations or settings. Although the intent was to capture a sample that was representative of an Appalachian population, the resulting sample did not display the demographic characteristics most often associated with Appalachians. Fourth, results should be interpreted with caution given violations of the assumption of normality for some variables used in the model. Lastly, reliability of the instruments to measure CHD knowledge and perceived severity were lower than the generally accepted threshold of $0.7 .^{34}$ The perceived severity instrument consisted of only 5 items, and was therefore susceptible to lower reliability. The decreased reliability of the knowledge instrument could be due to the fact that the various subscales (risk factors, diet, exercise, and stress reduction) were unrelated to one another, and it would not be expected that an individual who is knowledgeable about dietary factors related to CHD would necessarily be knowledgeable about exercise-related factors. However, reliability 
for the larger 40-item measure was shown to be adequate in prior research. ${ }^{24}$ Low reliability of the knowledge instrument may have influenced the lack of association between overall CHD knowledge and behavior demonstrated in this study, but this is unlikely due to the significant zero-order correlation found between these two constructs, without adjustment for other variables.

Conclusion

Dietary knowledge is positively associated with healthfulness of diet, while perceived risk is negatively associated. Other components of the HBM also play a role, such as perceived barriers, self-efficacy and cue to action. A better understanding of the factors that are associated with healthfulness of diet can inform patient education, as well as environment and policy change to help motivate healthy behavior. 


\section{References}

1. Stone NJ. The clinical and economic significance of atherosclerosis. Am J Med. Oct 8 1996;101(4A):4A6S-9S.

2. Trogdon JG, Finkelstein EA, Nwaise IA, Tangka FK, Orenstein D. The economic burden of chronic cardiovascular disease for major insurers. Health Promot Pract. Jul 2007;8(3):234-242.

3. van Jaarsveld $\mathrm{CH}$, Sanderman R, Miedema I, Ranchor AV, Kempen GI. Changes in health-related quality of life in older patients with acute myocardial infarction or congestive heart failure: a prospective study. J Am Geriatr Soc. Aug 2001;49(8):1052-1058.

4. Yusuf S, Hawken S, Ounpuu S, et al. Effect of potentially modifiable risk factors associated with myocardial infarction in 52 countries (the INTERHEART study): case-control study. Lancet. Sep 11-17 2004;364(9438):937-952.

5. Lloyd-Jones DM, Hong Y, Labarthe D, et al. Defining and setting national goals for cardiovascular health promotion and disease reduction: the American Heart Association's strategic Impact Goal through 2020 and beyond. Circulation. Feb 2 2010;121(4):586-613.

6. Barnett E, Elmes GA, Braham VE, Halverson JA, Lee JY, Loftus S. Heart Disease in Appalachia: An Atlas of County Economic Conditions, Mortality, and Medical Care Resources. Morgantown, WV: Prevention Research Center, West Virginia University; 1998. 
7. Halverson J, Ma L, Harner EJ. An analysis of disparities in health status and access to care in the Appalachian region. Washington, D.C.: Appalachian Regional Commission; 2004.

8. Amarasinghe A, D'Souza G, Brown C, Oh H, Borisova T. The influence of socioeconomic and environmental determinants on health and obesity: a West Virginia case study. Int J Environ Res Public Health. Aug 2009;6(8):2271-2287.

9. Wewers ME, Katz M, Fickle D, Paskett ED. Risky behaviors among Ohio Appalachian adults. Prev Chronic Dis. Oct 2006;3(4):A127.

10. Lichtenstein AH, Appel LJ, Brands M, et al. Diet and lifestyle recommendations revision 2006: a scientific statement from the American Heart Association Nutrition Committee. Circulation. Jul 4 2006;114(1):82-96.

11. United States Department of Health and Human Services CDC. Physical Activity and Health: A Report of the Surgeon General. Atlanta, GA: Author; 1996.

12. Rosenstock I. Historical Origins of the Health Belief Model. In: Becker MH, ed. The Health Belief Model and Personal Behavior. Thorofare, NJ: Slack, Inc.; 1974.

13. Thanavaro JL, Moore SM, Anthony M, Narsavage G, Delicath T. Predictors of health promotion behavior in women without prior history of coronary heart disease. Appl Nurs Res. Aug 2006;19(3):149-155.

14. Ali NS. Prediction of coronary heart disease preventive behaviors in women: a test of the health belief model. Women Health. 2002;35(1):83-96.

15. Pace R, Dawkins N, Wang B, Person S, Shikany JM. Rural African Americans' dietary knowledge, perceptions, and behavior in relation to cardiovascular disease. Ethn Dis. Winter 2008;18(1):6-12. 
16. Petrovici DA, Ritson C. Factors influencing consumer dietary health preventative behaviours. BMC Public Health. 2006;6:222.

17. Wolf RL, Lepore SJ, Vandergrift JL, et al. Knowledge, barriers, and stage of change as correlates of fruit and vegetable consumption among urban and mostly immigrant black men. J Am Diet Assoc. Aug 2008;108(8):1315-1322.

18. Oliver-McNeil S, Artinian NT. Women's perceptions of personal cardiovascular risk and their risk-reducing behaviors. Am J Crit Care. May 2002;11(3):221-227.

19. Mosca L, Mochari H, Christian A, et al. National study of women's awareness, preventive action, and barriers to cardiovascular health. Circulation. Jan 31 2006;113(4):525-534.

20. O'Brien $\mathrm{WH}$, VanEgeren L. Perceived susceptibility to heart disease and preventive health behavior among Type A and Type B individuals. Behav Med. Winter 1991;17(4):159-165.

21. US Census Bureau. State and County QuickFacts. Available at: http://quickfacts.census.gov/qfd/states/54/5455756.html. Accessed September 26, 2010.

22. Townsend MS, Sylva K, Martin A, Metz D, Wooten-Swanson P. Improving readability of an evaluation tool for low-income clients using visual information processing theories. J Nutr Educ Behav. May-Jun 2008;40(3):181-186.

23. Townsend MS, Kaiser LL, Allen LH, Joy AB, Murphy SP. Selecting items for a food behavior checklist for a limited-resource audience. J Nutr Educ Behav. MarApr 2003;35(2):69-77. 
24. Smith MM, Hicks VL, Heyward VH. Coronary heart disease knowledge test: developing a valid and reliable tool. Nurse Pract. Apr 1991;16(4):28, 31, 35-28.

25. Ammouri AA, Neuberger G. The Perception of Risk of Heart Disease Scale: development and psychometric analysis. J Nurs Meas. 2008;16(2):83-97.

26. Katz DA, Graber M, Birrer E, et al. Health beliefs toward cardiovascular risk reduction in patients admitted to chest pain observation units. Acad Emerg Med. May 2009;16(5):379-387.

27. Murdaugh $\mathrm{CL}$, Verran JA. Theoretical modeling to predict physiological indicants of cardiac preventive behaviors. Nurs Res. Sep-Oct 1987;36(5):284-291.

28. Murdaugh CL. Personal communication via electronic mail; 2009.

29. Sallis JF, Pinski RB, Grossman RM, L. PT, Nader PR. The development of selfefficacy scales for health-related diet and exercise behaviors. Health Educ Res. 1988;3(3):283-292.

30. PASW Statistics [computer program]. Version 18.0.0. Chicago, IL: SPSS, Inc.; 2009.

31. Yeh MC, Ickes SB, Lowenstein LM, et al. Understanding barriers and facilitators of fruit and vegetable consumption among a diverse multi-ethnic population in the USA. Health Promot Int. Mar 2008;23(1):42-51.

32. Brewer NT, Weinstein ND, Cuite CL, Herrington JE. Risk perceptions and their relation to risk behavior. Ann Behav Med. Apr 2004;27(2):125-130.

33. Von Ah D, Ebert S, Ngamvitroj A, Park N, Kang DH. Predictors of health behaviours in college students. J Adv Nurs. Dec 2004;48(5):463-474.

34. Nunnaly J. Psychometric Theory. New York: McGraw-Hill; 1978. 


\section{Figure 2.1: The Health}

Belief Model

(adapted from Rosenstock, 1974)

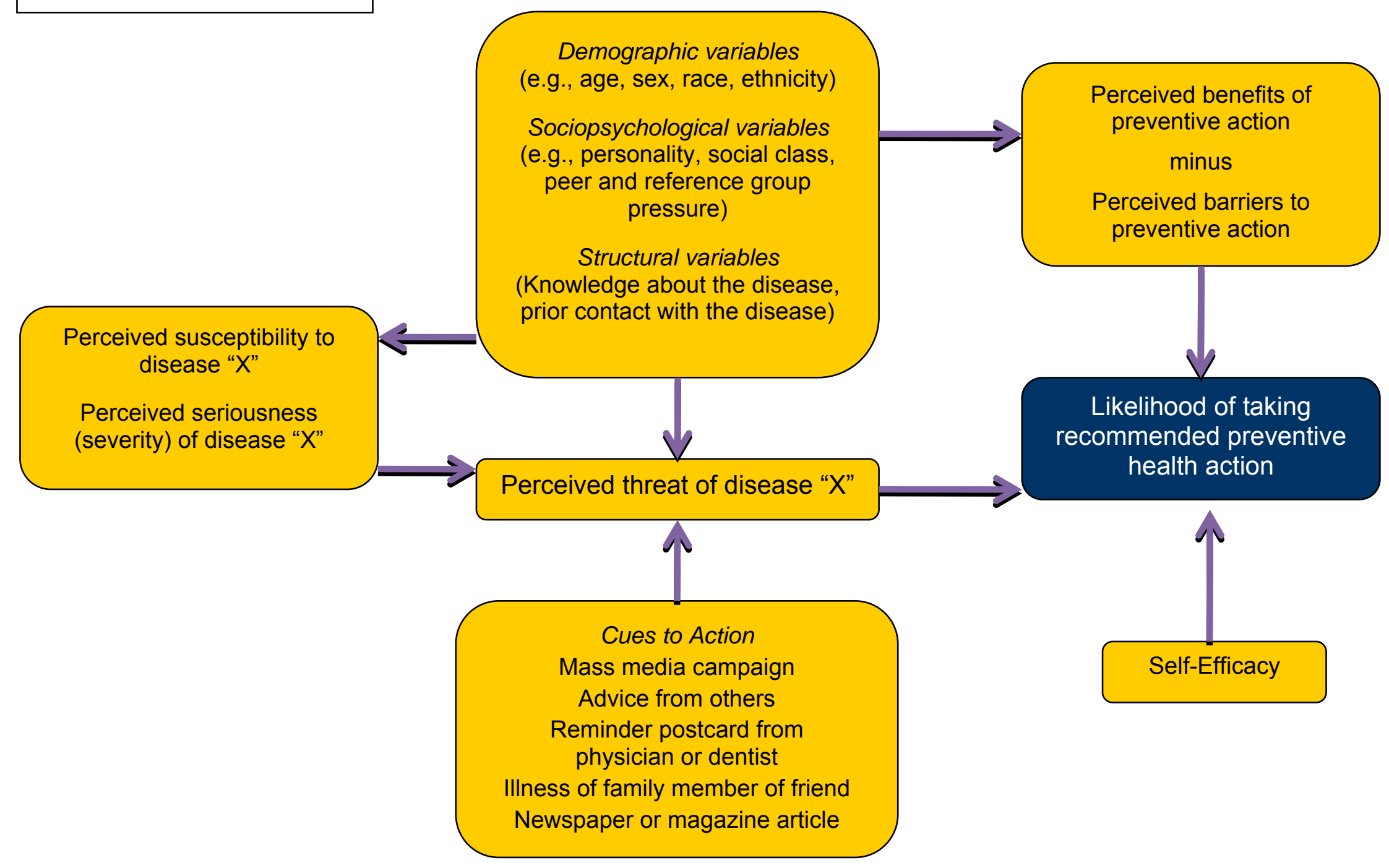


Table 2.1: Demographic Characteristics of the Sample

\begin{tabular}{|c|c|c|}
\hline Demographic Category & & Percent \\
\hline Age (years) & $18-29$ & 23.8 \\
\hline & $30-54$ & 59.5 \\
\hline & 55 and up & 16.7 \\
\hline Gender & Male & 15.3 \\
\hline & Female & 84.7 \\
\hline Education & High School & 8.6 \\
\hline & Some College or College Degree & 91.4 \\
\hline Marital Status & Single & 27.6 \\
\hline & Married & 59.8 \\
\hline & Separated/Divorced/Widowed & 12.6 \\
\hline Annual Household Income & $<\$ 20,000$ & 8.3 \\
\hline & $\$ 20,000-\$ 69,999$ & 46.9 \\
\hline & $\$ 70,000-\$ 139,999$ & 38.1 \\
\hline & $\$ 140,000$ or more & 6.7 \\
\hline BMI Category & Underweight & 1.6 \\
\hline & Healthy Weight & 43.5 \\
\hline & Overweight & 30.9 \\
\hline & Obese & 24.0 \\
\hline
\end{tabular}


Table 2.2: Components of the Health Belief Model and Instruments Used for Measurement

\begin{tabular}{|c|c|c|c|c|}
\hline Component of HBM & Instrument/Measure & Scale & Mean Score (SD) & $\begin{array}{l}\text { Internal } \\
\text { consistency } \\
\text { reliability* }\end{array}$ \\
\hline Dietary Behavior & Food Behavior Checklist & $0-48$ & $27.3(7.53)$ & 0.739 \\
\hline Knowledge of CHD & $\begin{array}{l}\text { Modified Coronary Heart } \\
\text { Disease Knowledge Test }\end{array}$ & $0-20$ & $13.8(2.25)$ & 0.463 \\
\hline Perceived Risk of CHD & $\begin{array}{l}\text { Perception of Risk of Heart } \\
\text { Disease Scale }\end{array}$ & $20-80$ & $54.7(6.05)$ & 0.790 \\
\hline Perceived Severity of CHD & $\begin{array}{l}\text { Perceived Seriousness of } \\
\text { Coronary Heart Disease Scale }\end{array}$ & $5-25$ & $16.5(2.59)$ & 0.621 \\
\hline Benefits of Behavior & Benefits Scale & $12-48$ & $41.8(4.40)$ & 0.864 \\
\hline Barriers to Behavior & Barriers Scale & $12-48$ & $22.4(4.81)$ & 0.821 \\
\hline Self-efficacy for Diet & $\begin{array}{l}\text { Eating and Exercise Confidence } \\
\text { Scale - Nutrition portion }\end{array}$ & $1-5$ & $4.0(0.57)$ & 0.856 \\
\hline Cue to Action for Diet & $\begin{array}{l}\text { "Has your health care provider } \\
\text { recommended that you change } \\
\text { your diet to be healthier?" }\end{array}$ & Yes/No & NA & NA \\
\hline
\end{tabular}

*Cronbach's alpha coefficients, except for Knowledge of CHD, which was assessed using Kuder-Richardson formula 20 
Table 2.3: Pearson Correlations

\begin{tabular}{|l|l|l|l|l|l|l|l|l|l|}
\hline & Diet & Knowledge & Risk & Severity & Benefits & Barriers & $\begin{array}{l}\text { Self- } \\
\text { efficacy } \\
\text { diet }\end{array}$ & $\begin{array}{l}\text { Age } \\
\text { diet quality }\end{array}$ \\
\hline Diet & 1 & & & & & & & \\
\hline Knowledge & $.139^{* *}$ & 1 & & & & & & \\
\hline Risk & $-.271^{* *}$ & -.038 & 1 & & & & & \\
\hline Severity & $-.107^{*}$ & $-.142^{* *}$ & $.224^{* *}$ & 1 & & & & \\
\hline Benefits & $.227^{* *}$ & .033 & -.042 & .000 & 1 & & & \\
\hline Barriers & $-.409^{* *}$ & $-.129^{*}$ & $.193^{* *}$ & $.150^{* *}$ & $-.593^{* *}$ & 1 & & \\
\hline Self-efficacy_diet & $.473^{* *}$ & -.021 & $-.186^{* *}$ & $-.161^{* *}$ & $.250^{* *}$ & $-.496^{* *}$ & 1 & \\
\hline Age & .033 & -.038 & $.204^{* *}$ & -.092 & $-.141^{* *}$ & .044 & .015 & 1 & \\
\hline $\begin{array}{l}\text { Self-rating of diet } \\
\text { quality }\end{array}$ & $.623^{* *}$ & $.142^{* *}$ & $-.459^{* *}$ & $-.228^{* *}$ & $.239^{* *}$ & $-.517^{* *}$ & $.488^{* *}$ & -.003 & \\
\hline
\end{tabular}

*Significant at the 0.05 level (two-tailed)

**Significant at the 0.01 level (two-tailed) 
Table 2.4: Hierarchical Regression - Food Behavior Checklist Score as Dependent Variable

\begin{tabular}{|c|c|c|c|c|c|c|c|c|}
\hline & \multicolumn{2}{|l|}{ Step 1} & \multicolumn{2}{|l|}{ Step 2} & \multicolumn{2}{|l|}{ Step 3} & \multicolumn{2}{|l|}{ Step 4} \\
\hline Predictor & $\begin{array}{l}\text { Standardized } \\
\text { Beta (B) }\end{array}$ & $\mathbf{p}$ & $\begin{array}{l}\text { Standardized } \\
\text { Beta (B) }\end{array}$ & $\mathbf{p}$ & $\begin{array}{l}\text { Standardized } \\
\text { Beta (B) }\end{array}$ & $\mathbf{p}$ & $\begin{array}{l}\text { Standardized } \\
\text { Beta (B) }\end{array}$ & p \\
\hline Female Dummy & $.114^{*}$ & .030 & .081 & .075 & .073 & .103 & .073 & .104 \\
\hline Married Dummy & -.059 & .393 & .043 & .477 & .056 & .349 & .058 & .330 \\
\hline $\begin{array}{l}\text { Separated/Divorced/ } \\
\text { Widowed Dummy }\end{array}$ & -.083 & .189 & -.024 & .664 & -.010 & .851 & -.013 & .805 \\
\hline$>$ High School Dummy & $.177^{* *}$ & .001 & $.105^{*}$ & .026 & $.114^{*}$ & .015 & .089 & .067 \\
\hline Income $\geq \$ 70 \mathrm{~K}$ Dummy & .085 & .155 & .053 & .301 & .051 & .315 & .042 & .408 \\
\hline Age & .080 & .176 & .070 & .179 & .097 & .064 & .097 & .063 \\
\hline Perceived Severity & & & .026 & .571 & .054 & .252 & .064 & .174 \\
\hline Perceived Benefits & & & .002 & .973 & .026 & .640 & .031 & .587 \\
\hline Perceived Barriers & & & $-.183^{* *}$ & .005 & $-.161^{*}$ & .012 & $-.147^{*}$ & .022 \\
\hline Self-Efficacy - Diet & & & $.343^{* * *}$ & $<.001$ & $.326^{* * *}$ & $<.001$ & $.339^{* * *}$ & $<.001$ \\
\hline Cue to Action Dummy & & & $-.160^{* *}$ & .001 & $-.120^{*}$ & .015 & $-.114^{*}$ & .021 \\
\hline Perceived Risk & & & & & $-.162^{\star *}$ & .001 & $-.165^{\star *}$ & .001 \\
\hline CHD Knowledge & & & & & & & .089 & .062 \\
\hline
\end{tabular}

${ }^{*} \mathrm{p}<.05,{ }^{* *} \mathrm{p}<.01,{ }^{* * *} \mathrm{p}<.001$

Model Fit Statistics: Step 1: $R^{2}=.057$, Adj $R^{2}=.041, F(6,352)=3.54^{* *}, R^{2}$ change $=.057^{* *} ;$ Step 2: $R^{2}=.312$, Adj $R^{2}=$ $.290, F(11,347)=14.28^{\star * *}, R^{2}$ change $=.255^{\star * *}$; Step $3: R^{2}=.332$, Adj $R^{2}=.309, F(12,346)=14.35^{\star * *}, R^{2}$ change $=$ $.021^{* *}$; Step 4: $R^{2}=.339$, Adj $R^{2}=.314, F(13,345)=13.61^{* * *}, R^{2}$ change $=.007$ 
CHAPTER 3 


\section{CHAPTER 3:}

\section{USE OF THE HEALTH BELIEF MODEL TO EXPLAIN PHYSICAL ACTIVITY BEHAVIOR: WHAT IS THE ASSOCIATION WITH CORONARY HEART DISEASE KNOWLEDGE AND PERCEIVED PERSONAL RISK?}

\section{Introduction}

The prevalence of coronary heart disease (CHD) is estimated at $7.9 \%$ in US adults 20 years of age and older. ${ }^{1}$ West Virginia has the highest rate of self-reported history of myocardial infarction (MI) (7.7\%) and of self-reported angina or CHD (8.1\%) in the US. ${ }^{2} \mathrm{CHD}$ is associated with substantial negative clinical, economic, and humanistic consequences. ${ }^{3-5}$ Modifiable risk factors account for much of the risk of heart disease, providing opportunities to decrease this societal burden. ${ }^{6}$ Sedentary lifestyle is among these modifiable risk factors, and is associated with several other chronic diseases, including obesity, type 2 diabetes, osteoporosis, depression, and breast and colon cancers. ${ }^{7}$ In a large, international case-control study, physical inactivity alone accounted for $12.2 \%$ of the risk of initial acute $\mathrm{MI}$, after adjusting for other risk factors, including smoking, diabetes, hypertension, abdominal obesity, fruit and vegetable consumption, alcohol intake, lipid profile, and psychosocial factors. ${ }^{6}$ In 2001, the estimated direct expenditure for cardiovascular disease associated with physical inactivity was $\$ 23.7$ billion. ${ }^{1}$

The Appalachian region of the United States has been associated with a history of underdevelopment, leading to rurality, lower levels of socioeconomic status and 
education, and greatly increased rates of premature death. ${ }^{8}$ Although economic conditions have improved over the last several decades, the Appalachian region still fares worse than other regions of the United States in health outcomes related to coronary heart disease. ${ }^{9}$ A culture of unhealthy lifestyle, including poor diet and sedentary behavior, are contributors to this trend..$^{10,11}$

The benefits of physical activity (PA) to prevent heart disease are welldocumented. ${ }^{7}$ There appears to be a dose-dependent relationship, with studies demonstrating decreasing rates of $\mathrm{CHD}$ with increasing levels of PA. ${ }^{12}$ Regular PA has been shown to modify risk factors for CHD by increasing high-density lipoprotein-C levels, decreasing triglyceride and low-density lipoprotein-C levels, lowering systolic and diastolic blood pressure, reducing insulin resistance and glucose intolerance, and helping to achieve and maintain weight loss. ${ }^{7}$ The American Heart Association recommends that, for maintenance of heart health, individuals should get 150 minutes or more per week of moderate physical activity or 75 minutes or more per week of vigorous physical activity (or an equivalent combination of the two). ${ }^{13}$

Despite efforts to improve behavioral risk factors for $\mathrm{CHD}$, lifestyle modifications can be difficult to adopt and even more difficult to maintain. A report by the Centers for Disease Control and Prevention states that maintenance of recommended lifestyle changes, including smoking cessation, medication adherence, diet, and exercise, was only $25-40 \%$ six months after initiation. ${ }^{14}$ Individual behavior change theories, such as the Health Belief Model (HBM), propose that factors such as individual perceptions of disease and costs vs. benefits of adopting health promoting behaviors together influence the likelihood an individual will make the desired behavior change. ${ }^{15}$ 
Components of the HBM include: perceived severity, perceived susceptibility, perceived benefits, perceived barriers, cues to action, and self-efficacy. (Fig. 3.1)

Factors demonstrated to modify the influence of these components on health behaviors include demographic (age, gender, ethnicity), sociopsychological (personality, social class, peer groups), and structural factors (knowledge of the health problem and prior experience). ${ }^{15}$ Research using the HBM has indicated associations between model components and physical activity behaviors, and specifically that knowledge ${ }^{16,17}$ and perceived personal risk of $\mathrm{CHD}^{17}$ are positively correlated with these behaviors. These findings have not been consistent across populations, however, suggesting that other factors, such as age and health status, may influence the associations.

According to the HBM, an individual's knowledge of CHD (risk factors, clinical consequences, and positive effects of lifestyle changes) can improve the likelihood of adopting preventive behaviors by modifying perceptions of susceptibility, severity, benefits and barriers. ${ }^{15}$ Studies assessing the relation between knowledge of $\mathrm{CHD}$ and preventive behaviors have demonstrated a positive association. Two studies in women with no prior history of CHD demonstrated a significant association between $\mathrm{CHD}$ knowledge and health promoting behaviors, including diet and PA. ${ }^{16,17}$ However, an association between CHD knowledge and preventive behavior, including physical activity, was not found in a study in women with a current diagnosis of CHD, suggesting a possible lack of influence of knowledge once an individual has been diagnosed. ${ }^{18}$ In addition, no association between reported levels of physical activity and knowledge of the relevance of physical activity to the development of heart disease was found in a study of college students. ${ }^{19}$ The relative youth of the study population (ages ranged 
from 17 to 30 years) may help explain the lack of association. These studies demonstrate a potential association between CHD knowledge and physical activity, but more research is needed to fully elucidate the relative strength of these associations and the factors which modify this relationship.

The HBM also states that perception of personal risk of CHD is influential in the adoption of risk-reducing behaviors. ${ }^{15}$ The association between perceived personal risk of CHD and health promoting behavior has not been extensively studied, and the few existing studies show conflicting results. A significant correlation between perceived susceptibility and preventive behavior, including diet and physical activity, was demonstrated in women without prior history of heart disease, with perceived susceptibility alone accounting for more than half the variance in preventive behavior. ${ }^{17}$ In contrast, another study showed an increased likelihood of visiting a health care provider in the past year in women who perceived themselves at high risk for heart disease, but no association between high perceived risk and actions to improve diet or physical activity. ${ }^{20}$ A study in women with CHD demonstrated similar findings, with no significant correlation between perceived risk and diet, PA, and other risk-reducing behaviors. ${ }^{18}$ No significant association was demonstrated between perceived risk of CHD and session attendance in a CHD exercise program. ${ }^{21}$ In a prospective study assessing readiness for exercise adoption, a significant negative correlation was demonstrated between perceived heart disease risk and exercise adoption in men between the ages of 20 and 40 , but no significant correlation in men over $40 .^{22}$ These studies suggest that other factors, such as prior diagnosis of CHD and age, modify the influence of perceived risk on health promoting behaviors in individuals. 
The primary objective of this study was to determine the association between knowledge and perceived risk of $\mathrm{CHD}$ and PA levels in an Appalachian population. The rationale for the study is to inform communication strategies for health care providers in order to improve patient adoption of recommended levels of PA to reduce risk of CHD. Our working hypothesis is that $\mathrm{CHD}$ knowledge and perceived risk of $\mathrm{CHD}$ will be associated with level of PA.

\section{Methods}

\section{Study Population}

The study population consisted of individuals who work or reside in a small college town within the Appalachian region, home to about 26,800 residents, $51 \%$ of whom are male and $90 \%$ are white..$^{23}$ Median household income is $\$ 20,650$ and $69 \%$ have greater than high school education. Participants were recruited using electronic postings and listserves, newspaper advertisements, and postings on community bulletin boards. Surveys were administered online and completed either off-site or in the research center. Inclusion criteria were age $\geq 18$ years and ability to read and understand English. Individuals were excluded if they had a prior history of heart disease based on self-report (if they answered affirmatively to either of the following questions: (1) "Have you ever been told by your healthcare provider that you have coronary heart disease, angina or have suffered a heart attack?" or (2) "Have you ever had coronary bypass surgery, coronary stent placement, or angioplasty?") Approval was obtained from the university's Institutional Review Board. 


\section{Questionnaire Battery}

The study design was cross-sectional and employed the use of an online questionnaire battery. The questionnaire battery contained items pertaining to demographic information, including gender, age, education, marital status, household income, height and weight, as well as instruments to measure each of the following constructs that comprise the HBM.

- Physical activity levels were assessed using six physical activity items from the Behavioral Risk Factor Surveillance System Survey (BRFSS). ${ }^{24}$ These items assessed self-reported levels of moderate and vigorous physical activity in a usual week in terms of minutes per day and days per week and were used to calculate minutes of moderate PA per week (or the equivalent, counting each minute of vigorous PA as two minutes of moderate PA).

- CHD knowledge was measured using the 20-item modified Coronary Heart Disease Knowledge Test, which contains multiple-choice questions pertaining to CHD risk factors, diet, exercise, and stress. ${ }^{18,25}$ Published internal-consistency reliability for this scale is 0.84 for the original 40 -item measure, assessed using the Kuder-Richardson formula 20 (KR-20). ${ }^{25}$

- Perception of risk of CHD was assessed using the 20-item Perception of Risk of Heart Disease Scale. ${ }^{26}$ This measure consists of statements of risk, such as, "I feel sure I will get heart disease," rated by the respondent on a four-point Likert- 
type scale, where $1=$ strongly disagree and $4=$ strongly agree. Published Cronbach's alpha for this scale is $0.80 .^{26}$

- Perceived severity was assessed using five items from the Perceived Seriousness of Coronary Heart Disease Scale. ${ }^{27}$ It consists of statements such as, "The thought of coronary heart disease scares me," and is rated by the respondent on a five-point Likert-type scale, where $1=$ strongly disagree and $5=$ strongly agree. Published Cronbach's alphas for this scale are 0.71 to $0.73 .{ }^{27}$

- Perceived benefits and barriers for preventive behavior were assessed by the 12item Benefits Scale and 12-item Barriers Scale, respectively. ${ }^{28}$ The benefits measure consists of statements such as, "Regular exercise may decrease my chances of a heart attack," and the barriers measure consists of statements such as, "Family can often get in the way when I want to make healthy changes." For both measures, statements are rated by respondents on a four-point Likert-type scale, where $1=$ strongly disagree and $4=$ strongly agree. Internal consistency reliability coefficients (Cronbach's alphas) for these measures are $0.72-0.79$ for the benefits scale and $0.72-0.76$ for the barriers scale. ${ }^{29}$

- Self-efficacy for physical activity was assessed by the Eating and Exercise Confidence Scale, which contains 12 exercise-related items. ${ }^{30}$ These measures ask the respondent to rate his or her level of confidence with statements such as, "Get up early, even on weekends, to exercise," based on a five-point Likert-type scale where $1=\mid$ know I cannot and $5=\mid$ know I can. Published internal consistency reliabilities, assessed using Cronbach's alpha, are 0.83 and 0.85 for the two factors of the exercise confidence scale. ${ }^{30}$ 
- Cue to action for physical activity was assessed using the question, "Has your healthcare provider recommended that you increase your level of physical activity to be healthier?"

Permission to use all instruments was obtained prior to the study.

\section{Data Analysis}

Body Mass Index (BMI) (weight in $\mathrm{kg} /$ height in $\mathrm{m}^{2}$ ) was calculated using selfreported height and weight, and used to categorize participants as underweight $(<18.5)$, healthy weight (18.5-24.5), overweight (25-29.5), or obese $(\geq 30)$. Scores for the instruments were calculated using standard scoring mechanisms, when available, such that higher scores indicated higher levels of the constructs (e.g., higher perceived risk score $=$ greater perception of risk). These scores, along with gender, age (years), education ( $\leq$ high school, $>$ high school), total annual household income $(<\$ 70,000$, $\$ 70,000$ or more), marital status (single, married, widowed/divorced/separated) and cue to action (yes,no) were analyzed using hierarchical linear regression to determine the association between knowledge of CHD, perceived CHD risk and behavior. The score for physical activity was utilized as the dependent variable, while scores for the remaining measures related to PA were utilized as independent variables. Dummy variables for gender, income, education, marital status, and cue to action, and a continuous variable representing age were also entered as independent variables.

Demographic variables were entered in the first step, followed by variables representing perceived severity, perceived benefits, perceived barriers, self-efficacy and cue to 
action in the second to determine the unique variance in PA behavior explained by the model, after accounting for demographic factors. Perceived risk and CHD knowledge were entered in the third and fourth steps, respectively, to determine additional variance in behavior explained by each. Standardized beta coefficients were used to assess strength of association between knowledge and behavior, and perceived risk and behavior, holding other factors constant. PASW (version 18.0.0) was used for data analysis. ${ }^{31}$

\section{Results}

Demographics of the Sample

373 participants completed the online questionnaire. Demographic characteristics of the sample appear in Table 3.1. Of the participants, the majority was female, currently married, had greater than high school education, and had a total household income $<\$ 70,000$. Mean age was 42 years \pm 12.77 . More than half (55\%) of participants were categorized as either overweight or obese based on self-reported height and weight.

Physical Activity and HBM Component Scales

Reliability and descriptive statistics for the measures appear in Table 3.2. Using the physical activity guidelines for adults ${ }^{32}$ (at least 150 minutes per week of moderate or 75 minutes per week of vigorous physical activity, or an equivalent combination of the 
two) $69.4 \%$ of participants met the guidelines. Internal consistency reliability for each of the HBM component scales was examined using Cronbach's alpha coefficients. Results indicated good reliability ( $\alpha>0.7)$ for most scales, with the exception of Perceived Severity $(\alpha=0.621)$ and Knowledge $(\alpha=0.463)$. Average percent correct for the knowledge test was $68.8 \%$ (69.8\% for risk factor knowledge, $77.5 \%$ for diet knowledge, $68.8 \%$ for exercise knowledge, and $65.2 \%$ for stress knowledge.) On a scale of $20-80$, mean score for perceived risk was $54.7 \pm 6.05$, indicating a moderate perception of risk among participants. Mean score for perceived severity of CHD was $16.5 \pm 2.59$ on a scale of $5-25$. There was a much greater perception of benefits of preventive behavior among respondents compared to barriers, with mean scores of $41.8 \pm 4.40$ and $22.4 \pm 4.81$, respectively (on a scales of $12-48$ ). Respondents also indicated a moderately high degree of PA-related self-efficacy, with a mean score of 3.6 \pm 0.89 on a scale of $1-5$. Almost half $(43.4 \%)$ of participants reported having received a healthcare provider recommendation to increase their physical activity levels.

\section{Examination for Outliers and Normality of Distributions}

Data were examined for outliers and to ensure normality of distribution for variables used in the model. Calculating $z$ scores and using $>3$ standard deviations from the mean as the criterion for exclusion, eleven cases were excluded from the model as outliers. After exclusion of these outliers, skewness and kurtosis for all continuous variables fell within the desired range except for PA score, (which was positively skewed), perceived benefits and age, which had bimodal distributions, and 
knowledge, which was slightly negatively skewed. PA score was transformed using a square root transformation, which resulted in a distribution that more closely approximated normal, with skewness and kurtosis within the acceptable range.

Correlations and Mean Comparisons

Pearson product-moment bivariate correlation coefficients were calculated for all continuous variables in the model (Table 3.3). Overall CHD knowledge was significantly positively correlated with PA level $(p=.014)$. Perceived benefits and self-efficacy for exercise were also significantly positively correlated with PA level, and perceived risk, perceived barriers and age were significantly negatively correlated with PA level (all ps $<.01)$. Mean square root-transformed PA score was significantly lower for those respondents who reported receiving a recommendation to increase their levels of PA from their healthcare provider $(12.8 \pm 7.28)$ compared to those who did not $(19.7 \pm 8.70)$ $[\mathrm{t}(354)=8.14, p<.001]$. Mean square root-transformed PA score was significantly lower for participants identified as being overweight or obese $(14.6 \pm 8.37)$ compared to those categorized as underweight or at a healthy weight $(19.4 \pm 8.51)$ [t(348) $=5.26, p<.001]$.

\section{Hierarchical Regression}

Results of the hierarchical regression are show in Table 3.4. One additional case was found to be an outlier based on a standardized residual of -3.164 and was removed, resulting in a final $n=345$. The final model explained $41.9 \%$ of the variance in 
PA behaviors, using adjusted $R^{2}$. Demographic variables alone explained only $4.7 \%$ of the variance in PA behaviors. There was a significant improvement over Step 1 with the addition of perceived severity, perceived benefits, perceived barriers, self-efficacy, and cue to action, which explained an additional $37.1 \%$ of the variance in PA behavior. The $\mathrm{R}^{2}$ change for Step 3 was $.005(p=.083)$, indicating that perceived risk did not explain any additional variance over the model that contained other HBM components as well as demographic variables. Likewise, when overall CHD knowledge was added (in Step 4) the additional variance explained was insignificant $(p=.324)$. In the final model, younger age, high perceived self-efficacy and having received no cue to action from a healthcare provider were significant predictors of increased levels of PA. DurbinWatson test statistic for the model was 1.983 , which is in the acceptable range of 1.5 to 2.5 , indicating there were no issues with autocorrelation in residuals. Variance inflation factor (VIF) and tolerance values for all variables in the model fell within the acceptable ranges of $<4$ and $>0.2$, respectively, indicating no concerns with multicollinearity. To test for heteroskedasticity, a histogram of standardized residuals was inspected for normality of distribution. Skewness and kurtosis were found to be acceptable, indicating no major issues with heterogeneity of variance.

Given that the overall score on the knowledge test was not a significant predictor of level of physical activity, the regression was repeated, using the domain-specific knowledge subscale score, exercise knowledge. Greater knowledge pertaining to exercise became a significant predictor of increased levels of PA (Beta=.092, $p=.032$ ). This model explained $42.8 \%$ of the variance in PA behavior. 


\section{Discussion}

As predicted by the HBM, higher levels of disease-related knowledge, perceived benefits of preventive behaviors, and self-efficacy, and lower levels of perceived barriers to preventive behaviors were correlated with increased levels of PA in this Appalachian population. When these factors were included in a multivariable model, along with demographic variables, however, only increased self-efficacy, younger age, and not having been advised by a healthcare provider to increase levels of PA were significant predictors of behavior.

As hypothesized, knowledge and perceived risk were correlated with PA levels, with knowledge demonstrating a weaker association than perceived risk. Interestingly, higher perceived risk of CHD and cue to action were associated with lower levels of physical activity, contrary to the direction of association predicted by the HBM. The likely cause of the counter-predicted direction may be the temporal relationship with behavior. For perceived risk, this may indicate that those individuals who participate in high levels of physical activity have subsequently, and accurately, assessed their risk as being lower. This is in agreement with the risk-reappraisal hypothesis, postulated by Brewer, et al. ${ }^{33}$ Likewise, those individuals who are already physically active would then be less likely to receive recommendations from their healthcare provider to increase PA levels (cue to action), as findings from the current study demonstrate. The fact that younger age was associated with higher levels of PA is in accordance with recent findings in the US adult population. ${ }^{1}$ It is important to note that, when adjusted for demographic variables and other elements of the HBM, knowledge and perceived risk 
were no longer significant predictors of behavior, indicating that these constructs are less important in explaining PA behavior.

It is not surprising that high self-efficacy for exercise was a significant predictor of PA levels. Self-efficacy, a critical component of Bandura's Social Cognitive Theory, is defined as an individual's belief in his or her ability to carry out a specific course of action in order to accomplish a goal, and has been shown to be highly correlated with preventive health behaviors. ${ }^{34,35}$ Not explicitly included in the original HBM, selfefficacy was added later due to its demonstrated importance in explaining preventive health behavior. ${ }^{36}$ The HBM was originally developed to explain simple, often one-time behaviors, such as immunization and screening, and thus did not require the concept of self-efficacy. However, as the model has been increasingly used to explain preventive behaviors that require more sustained effort, such as smoking cessation, improved diet and increased PA levels, there has been a greater need to account for this concept. Self-efficacy has indeed been demonstrated as a significant predictor of physical activity behavior in previous research. A study in over 1200 men and women aged 18-62 demonstrated a significant positive association between self-efficacy for daily physical activity and intention to engage in PA, actual PA behavior, and physical fitness. ${ }^{37}$ Another study in boys and girls in grades 8 and 9 found that self-efficacy was a strong predictor of intentions to participate in PA. ${ }^{38}$

Over two-thirds of the study sample met the guidelines for physical activity, based on self-report. This finding is similar to results from the 2007 BRFSS, which demonstrated that $65 \%$ of US adults met the PA guidelines, with highest prevalence in young adults (ages 18-24), white non-Hispanics, and college graduates. ${ }^{39}$ The current 
study sample consisted of residents of a community with a mostly white, non-Hispanic population, and containing a large university. Many of the study participants were faculty, staff, or students of the university, and represent a highly educated demographic, as indicated by the fact that over $90 \%$ of participants reported having some college education. In addition, advertisements for the study contained language such as "free from heart disease" and "healthy heart study", which could have been more likely to discourage participation by individuals with sedentary lifestyles, who may have assessed themselves as ineligible. It has been suggested that the BRFSS may overestimate the level of physical activity by asking for any activity that causes increased breathing or heart rate (e.g., vacuuming), which could lead to inclusion of activities that do not meet the requirement for moderate intensity. ${ }^{40}$ In addition, asking respondents to sum minutes and frequencies for moderate-intensity and vigorousintensity activities separately may lead to overestimation of the totals. In response to these issues, beginning in 2011, the BRFSS will measure aerobic and leisure-time PA only, and include the types of physical activities in which individuals participate, as well as adding an item related to muscle strengthening activities.

As is true for cross-sectional survey research in general, these results must be interpreted with caution in light of several limitations. First, the cross-sectional nature of the study design does not allow for establishment of causation. Second, all measures were based on self-report, introducing the potential for recall or social desirability bias. Third, the sample tended to be highly educated and mostly female, limiting generalizability to other populations or settings. Although the intent was to capture a sample that was representative of an Appalachian population, the resulting sample did 
not display the demographic characteristics most often associated with Appalachians. Fourth, results should be interpreted with caution given violations of the assumption of normality for some variables used in the model. Lastly, reliability of the instruments to measure CHD knowledge and perceived severity were lower than the generally accepted threshold of $0.7 .^{41}$ The perceived severity instrument consisted of only 5 items, and was therefore susceptible to lower reliability. The decreased reliability of the knowledge instrument could be due to the fact that the various subscales (risk factors, diet, exercise, and stress reduction) were unrelated to one another, and it would not be expected that an individual who is knowledgeable about dietary factors related to CHD would necessarily be knowledgeable about exercise-related factors. However, reliability for the larger 40 -item measure was shown to be adequate in prior research. ${ }^{25}$ Low reliability of the knowledge instrument may have influenced the lack of association between overall CHD knowledge and behavior demonstrated in this study, but this is unlikely due to the significant zero-order correlation found between these two constructs, without adjustment for other variables.

Conclusion

CHD-related and exercise-specific knowledge was positively associated with levels of physical activity, while perceived risk was negatively associated, although neither were significant predictors when adjusted for other components of the HBM. Exercise-related self-efficacy was the strongest predictor of physical activity levels. A better understanding of the factors that are associated with physical activity behavior 
can inform patient education, as well as environment and policy change to help motivate healthy behavior. 


\section{References}

1. Lloyd-Jones D, Adams RJ, Brown TM, et al. Heart disease and stroke statistics-2010 update: a report from the American Heart Association. Circulation. Feb 23 2010;121(7):e46-e215.

2. CDC. Prevalence and trends database. Available at: http://www.cdc.gov/brfss/. Accessed October 16, 2010.

3. Stone NJ. The clinical and economic significance of atherosclerosis. Am J Med. Oct 8 1996;101(4A):4A6S-9S.

4. Trogdon JG, Finkelstein EA, Nwaise IA, Tangka FK, Orenstein D. The economic burden of chronic cardiovascular disease for major insurers. Health Promot Pract. Jul 2007;8(3):234-242.

5. van Jaarsveld $\mathrm{CH}$, Sanderman R, Miedema I, Ranchor AV, Kempen GI. Changes in health-related quality of life in older patients with acute myocardial infarction or congestive heart failure: a prospective study. J Am Geriatr Soc. Aug 2001;49(8):1052-1058.

6. Yusuf S, Hawken S, Ounpuu S, et al. Effect of potentially modifiable risk factors associated with myocardial infarction in 52 countries (the INTERHEART study): case-control study. Lancet. Sep 11-17 2004;364(9438):937-952.

7. Thompson PD, Buchner D, Pina IL, et al. Exercise and physical activity in the prevention and treatment of atherosclerotic cardiovascular disease: a statement from the Council on Clinical Cardiology (Subcommittee on Exercise, Rehabilitation, and Prevention) and the Council on Nutrition, Physical Activity, 
and Metabolism (Subcommittee on Physical Activity). Circulation. Jun 24 2003;107(24):3109-3116.

8. Barnett E, Elmes GA, Braham VE, Halverson JA, Lee JY, Loftus S. Heart Disease in Appalachia: An Atlas of County Economic Conditions, Mortality, and Medical Care Resources. Morgantown, WV: Prevention Research Center, West Virginia University; 1998.

9. Halverson J, Ma L, Harner EJ. An analysis of disparities in health status and access to care in the Appalachian region. Washington, D.C.: Appalachian Regional Commission; 2004.

10. Amarasinghe A, D'Souza G, Brown C, Oh H, Borisova T. The influence of socioeconomic and environmental determinants on health and obesity: a West Virginia case study. Int J Environ Res Public Health. Aug 2009;6(8):2271-2287.

11. Wewers ME, Katz M, Fickle D, Paskett ED. Risky behaviors among Ohio Appalachian adults. Prev Chronic Dis. Oct 2006;3(4):A127.

12. Tanasescu M, Leitzmann MF, Rimm EB, Willett WC, Stampfer MJ, Hu FB. Exercise type and intensity in relation to coronary heart disease in men. Jama. Oct 23-30 2002;288(16):1994-2000.

13. Lloyd-Jones DM, Hong Y, Labarthe D, et al. Defining and setting national goals for cardiovascular health promotion and disease reduction: the American Heart Association's strategic Impact Goal through 2020 and beyond. Circulation. Feb 2 2010;121(4):586-613.

14. United States Department of Health and Human Services CDC. Physical Activity and Health: A Report of the Surgeon General. Atlanta, GA: Author; 1996. 
15. Rosenstock I. Historical Origins of the Health Belief Model. In: Becker MH, ed. The Health Belief Model and Personal Behavior. Thorofare, NJ: Slack, Inc.; 1974.

16. Thanavaro JL, Moore SM, Anthony M, Narsavage G, Delicath T. Predictors of health promotion behavior in women without prior history of coronary heart disease. Appl Nurs Res. Aug 2006;19(3):149-155.

17. Ali NS. Prediction of coronary heart disease preventive behaviors in women: a test of the health belief model. Women Health. 2002;35(1):83-96.

18. Oliver-McNeil S, Artinian NT. Women's perceptions of personal cardiovascular risk and their risk-reducing behaviors. Am J Crit Care. May 2002;11(3):221-227.

19. Haase A, Steptoe A, Sallis JF, Wardle J. Leisure-time physical activity in university students from 23 countries: associations with health beliefs, risk awareness, and national economic development. Prev Med. Jul 2004;39(1):182190.

20. Mosca L, Mochari H, Christian A, et al. National study of women's awareness, preventive action, and barriers to cardiovascular health. Circulation. Jan 31 2006;113(4):525-534.

21. Mirotznik J, Feldman L, Stein R. The health belief model and adherence with a community center-based, supervised coronary heart disease exercise program. $J$ Community Health. Jun 1995;20(3):233-247.

22. Lindsay-Reid E, Osborn RW. Readiness for exercise adoption. Soc Sci Med Med Psychol Med Sociol. Mar 1980;14A(2):139-146. 
23. US Census Bureau. State and County QuickFacts. Available at: http://quickfacts.census.gov/qfd/states/54/5455756.html. Accessed September 26, 2010.

24. CDC. Behavioral Risk Factor Surveillance System Survey Questionnaire. Atlanta, GA: US Department of Health and Human Services, Centers for Disease Control and Prevention; 2009.

25. Smith MM, Hicks VL, Heyward VH. Coronary heart disease knowledge test: developing a valid and reliable tool. Nurse Pract. Apr 1991;16(4):28, 31, 35-28.

26. Ammouri AA, Neuberger G. The Perception of Risk of Heart Disease Scale: development and psychometric analysis. J Nurs Meas. 2008;16(2):83-97.

27. Katz DA, Graber M, Birrer E, et al. Health beliefs toward cardiovascular risk reduction in patients admitted to chest pain observation units. Acad Emerg Med. May 2009;16(5):379-387.

28. Murdaugh $\mathrm{CL}$, Verran JA. Theoretical modeling to predict physiological indicants of cardiac preventive behaviors. Nurs Res. Sep-Oct 1987;36(5):284-291.

29. Murdaugh CL. Personal communication via electronic mail; 2009.

30. Sallis JF, Pinski RB, Grossman RM, L. PT, Nader PR. The development of selfefficacy scales for health-related diet and exercise behaviors. Health Educ Res. 1988;3(3):283-292.

31. PASW Statistics [computer program]. Version 18.0.0. Chicago, IL: SPSS, Inc.; 2009.

32. USDHHS. 2008 physical activity guidelines for Americans. Washington, DC: USDHHS; 2008. 
33. Brewer NT, Weinstein ND, Cuite CL, Herrington JE. Risk perceptions and their relation to risk behavior. Ann Behav Med. Apr 2004;27(2):125-130.

34. Bandura A. Self-efficacy: toward a unifying theory of behavioral change. Psychol Rev. Mar 1977;84(2):191-215.

35. Bandura A. Self-Efficacy: The Exercise of Control. New York: W. H. Freeman and Company; 1997.

36. Rosenstock IM, Strecher VJ, Becker MH. Social learning theory and the Health Belief Model. Health Educ Q. Summer 1988;15(2):175-183.

37. Sassen B, Kok G, Schaalma Dagger H, Kiers H, Vanhees L. Cardiovascular risk profile: Cross-sectional analysis of motivational determinants, physical fitness and physical activity. BMC Public Health. Oct 7 2010;10(1):592.

38. Hagger MS, Chatzisarantis N, Biddle SJ. The influence of self-efficacy and past behaviour on the physical activity intentions of young people. J Sports Sci. Sep 2001;19(9):711-725.

39. Prevalence of self-reported physically active adults--United States, 2007. MMWR Morb Mortal Wkly Rep. Dec 5 2008;57(48):1297-1300.

40. CDC. 2011 BRFSS physical activity rotating core: Summary of proposed changes. Available at: http://www.chronicdisease.org/files/public/DC BRFSS Summary.pdf. Accessed October 16, 2010.

41. Nunnaly J. Psychometric Theory. New York: McGraw-Hill; 1978. 


\section{Figure 3.1: The Health \\ Belief Model}

(adapted from Rosenstock, 1974)

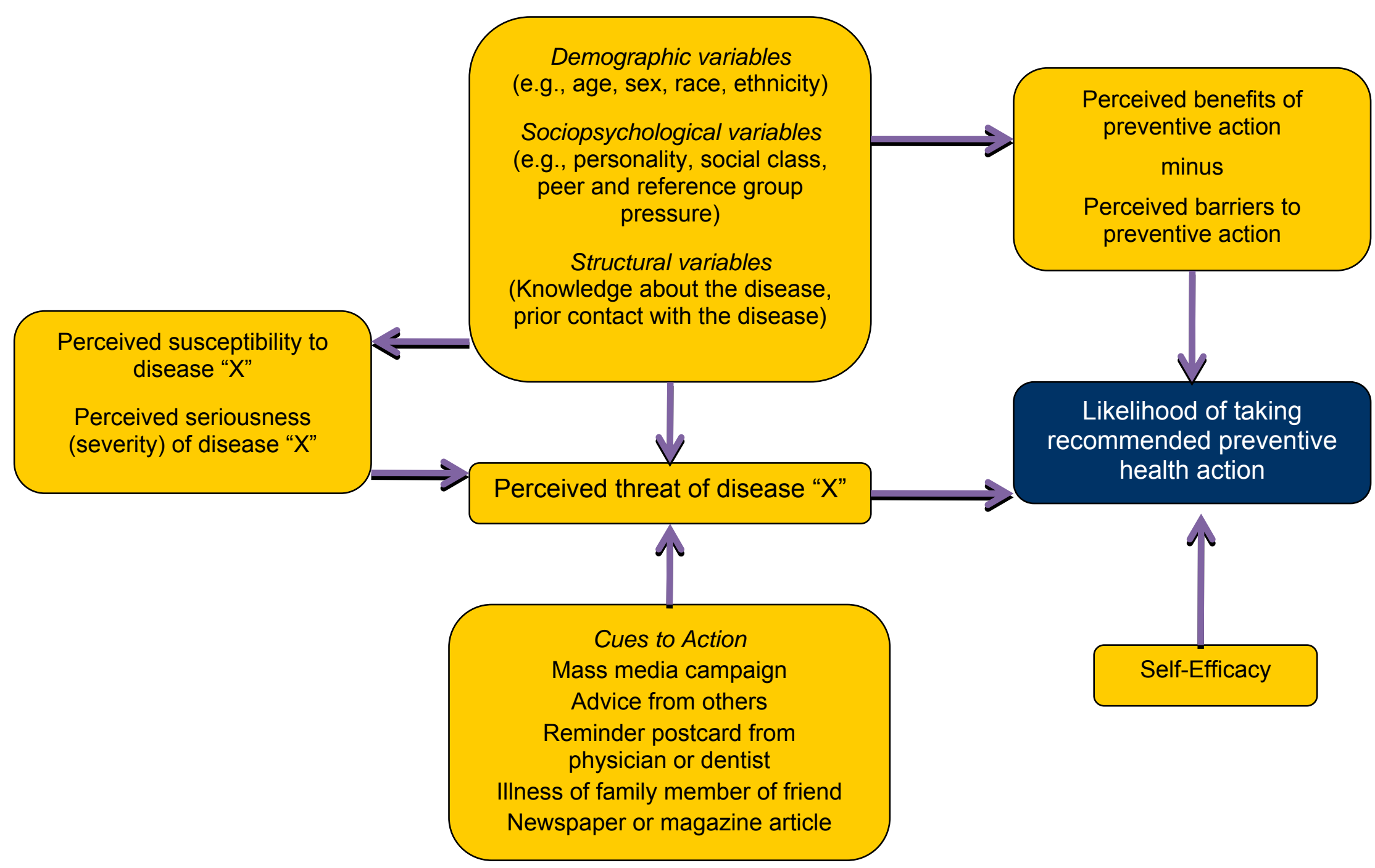


Table 3.1: Demographic Characteristics of the Sample

\begin{tabular}{|c|c|c|}
\hline Demographic Category & & Percent \\
\hline Age (years) & $18-29$ & 23.8 \\
\hline & $30-54$ & 59.5 \\
\hline & 55 and up & 16.7 \\
\hline Gender & Male & 15.3 \\
\hline & Female & 84.7 \\
\hline Education & High School & 8.6 \\
\hline & Some College or College Degree & 91.4 \\
\hline Marital Status & Single & 27.6 \\
\hline & Married & 59.8 \\
\hline & Separated/Divorced/Widowed & 12.6 \\
\hline Annual Household Income & $<\$ 20,000$ & 8.3 \\
\hline & $\$ 20,000-\$ 69,999$ & 46.9 \\
\hline & $\$ 70,000-\$ 139,999$ & 38.1 \\
\hline & $\$ 140,000$ or more & 6.7 \\
\hline BMI Category & Underweight & 1.6 \\
\hline & Healthy Weight & 43.5 \\
\hline & Overweight & 30.9 \\
\hline & Obese & 24.0 \\
\hline
\end{tabular}


Table 3.2: Components of the Health Belief Model and Instruments Used for Measurement

\begin{tabular}{|c|c|c|c|c|}
\hline Component of HBM & Instrument/Measure & Scale & Mean Score (SD) & $\begin{array}{l}\text { Internal } \\
\text { consistency } \\
\text { reliability*** }\end{array}$ \\
\hline Physical Activity & BRFSS PA items & $0-20,160^{*}$ & $16.6(8.80)^{\star *}$ & NA \\
\hline Knowledge of CHD & $\begin{array}{l}\text { Modified Coronary Heart Disease } \\
\text { Knowledge Test }\end{array}$ & $0-20$ & $13.8(2.25)$ & 0.463 \\
\hline Perceived Risk of CHD & $\begin{array}{l}\text { Perception of Risk of Heart } \\
\text { Disease Scale }\end{array}$ & $20-80$ & $54.7(6.05)$ & 0.790 \\
\hline Perceived Severity of CHD & $\begin{array}{l}\text { Perceived Seriousness of } \\
\text { Coronary Heart Disease Scale }\end{array}$ & $5-25$ & $16.5(2.59)$ & 0.621 \\
\hline Benefits of Behavior & Benefits Scale & $12-48$ & $41.8(4.40)$ & 0.864 \\
\hline Barriers to Behavior & Barriers Scale & $12-48$ & $22.4(4.81)$ & 0.821 \\
\hline Self-efficacy for PA & $\begin{array}{l}\text { Eating and Exercise Confidence } \\
\text { Scale - Exercise portion }\end{array}$ & $1-5$ & $3.6(0.89)$ & 0.940 \\
\hline Cue to Action for PA & $\begin{array}{l}\text { "Has your health care provider } \\
\text { recommended that you increase } \\
\text { your level of PA be healthier?" }\end{array}$ & Yes/No & NA & NA \\
\hline
\end{tabular}

*The maximum possible score for PA is based on 60 minutes per hour $\times 24$ hours per day $\times 7$ days per week $\times 2$ (for time spent in vigorous $\mathrm{PA}$ )

${ }^{* *}$ Mean score and SD calculated using square root-transformed values

${ }^{* * *}$ Cronbach's alpha coefficients, except for Knowledge of CHD, which was assessed using Kuder-Richardson formula 20 
Table 3.3: Pearson Correlations

\begin{tabular}{|c|c|c|c|c|c|c|c|c|}
\hline & $\begin{array}{l}\text { Square } \\
\text { Root PA }\end{array}$ & Knowledge & Risk & Severity & Benefits & Barriers & $\begin{array}{l}\text { Self-efficacy } \\
\text { - PA }\end{array}$ & Age \\
\hline Square Root PA & 1 & & & & & & & \\
\hline Knowledge & $.132^{*}$ & 1 & & & & & & \\
\hline Risk & $-.289^{* *}$ & -.036 & 1 & & & & & \\
\hline Severity & -.049 & $-.140^{* *}$ & $218^{* *}$ & 1 & & & & \\
\hline Benefits & $.190^{* *}$ & .035 & -.042 & .001 & 1 & & & \\
\hline Barriers & $-.387^{* *}$ & $-.131^{*}$ & $.188^{* *}$ & $.145^{* *}$ & $-.593^{* *}$ & 1 & & \\
\hline Self-efficacy - PA & $.594^{* *}$ & .075 & $-.266^{* *}$ & $-.142^{\star *}$ & $.239^{* *}$ & $-.541^{* *}$ & 1 & \\
\hline Age & $-.161^{* *}$ & -.034 & $.210^{* *}$ & -.090 & $-.151^{* *}$ & .059 & -.018 & 1 \\
\hline
\end{tabular}

*Significant at the 0.05 level (two-tailed)

${ }^{* *}$ Significant at the 0.01 level (two-tailed) 
Table 3.4: Hierarchical Regression - Square Root of Physical Activity Score as Dependent Variable

\begin{tabular}{|c|c|c|c|c|c|c|c|c|}
\hline & \multicolumn{2}{|l|}{ Step 1} & \multicolumn{2}{|l|}{ Step 2} & \multicolumn{2}{|l|}{ Step 3} & \multicolumn{2}{|l|}{ Step 4} \\
\hline Predictor & $\begin{array}{l}\text { Standardized } \\
\text { Beta (B) }\end{array}$ & $\mathbf{p}$ & $\begin{array}{l}\text { Standardized } \\
\text { Beta (B) }\end{array}$ & $\mathbf{p}$ & $\begin{array}{l}\text { Standardized } \\
\text { Beta (B) }\end{array}$ & p & $\begin{array}{l}\text { Standardized } \\
\text { Beta (B) }\end{array}$ & p \\
\hline Female Dummy & -.068 & .205 & -.067 & .110 & -.071 & .090 & -.070 & .094 \\
\hline Married Dummy & -.113 & .107 & -.002 & .969 & .003 & .959 & .003 & .963 \\
\hline $\begin{array}{l}\text { Separated/Divorced/ } \\
\text { Widowed Dummy }\end{array}$ & -.051 & .432 & -.023 & .647 & -.017 & .735 & -.019 & .702 \\
\hline$>$ High School Dummy & $.114^{*}$ & .040 & .070 & .111 & .074 & .093 & .061 & .179 \\
\hline Income $\geq \$ 70 \mathrm{~K}$ Dummy & .104 & .085 & .053 & .264 & .051 & .278 & .046 & .331 \\
\hline Age & $-.121^{*}$ & .045 & $-.112^{*}$ & .021 & $-.100^{*}$ & .042 & $-.100^{*}$ & .042 \\
\hline Perceived Severity & & & .049 & .254 & .062 & .152 & .066 & .130 \\
\hline Perceived Benefits & & & -.028 & .598 & -.019 & .722 & -.017 & .749 \\
\hline Perceived Barriers & & & -.029 & .642 & -.024 & .696 & -.021 & .731 \\
\hline Self-Efficacy - Exercise & & & $.523^{* * *}$ & $<.001$ & $.511^{* * *}$ & $<.001$ & $.513^{* * *}$ & $<.001$ \\
\hline Cue to Action Dummy & & & $-.186^{* * *}$ & $<.001$ & $-.166^{* *}$ & .001 & $-.159^{* *}$ & .001 \\
\hline Perceived Risk & & & & & -.081 & .083 & -.083 & .075 \\
\hline CHD Knowledge & & & & & & & .044 & .324 \\
\hline
\end{tabular}

\section{${ }^{*} p<.05,{ }^{* *} p<.01,{ }^{* * *} p<.001$}

Model Fit Statistics: Step 1: $R^{2}=.064$, Adj $R^{2}=.047, F(6,338)=3.83^{* *}, R^{2}$ change $=.064^{* *}$; Step 2: $R^{2}=.434$, Adj $R^{2}=$ $.416, F(11,333)=23.24^{* * *}, R^{2}$ change $=.371^{* * *}$; Step 3: $R^{2}=.439$, Adj $R^{2}=.419, F(12,332)=21.68^{\star * *}, R^{2}$ change $=$ $.005 ;$ Step 4: $R^{2}=.441$, Adj $R^{2}=.419, F(13,331)=20.09^{\star * *}, R^{2}$ change $=.002$ 
CHAPTER 4 


\section{CHAPTER 4:}

\section{ASSOCIATION BETWEEN DELAY DISCOUNTING AND DIETARY AND PHYSICAL ACTIVITY BEHAVIORS}

\section{Introduction}

As the leading cause of death in both men and women in industrialized nations, coronary heart disease (CHD) carries with it substantial negative clinical, economic, and

humanistic consequences. ${ }^{1-3}$ Fortunately, many risk factors for $\mathrm{CHD}$ are modifiable with lifestyle changes and drug therapy. Modifiable risk factors have been shown to account for over $90 \%$ of the risk of initial acute myocardial infarction. ${ }^{4}$ Such risk factors include behavioral factors (smoking, sedentary lifestyle, low fruit and vegetable consumption), physiologic factors (abdominal obesity, hypercholesterolemia, hypertension, diabetes), and psychosocial factors (depression, locus of control, perceived stress, life events). Lowering the prevalence of these modifiable risk factors would lead to a substantial decrease in morbidity and mortality from coronary heart disease.$^{5}$

The Appalachian region of the United States has been associated with a history of underdevelopment, leading to rurality, lower levels of socioeconomic status and education, and greatly increased rates of premature death. ${ }^{6}$ Although economic conditions have improved over the last several decades, the Appalachian region still fares worse than other regions of the United States in health outcomes related to coronary heart disease. ${ }^{7}$ A culture of unhealthy lifestyle, including poor diet and sedentary behavior, are contributors to this trend..$^{8,9}$ 
Behavioral risk factors are often the target of individual interventions (patient counseling delivered by health care providers and other health educators), as well as population-level interventions (policy implementation or environmental modifications) with the purpose of producing changes in behavior necessary to reduce risk of CHD. For example, modifying diet to include adequate amounts of fruits, vegetables, fish and whole grains and reduced amounts of saturated fat, sodium, and sugar-sweetened beverages, and participating in an adequate amount of physical activity (150 minutes or more per week of moderate physical activity or 75 minutes or more per week of vigorous physical activity or an equivalent combination of the two) is recommended by the American Heart Association to achieve cardiovascular health. ${ }^{5}$ Despite these efforts, lifestyle modifications to improve diet and increase physical activity can be difficult to adopt and even more difficult to maintain. A report by the Centers for Disease Control and Prevention states that maintenance of recommended lifestyle changes, including smoking cessation, medication adherence, diet, and exercise, was only $25-40 \%$ six months after initiation. ${ }^{10}$

Individual behavior change theories, such as the Health Belief Model (HBM), propose that factors such as individual perceptions of disease and costs vs. benefits of adopting health promoting behaviors together influence the likelihood an individual will make the desired behavior change. ${ }^{11}$ Components of the HBM include: perceived severity, perceived susceptibility (risk), perceived benefits, perceived barriers, cues to action, and self-efficacy. Factors demonstrated to modify the influence of these components on health behaviors include demographic (age, gender, ethnicity), sociopsychological (personality, social class, peer groups), and structural factors 
(knowledge of the health problem and prior experience) ${ }^{11}$ According to a review of HBM research by Janz and Becker, the most important components of the model in explaining health behavior are, in order of importance, perceived barriers, perceived risk, perceived benefits, and perceived severity. ${ }^{12}$ A significant correlation between perceived risk and preventive behaviors, including diet and physical activity, was demonstrated in women without prior history of heart disease, with perceived risk alone accounting for more than half the variance $(50.7 \%)$ in preventive behavior. ${ }^{13}$

One criticism of the HBM is that it does not include a time component. ${ }^{14}$ In other words, the time course of taking the preventive action and later reaping the benefits of decreased disease risk is not taken into account. The HBM and other models like it are value-expectancy theories, meaning that behavior is influenced by what the individual expects will result from behavior change and the value the individual places on that outcome. ${ }^{11}$ Given that value placed on an outcome differs with respect to time, and there is a trade-off between current costs and future benefits, the temporal relation between behavior change and receipt of reward becomes a relevant factor. One concept from economics literature that does incorporate a time component is delay discounting. Delay discounting refers to the idea that individuals will discount the future to varying degrees depending on how far into the future rewards are received. This phenomenon is also known as time preference. A high rate of discounting indicates an individual's preference toward more immediate rewards and a lower value placed on the future. Traditional Discounted Utility Theory states that individuals discount the future at a constant rate per unit of delay (exponential discounting function). ${ }^{15}$ With exponential discounting, relative preference for future outcomes will not change as the timing of the 
choice of outcome moves in closer proximity to the receipt of the outcome. Contrary to this theory, research has demonstrated that actual behavior follows a more hyperbolic discounting function, where rewards are discounted more steeply in the near future, leveling off as delay to reward increases. ${ }^{16}$ The implication of this discrepancy is that a preference reversal can occur, in which an individual changes his or her preference from the smaller, sooner reward (SSR) to the larger later reward (LLR) as delay to the SSR increases.

Degree of delay discounting has been examined in regard to several negative health behaviors, and has been found to be greater in smokers, ${ }^{17}$ alcohol abusers, ${ }^{18}$ and illicit drug users ${ }^{19}$ compared to controls. For example, one study demonstrated that current smokers have a significantly higher rate of discounting of monetary rewards compared to ex- and never-smokers. ${ }^{17}$ Neuroimaging studies have investigated the association between delay discounting and activation of specific portions of the brain involved in impulsive choice. A study in abstinent alcoholics and non-substance abusing controls demonstrated a significant positive correlation between impulsive choice and activity in particular portions of the brain (the dorsal prefrontal cortex, the posterior parietal cortex, and the anterior parahippocampal gyrus), suggesting a possible biological mechanism for this behavior. ${ }^{20}$ In addition to these effects in addictive disorders, discount rates have also been shown to be greater in children with Attention Deficit/Hyperactivity Disorder compared to controls. ${ }^{21}$

Despite a growing body of literature on delay discounting in addictive behaviors, there have been relatively few studies of delay discounting in preventive health behaviors. In an early exploratory study by Fuchs, rate of delay discounting was not 
found to be associated with seat belt use, exercise frequency, being overweight, or frequency of dental visits. ${ }^{22}$ However, the author suggested that the method used to elicit discount rates in this study was flawed, leading to inconsistent results and the suggestion to refine survey methods, specifically, increasing the number of binary choices in future research. A more recent investigation by Chapman with 60 community-members in Chicago found a significant association between exercise frequency and discount rate, but in the counter-predicted direction. ${ }^{23}$ In this research, participants completed discounting procedures for both health and monetary rewards, and were asked how many times per week they exercised, and how long they exercised during each session. Approximately half of the participants were recruited from an exercise class, possibly biasing the sample. Chapman suggested that the discrepancy in significance of association between discount rate and addictive behaviors compared to preventive health behaviors may be explained by the effect of addiction on time preferences, rather than vice versa. ${ }^{14}$ In other words, an addictive substance itself may increase tendency to make impulsive choices (and thus produce a higher discount rate), due to biological effects on the brain. This idea is reinforced by research that has shown a decrease in discount rate with prolonged abstinence from addictive substances. $^{24}$

In a large, nationally-representative sample of adults, degree of time preference explained more of the variance in diet quality than market or socio-cultural factors and was found to be a significant predictor of healthfulness of diet. ${ }^{25}$ However, time preference was not measured directly, but assessed using proxy variables, including education, smoking, exercise, nutrition knowledge, and regular use of nutrition labels. 
Selection of these variables was based on their theoretical association with time preference, and the authors suggest that studies utilizing more direct measures of future discounting are needed.

A pilot study of patients with hypertension revealed a significant association between discount rate and likelihood of altering diet and exercise behaviors. ${ }^{26}$ In this study, implicit discount rates were inferred using five binary choice questions and imputed using interval regression. Individuals with an imputed discount rate in the highest quintile were compared to those with rates in the four lowest quintiles. However, likelihood of diet- and exercise-related behavior change was assessed indirectly using a single item that asked whether the individual would rather eat, drink, and live life the way they want and have poorer health in 5 years, or would rather forgo these habits and enjoy better health in 5 years. A more recently published study, conducted in a sample of adults 50 years of age or older and their spouses or partners, utilized a similar method to assess discount rates and demonstrated a significant association between high discount rate and lower rates of healthy behaviors, including weekly vigorous physical activity. ${ }^{27}$ Health maintenance behaviors were assessed using data from the Health and Retirement Survey, and included mammograms, breast examinations, Pap smears, prostate examinations, dental visits, cholesterol testing, flu shots, and non-smoking status, in addition to physical activity. Higher discount rates were associated with significantly lower rates of all healthy behaviors, except for breast examination and Pap smears in women.

Several studies have also demonstrated a significant positive association between obesity and time preference for immediate rewards. ${ }^{28-31}$ Other studies have 
not found a significant association between time preference and obesity. ${ }^{32,33}$ While these studies may suggest that delay discounting is associated with energy balance, and thus with diet and physical activity behaviors, they did not examine these behaviors specifically, and methods to measure time preference vary widely among these studies. While it may appear that the association between delay discounting and body mass index (BMI) reflects the association between delay discounting and behaviors that impact BMI, specifically diet and physical activity, some suggest a more complex relationship. ${ }^{29}$ More research is needed to better understand the influence of delay discounting on preventive behaviors and obesity.

The primary objective of this study was to describe the association among rate of discounting and diet and physical activity behaviors, using both health and monetary rewards, in an Appalachian population. A secondary objective was to determine how perceived risk of $\mathrm{CHD}$ influences this association, given the theoretical importance of this variable in explaining preventive behaviors. The third objective was to explore the relation between $\mathrm{BMI}$, delay discounting, and dietary and physical activity behaviors for possible interactions. Our working hypothesis is that individuals with higher rates of discounting will exhibit less healthy dietary behaviors and lower levels of physical activity. In addition, we hypothesize that this association will hold true after controlling for perceived risk of CHD. 


\section{Methods}

\section{Study Population}

The study population consisted of individuals who work or reside in a small college town within the Appalachian region, home to about 26,800 residents, $51 \%$ of whom are male and $90 \%$ are white..$^{34}$ Median household income is $\$ 20,650$ and $69 \%$ have greater than high school education. Participants were recruited using electronic postings and listserves, newspaper advertisements, and postings on community bulletin boards. Online questionnaires were completed either off-site or in the research center, and the delay discounting procedure was administered via computer on-site. Inclusion criteria were age $\geq 18$ years and ability to read and understand English. Individuals were excluded if they had a prior history of heart disease based on self-report (if they answered affirmatively to either of the following questions: (1) "Have you ever been told by your healthcare provider that you have coronary heart disease, angina or have suffered a heart attack?" or (2) "Have you ever had coronary bypass surgery, coronary stent placement, or angioplasty?"). The study design was cross-sectional. Approval was obtained from the university's Institutional Review Board.

\section{Questionnaire Battery}

The questionnaire battery contained items pertaining to demographic information, including gender, age, education, marital status, household income, height and weight, as well as instruments to measure dietary and physical activity behaviors and perceived risk of $\mathrm{CHD}$. 
- The 16-item Food Behavior Checklist (FBC) was used to assess current dietary behaviors. ${ }^{35}$ It contains 15 items regarding diet quality in terms of fruit and vegetable, fat/cholesterol, milk/dairy and sugar-sweetened beverage consumption, and one item that measures self-rating of diet quality.

Published Cronbach's alpha coefficients for this measure are 0.8 for fruit and vegetable intake, 0.61 for diet quality, and Spearman's correlation was 0.47 for milk consumption (two items). ${ }^{36}$

- Physical activity (PA) levels were assessed using six physical activity items from the Behavioral Risk Factor Surveillance System Survey (BRFSS). ${ }^{37}$ These items assessed self-reported levels of moderate and vigorous physical activity in a usual week in terms of minutes per day and days per week and were used to calculate minutes of moderate PA per week (or the equivalent, counting each minute of vigorous PA as two minutes of moderate PA).

- Perception of risk of CHD was assessed using the 20-item Perception of Risk of Heart Disease Scale. ${ }^{38}$ This measure consists of statements of risk, such as, "I feel sure I will get heart disease," rated by the respondent on a fourpoint Likert-type scale, where $1=$ strongly disagree and $4=$ strongly agree. Published Cronbach's alpha for this scale is $0.80 .^{38}$

Permission to use all instruments was obtained prior to the study. 


\section{Delay Discounting Procedure}

To determine degree of delay discounting, we employed a widely used binary choice delay discounting procedure that elicits self-reported preferences for money and health at varying values and delays. ${ }^{39,40}$ The procedure was carried out via computeradministered survey, using a decreasing adjustment algorithm. ${ }^{41}$

\section{Binary Choice Discounting Procedure for Hypothetical Monetary Rewards:}

Participants were given a hypothetical choice of a smaller, sooner reward (SSR) or a larger, later reward (LLR) after a delay (D). Commonly used starting points and delays were utilized. The starting point was $\$ 1000$ for the LLR and 1 month for the delay. The starting point of the SSR was half of the LLR $(\$ 500)$. For each subsequent choice, the value of the SSR was adjusted by half of the previous adjustment. Six trials for each delay were presented. The indifference point was defined as the value of the SSR that would have been presented in the seventh trial. Indifference points represent the subjective present value of the reward for that particular delay. The process was repeated for delays of 1 year, 2 years, 5 years, 10 years, and 20 years, allowing for calculation of indifference points at each of the six delays.

\section{Binary Choice Discounting Procedure for Hypothetical Health Rewards:}

Participants were given a hypothetical health scenario, depicting the health status of a patient with CHD, and asked to imagine themselves in that state of health for the remainder of their lives (adapted from Chapman and Elstein, 1995). ${ }^{40}$ 
"Imagine that for the past two years your state of health has fit this description:

Because of your doctor's instructions, you need to take multiple medications each day. To monitor the effects of these medications, you must get blood drawn at your doctor's office at least once per month. You must also be very careful about what you eat and drink. You have to limit the amount of salt you eat and fluids you drink. You often have swollen ankles. You sometimes have chest pain, for which you must take nitroglycerin tablets. You have to visit the bathroom often to urinate. You often feel tired and cannot walk more than 20 feet without getting short of breath. You often do not have the energy for sexual activity. Sometimes, you feel depressed about your health."

After presenting this scenario, the participant was given a choice of a smaller, sooner reward (SSR) or a larger, later reward (LLR) after a delay (D). These rewards were in terms of hypothetical treatments, each of which would return the participant to full health for $\mathrm{X}$ number of years, but not taking effect until after a particular delay. The starting point for $X$ was 10 years for the LLR and 1 month for the delay. The starting point of the SSR was half of the LLR (5 years). For each subsequent choice, the value of the SSR was adjusted by half of the previous adjustment. Six trials were presented. The indifference point was defined as the value of the SSR that would have been presented in the seventh trial. The process was repeated for delays of 1 year, 2 years, 5 years, 10 years, and 20 years, allowing calculation of indifference points at each of six delays. 
For each participant, area under the curve (AUC) was calculated for both monetary rewards and health rewards to represent degree of discounting, using the method proposed by Myerson et al. ${ }^{42}$ An advantage to using AUC, rather than calculating discount rate to measure degree of discounting, is the avoidance of the need to fit the curve to a hyperbolic form. AUC is considered theory-neutral, and is also less likely to produce a skewed distribution. To obtain AUCs between 0 (steepest discounting) and 1 (no discounting), delays and indifference points were normalized for each data point. To do this, each delay was divided by the maximum delay (20 years) and each indifference point was divided by the LLR (representing nominal value of the reward). The graph of subjective value (ordinate) vs. delay (abscissa) was then subdivided into a series of trapezoids. Area of each trapezoid was calculated using the formula: $\left(x_{2}-x_{1}\right)\left[\left(y_{1}-y_{2}\right) / 2\right]$, and areas were summed to obtain AUC. AUC is inversely related to degree of discounting (the higher the degree of discounting, the lower the AUC), and thus directly related to the individual's value of the future.

The procedure for the decreasing adjustment algorithm described by Du et al was utilized. ${ }^{41}$ The participant was offered an initial choice between the starting LLR and a SSR whose amount is half the amount of the LLR. If the SSR was chosen, the SSR in the subsequent choice was decreased. If the LLR was chosen, the subsequent SSR was increased. The amount of increase or decrease was equal to half the amount of the previous adjustment. This process continued until six choices were made. This entire process was repeated for each of six delays, resulting in a total of 36 trials per participant for each of the two procedures (monetary and health rewards). 


\section{Data Analysis}

Scores for the instruments were calculated using standard scoring mechanisms, when available, such that higher scores indicated higher levels of the constructs (e.g., higher diet score $=$ healthier diet). Descriptive statistics were calculated for the sample, including demographic variables and instrument scores. Pearson product-moment bivariate correlation coefficients were calculated for all continuous variables to determine the association between degree of discounting and diet and PA behaviors (objective 1).

Instrument scores, along with gender, age (years), education ( $\leq$ high school, $>$ high school), total annual household income $(<\$ 70,000, \$ 70,000$ or more $)$, and marital status (single, married, widowed/divorced/separated) were analyzed using hierarchical linear regression to determine the association between degree of delay discounting, perceived CHD risk and behavior (objective 2). To examine effect on dietary behavior, the score for current dietary habits was utilized as the dependent variable, while scores for the delay discounting procedure and perceived risk instrument were utilized as independent variables. Dummy variables for gender, income, education, and marital status, and a continuous variable representing age were also entered as independent variables. Demographic variables were entered in the first step. AUC as a measure of degree of discounting was entered in the second step, using AUC for monetary rewards in one regression model and AUC for health rewards in a second regression. Lastly, perceived risk of $\mathrm{CHD}$ was entered in the third step to determine unique variance explained by this variable. A similar pair of regressions utilizing physical activity as the dependent variable was performed to examine effect of discounting and perceived risk 
on physical activity levels. Standardized beta coefficients were used to assess strength of association between degree of discounting and dietary and PA behaviors, holding other factors constant. The goal sample size was 150 , to achieve $80 \%$ power to detect an effect size of .075 for the hierarchical regression $(\alpha=.05)$.

Chi square, Pearson's correlations and Student's t tests were used to explore the relation between discounting, BMI, and diet and PA behaviors (objective 3). PASW (version 18.0.0) was used for data analysis. ${ }^{43}$

\section{Results}

Demographics of the Sample

172 participants completed both the online questionnaire and delay discounting task. Demographic characteristics of the sample appear in Table 4.1. Of the respondents, the majority was female, currently married, had greater than high school education, and had a total household income $<\$ 70,000$. Mean age was 43 years \pm 13.68. More than half $(53.6 \%)$ of participants were categorized as either overweight or obese based on self-reported height and weight, and mean BMI was $26.1 \pm 5.81$.

\section{Examination for Outliers and Normality of Distribution}

Data were examined for outliers and to ensure normality of distribution for variables used in the model. Calculating $z$ scores and using $>3$ standard deviations from the mean as the criterion for exclusion, five cases were excluded from the models 
as outliers. After exclusion of these outliers, skewness and kurtosis for all continuous variables fell within the desired range except for PA score, AUC for money and AUC for health, (which were all positively skewed), indicating adequate normality of distributions for these variables. PA score and AUCs were transformed using a square root transformation, which resulted in distributions that more closely approximated normal, with skewness and kurtosis within the acceptable range.

\section{Descriptive Statistics}

Mean scores for each component of the models are shown in Table 4.2. Mean diet score was $27.7 \pm 7.04$, on a scale of $0-48$. Internal consistency reliability, assessed using Cronbach's alpha for the diet scale was 0.688 . Using the physical activity guidelines for adults ${ }^{44}$ (at least 150 minutes per week of moderate or 75 minutes per week of vigorous physical activity, or an equivalent combination of the two), $70.9 \%$ of participants met the guidelines. On a scale of $20-80$, mean score for perceived risk was $54.5 \pm 6.48$, indicating a moderate perception of risk among participants. Internal consistency reliability, assessed using Cronbach's alpha for the perceived risk scale was 0.814 . There was no significant difference between mean square root-transformed AUC for monetary rewards (0.547) and mean square root-transformed AUC for health rewards $(0.553)[t(171)=.289, p=.773]$. There were also no significant differences in degree of discounting for either monetary or health rewards based on gender, marital status, or income. Mean square root-transformed AUC for monetary rewards was significantly lower for participants with $\leq$ high school education $(0.399 \pm .221)$ compared 
to those with $>$ high school education $(0.563 \pm .224)[t(170)=2.89, p=.004]$. There was no significant difference in degree of discounting of health rewards based on education level.

Consistency of responses in the delay discounting procedure was examined for both monetary and health rewards. A consistent response is defined as one that produced indifference points that are greater than or equal in subjective value to those for longer delays. In other words, a curve plotted with value of indifference points on the ordinate and delay on the abscissa would be either monotonically decreasing or level, and never turn upward. Three-fourths (76\%) of participants gave consistent responses for monetary rewards and $62 \%$ of participants gave consistent responses for health rewards.

Correlations

Pearson product-moment bivariate correlation coefficients were calculated for all continuous variables (Table 4.3). AUC for monetary rewards was significantly correlated with AUC for health rewards $(r=.253, p=.001)$. Contrary to prediction, neither diet score nor PA score was significantly correlated with either AUC for monetary rewards or AUC for health rewards. Perceived risk of CHD was not significantly correlated with either AUC for monetary rewards or AUC for health rewards. Age was significantly negatively correlated with AUC for health rewards $(r=-.292, p<.001)$ but not with AUC for monetary rewards. 
Hierarchical Regressions - Diet

Results of the hierarchical regressions using diet score as the dependent variable are show in Tables 4.4 and 4.5. Two additional cases were found to be outliers based on standardized residuals $<-3$ and were removed, resulting in a final $n=168$ after listwise exclusion for missing values. The final model incorporating discounting of monetary rewards explained $21.4 \%$ of the variance in dietary behavior, using adjusted $R^{2}$ (Table 4.4). Demographic variables alone explained $13.4 \%$ of the variance in diet behaviors. The $\mathrm{R}^{2}$ change for Step 2 was $.011(p=.148)$, indicating that degree of discounting of monetary rewards did not explain any additional variance over the model that contained only demographic variables. There was a significant improvement over Step 2 with the addition of perceived risk of CHD, which explained an additional $7.6 \%$ of the variance in dietary behavior. In the final model, female gender, > high school education, increased age, and decreased perceived risk were associated with increased diet score. Durbin-Watson test statistic for the model was 2.020, which is in the acceptable range of 1.5 to 2.5 , indicating there were no issues with autocorrelation in residuals. Variance inflation factor (VIF) and tolerance values for all variables in the model fell within the acceptable ranges of $<4$ and $>0.2$, respectively, indicating there were no concerns with multicollinearity. When the regression was repeated using only consistent responses for discounting of monetary rewards $(n=127)$, the full model explained only $17.9 \%$ of the variance in dietary behavior; otherwise results were unaffected.

Similar results were demonstrated when AUC for health rewards was included, with no significant contribution of degree of discounting of health rewards to explain 
dietary behavior (Table 4.5). When only consistent responses for discounting of health rewards were included $(n=105)$, the final model explained $23.8 \%$ of the variance in dietary behavior, but was otherwise unaffected.

Hierarchical Regressions - Physical Activity

Results of the hierarchical regressions using square root-transformed PA score as the dependent variable are show in Tables 4.6 and 4.7. No outliers were detected using standardized residuals, leaving a final $n=163$ after listwise exclusion for missing values. The final model incorporating discounting of monetary rewards explained only $8.8 \%$ of the variance in PA behavior, using adjusted $\mathrm{R}^{2}$ (Table 4.6). Demographic variables alone explained only $2.3 \%$ of the variance in $\mathrm{PA}$ behavior. The $\mathrm{R}^{2}$ change for Step 2 was $.007(p=.295)$, indicating that degree of discounting of monetary rewards did not explain any additional variance over the model that contained only demographic variables. There was a significant improvement over Step 2 with the addition of perceived risk of $\mathrm{CHD}$, which explained an additional $6.7 \%$ of the variance in PA behavior. Durbin-Watson test statistic for the model was 2.202, which is in the acceptable range of 1.5 to 2.5 , indicating there were no issues with autocorrelation in residuals. Variance inflation factor (VIF) and tolerance values for all variables in the model fell within the acceptable ranges of $<4$ and $>0.2$, respectively, indicating there were no concerns with multicollinearity. When the regression was repeated using only consistent responses for discounting of monetary rewards $(n=122)$, the full model explained $11.3 \%$ of the variance, but was otherwise unaffected. 
Similar results were demonstrated when AUC for health rewards was included, with no significant contribution of degree of discounting of health rewards to explain PA behavior (Table 4.7). When only consistent responses for discounting of health rewards were included $(n=102)$, the final model explained only $6.4 \%$ of the variance in PA behavior, but was otherwise unaffected.

Association with Body Mass Index

Neither AUC for monetary rewards nor AUC for health rewards was significantly correlated with BMI as a continuous variable. However, when the sample was dichotomized as underweight/healthy weight vs. overweight/obese, associations were found. Mean square root-transformed AUC for monetary rewards was significantly lower in overweight/obese individuals $(0.516 \pm 0.219)$ compared to underweight/healthy weight individuals $(0.590 \pm 0.236)[t(166)=2.11, p=.037]$. Mean square roottransformed AUC for health rewards was lower in overweight/obese individuals $(0.535 \pm$ $0.242)$ compared to underweight/healthy weight individuals $(0.581 \pm 0.233)$, but this did not reach statistical significance $[\mathrm{t}(166)=1.25, \mathrm{p}=.214]$. Mean square root-transformed PA score was significantly lower for participants identified as overweight or obese (14.7 \pm 8.43 ) compared to those categorized as underweight or healthy weight $(20.7 \pm 8.29)$ $[t(159)=4.52 p<.001]$. Fewer overweight or obese participants met the guidelines for weekly PA (62\%) compared to underweight or healthy weight participants $(84 \%)$ $\left(X^{2}=9.96, p=.002\right)$. Diet score was significantly lower for participants identified as overweight or obese $(25.8 \pm 7.04)$ compared to those categorized as underweight or 
healthy weight $(29.9 \pm 6.27)[t(166)=3.95, p<.001]$. Square root-transformed AUC for monetary rewards was significantly correlated with diet score in underweight/healthy weight individuals $(r=.255, p=.024)$, but not in overweight/obese individuals. Square root-transformed AUC for health rewards was not significantly correlated with diet score in either BMI group. Square root-transformed PA score was not significantly correlated with square root-transformed AUC for monetary rewards or square root-transformed AUC for health rewards in either BMI group.

\section{Discussion}

Degree of delay discounting, assessed using a binary choice discounting procedure, was not shown to be associated with CHD preventive behaviors, specifically diet and PA. A positive association was found between AUC for monetary rewards and education level, with participants with > high school education showing a greater value of the future compared to less educated participants. Age was negatively associated with value of the future in terms of discounting of health rewards. Perceived risk was found to be negatively associated with preventive behaviors, but no association with degree of discounting was shown. When associations between value of the future and preventive behaviors were explored in terms of BMI category, a positive correlation was demonstrated between AUC and dietary behavior in underweight/healthy participants, but no association was found in overweight/obese participants. In addition, overweight/obese individuals discounted the future to a significantly greater degree than underweight/healthy weight individuals. 
In accordance with these findings, the well-documented association between degree of discounting and addictive behaviors ${ }^{17-19}$ has not been universally found in preventive health behaviors. Given the complexity of diet and PA behaviors, there may truly be a lack of direct association. It is possible that the environment is a stronger predictor of diet and PA behaviors than individual characteristics, such as value of the future. Recently, there has been an increasing focus on environmental factors that lead to obesity ${ }^{45}$ as well as a public health focus on environmental policy change to improve nutrition and physical activity. ${ }^{46-48}$ Some have suggested that improvements in food technology, decreased time cost and real cost of food, reductions in strenuous labor, and urban sprawl have created an environment that promotes unhealthy food consumption and decreased PA, contributing to rising obesity rates. ${ }^{30}$

In contrast, there may be an association between degree of discounting and diet and PA behaviors, but the magnitude of effect is so small that it would require a much larger sample size to detect it. It is also possible that these associations were not demonstrated in this relatively physically active, highly educated study population, but may be demonstrated in other populations. With more than $70 \%$ of the study sample reporting meeting the guidelines for $\mathrm{PA}$, there may not have been enough variation in behavior to reveal an association. More research in large, more diverse populations are needed to determine if such an association truly exists.

Perceived risk was negatively associated with both dietary and PA behaviors, counter to the direction of association postulated by the HBM. This may be due to the fact that individuals who practice healthy dietary habits and get adequate amounts of PA accurately assess that they are at lower risk for CHD because of their behavior. 
This explanation is consistent with the risk reappraisal hypothesis, which states that individuals who perceive themselves at high risk for disease may adopt preventive behaviors, and subsequently reassess their risk as lower after adoption of the behavior. ${ }^{49}$ This hypothesis was tested and supported in a longitudinal study that assessed Lyme disease vaccination and risk perception. ${ }^{49}$ Individuals who perceived themselves to be at higher risk for Lyme disease at Time 1 were more likely to get vaccinated. Those who subsequently received the vaccine were found to have a lower perceived risk at Time 2 compared with Time 1. In addition, those who received the vaccine more accurately assessed their risk, having a lower perception of risk compared to those who did not receive the vaccine. Depending upon the time at which perceived risk and behavior are measured, results may demonstrate an association between perceived risk and preventive behavior in the direction opposite that predicted by the HBM, which holds that a higher perception of disease risk leads to increased likelihood of participation in preventive behaviors. Unfortunately, this phenomenon cannot always be avoided in cross-sectional studies such as this one.

When associations between diet and PA behaviors and degree of discounting were analyzed in terms of BMI category, interesting findings were uncovered. Not surprisingly, greater delay discounting was demonstrated in overweight/obese individuals compared to underweight/healthy weight individuals. Similar results have been demonstrated in other studies. ${ }^{28-31}$ What was unexpected is the finding that better diet quality was associated with greater value of the future in underweight/healthy weight individuals, but not in overweight/obese individuals. This may indicate a more complex association between self-controlled choice and behavior in overweight/obese 
individuals. It has been suggested that differences in activation of certain portions of the brain in overweight/obese individuals may lead to lesser inhibitory response to hedonic food cues, resulting in impaired weight management. ${ }^{31}$ Further research using larger sample sizes is needed to untangle these complex associations.

As is true for cross-sectional survey research in general, these results must be interpreted with caution in light of several limitations. First, the cross-sectional nature of the study design does not allow for establishment of causation. Second, all measures were based on self-report, introducing the potential for recall or social desirability bias. Third, the sample tended to be highly educated and mostly female, limiting generalizability to other populations or settings. Although the intent was to capture a sample that was representative of an Appalachian population, the resulting sample did not display the demographic characteristics most often associated with Appalachians.

\section{Conclusion}

In this Appalachian population, degree of delay discounting was shown to be significantly associated with dietary behaviors, but only in underweight/healthy weight individuals. No association was found between degree of discounting and PA behaviors. More research is needed to fully understand the nature of these associations. 


\section{References}

1. Stone NJ. The clinical and economic significance of atherosclerosis. Am J Med. Oct 8 1996;101(4A):4A6S-9S.

2. Trogdon JG, Finkelstein EA, Nwaise IA, Tangka FK, Orenstein D. The economic burden of chronic cardiovascular disease for major insurers. Health Promot Pract. Jul 2007;8(3):234-242.

3. van Jaarsveld $\mathrm{CH}$, Sanderman R, Miedema I, Ranchor AV, Kempen GI. Changes in health-related quality of life in older patients with acute myocardial infarction or congestive heart failure: a prospective study. J Am Geriatr Soc. Aug 2001;49(8):1052-1058.

4. Yusuf S, Hawken S, Ounpuu S, et al. Effect of potentially modifiable risk factors associated with myocardial infarction in 52 countries (the INTERHEART study): case-control study. Lancet. Sep 11-17 2004;364(9438):937-952.

5. Lloyd-Jones DM, Hong Y, Labarthe D, et al. Defining and setting national goals for cardiovascular health promotion and disease reduction: the American Heart Association's strategic Impact Goal through 2020 and beyond. Circulation. Feb 2 2010;121(4):586-613.

6. Barnett E, Elmes GA, Braham VE, Halverson JA, Lee JY, Loftus S. Heart Disease in Appalachia: An Atlas of County Economic Conditions, Mortality, and Medical Care Resources. Morgantown, WV: Prevention Research Center, West Virginia University; 1998. 
7. Halverson J, Ma L, Harner EJ. An analysis of disparities in health status and access to care in the Appalachian region. Washington, D.C.: Appalachian Regional Commission; 2004.

8. Amarasinghe A, D'Souza G, Brown C, Oh H, Borisova T. The influence of socioeconomic and environmental determinants on health and obesity: a West Virginia case study. Int J Environ Res Public Health. Aug 2009;6(8):2271-2287.

9. Wewers ME, Katz M, Fickle D, Paskett ED. Risky behaviors among Ohio Appalachian adults. Prev Chronic Dis. Oct 2006;3(4):A127.

10. United States Department of Health and Human Services CDC. Physical Activity and Health: A Report of the Surgeon General. Atlanta, GA: Author; 1996.

11. Rosenstock I. Historical Origins of the Health Belief Model. In: Becker MH, ed. The Health Belief Model and Personal Behavior. Thorofare, NJ: Slack, Inc.; 1974.

12. Janz NK, Becker MH. The Health Belief Model: a decade later. Health Educ Q. Spring 1984;11(1):1-47.

13. Ali NS. Prediction of coronary heart disease preventive behaviors in women: a test of the health belief model. Women Health. 2002;35(1):83-96.

14. Chapman GB. Short-term cost for long-term benefit: time preference and cancer control. Health Psychol. Jul 2005;24(4 Suppl):S41-48.

15. Loewenstein G, Prelec D. Anomalies in intertemporal choice: Evidence and an interpretation. Q J Econ. May 1992;107(2):573-597.

16. Ainslie G. Specious reward: a behavioral theory of impulsiveness and impulse control. Psychol Bull. Jul 1975;82(4):463-496. 
17. Bickel WK, Odum AL, Madden GJ. Impulsivity and cigarette smoking: delay discounting in current, never, and ex-smokers. Psychopharmacology (Berl). Oct 1999;146(4):447-454.

18. Vuchinich RE, Simpson CA. Hyperbolic temporal discounting in social drinkers and problem drinkers. Exp Clin Psychopharmacol. Aug 1998;6(3):292-305.

19. Madden GJ, Petry NM, Badger GJ, Bickel WK. Impulsive and self-control choices in opioid-dependent patients and non-drug-using control participants: drug and monetary rewards. Exp Clin Psychopharmacol. Aug 1997;5(3):256-262.

20. Boettiger CA, Mitchell JM, Tavares VC, et al. Immediate reward bias in humans: fronto-parietal networks and a role for the catechol-O-methyltransferase 158(Val/Val) genotype. J Neurosci. Dec 26 2007;27(52):14383-14391.

21. Barkley RA, Edwards G, Laneri M, Fletcher K, Metevia L. Executive functioning, temporal discounting, and sense of time in adolescents with attention deficit hyperactivity disorder (ADHD) and oppositional defiant disorder (ODD). J Abnorm Child Psychol. Dec 2001;29(6):541-556.

22. Fuchs VR. Time preference and health: An exploratory study. NBER Working Paper No. W0539. Cambridge, MA: National Bureau of Economic Research; August 1980.

23. Chapman GB. Sooner or Later: The Psychology of Intertemporal choice. In: Medin DL, ed. The Psychology of Learning and Motivation. Vol 38. New York, NY: Academic Press; 1998:83-113. 
24. Petry NM. Delay discounting of money and alcohol in actively using alcoholics, currently abstinent alcoholics, and controls. Psychopharmacology (Berl). Mar 2001;154(3):243-250.

25. Huston SJ, Finke MS. Diet choice and the role of time preference. J Consum Aff. 2003;37(1):143-160.

26. Axon RN, Bradford WD, Egan BM. The role of individual time preferences in health behaviors among hypertensive adults: a pilot study. J Am Soc Hypertens. Jan-Feb 2009;3(1):35-41.

27. Bradford WD. The association between individual time preferences and health maintenance habits. Med Decis Making. Jan-Feb 2010;30(1):99-112.

28. Komlos J, Smith PK, Bogin B. Obesity and the rate of time preference: is there a connection? J Biosoc Sci. Mar 2004;36(2):209-219.

29. Smith PK, Bogin B, Bishai D. Are time preference and body mass index associated? Evidence from the National Longitudinal Survey of Youth. Econ Hum Biol. Jul 2005;3(2):259-270.

30. Zhang L, Rashad I. Obesity and time preference: the health consequences of discounting the future. J Biosoc Sci. Jan 2008;40(1):97-113.

31. Weller RE, Cook EW, 3rd, Avsar KB, Cox JE. Obese women show greater delay discounting than healthy-weight women. Appetite. Nov 2008;51(3):563-569.

32. Nederkoorn C, Smulders FT, Havermans RC, Roefs A, Jansen A. Impulsivity in obese women. Appetite. Sep 2006;47(2):253-256.

33. Borghans L, Golsteyn BH. Time discounting and the body mass index. Evidence from the Netherlands. Econ Hum Biol. Jan 2006;4(1):39-61. 
34. US Census Bureau. State and County QuickFacts. Available at: http://quickfacts.census.gov/qfd/states/54/5455756.html. Accessed September 26, 2010.

35. Townsend MS, Sylva K, Martin A, Metz D, Wooten-Swanson P. Improving readability of an evaluation tool for low-income clients using visual information processing theories. J Nutr Educ Behav. May-Jun 2008;40(3):181-186.

36. Townsend MS, Kaiser LL, Allen LH, Joy AB, Murphy SP. Selecting items for a food behavior checklist for a limited-resource audience. J Nutr Educ Behav. MarApr 2003;35(2):69-77.

37. CDC. Behavioral Risk Factor Surveillance System Survey Questionnaire. Atlanta, GA: US Department of Health and Human Services, Centers for Disease Control and Prevention; 2009.

38. Ammouri AA, Neuberger G. The Perception of Risk of Heart Disease Scale: development and psychometric analysis. J Nurs Meas. 2008;16(2):83-97.

39. Lagorio $\mathrm{CH}$, Madden GJ. Delay discounting of real and hypothetical rewards III: steady-state assessments, forced-choice trials, and all real rewards. Behav Processes. May 31 2005;69(2):173-187.

40. Chapman GB, Elstein AS. Valuing the future: temporal discounting of health and money. Med Decis Making. Oct-Dec 1995;15(4):373-386.

41. Du W, Green L, Myerson J. Cross-cultural comparisons of discounting delayed and probabilistic rewards. Psychol Rec. 2002;52:479-492.

42. Myerson J, Green L, Warusawitharana M. Area under the curve as a measure of discounting. J Exp Anal Behav. Sep 2001;76(2):235-243. 
43. PASW Statistics [computer program]. Version 18.0.0. Chicago, IL: SPSS, Inc.; 2009.

44. USDHHS. 2008 physical activity guidelines for Americans. Washington, DC: USDHHS; 2008.

45. Hill JO. Understanding and addressing the epidemic of obesity: an energy balance perspective. Endocr Rev. Dec 2006;27(7):750-761.

46. Glanz K, Yaroch AL. Strategies for increasing fruit and vegetable intake in grocery stores and communities: policy, pricing, and environmental change. Prev Med. Sep 2004;39 Suppl 2:S75-80.

47. Sallis JF, Glanz K. The role of built environments in physical activity, eating, and obesity in childhood. Future Child. Spring 2006;16(1):89-108.

48. Sallis JF, Cervero RB, Ascher W, Henderson KA, Kraft MK, Kerr J. An ecological approach to creating active living communities. Annu Rev Public Health. 2006;27:297-322.

49. Brewer NT, Weinstein ND, Cuite CL, Herrington JE. Risk perceptions and their relation to risk behavior. Ann Behav Med. Apr 2004;27(2):125-130. 
Table 4.1: Demographic Characteristics of the Sample

\begin{tabular}{|c|c|c|}
\hline Demographic Category & & Percent \\
\hline Age (years) & $18-29$ & 23.4 \\
\hline & $30-54$ & 55.6 \\
\hline & 55 and up & 21.0 \\
\hline Gender & Male & 17.4 \\
\hline & Female & 82.6 \\
\hline Education & High School & 9.9 \\
\hline & Some College or College Degree & 90.1 \\
\hline Marital Status & Single & 32.0 \\
\hline & Married & 57.6 \\
\hline & Separated/Divorced/Widowed & 10.4 \\
\hline Annual Household Income & $<\$ 20,000$ & 13.4 \\
\hline & $\$ 20,000$ - $\$ 69,999$ & 39.5 \\
\hline & $\$ 70,000-\$ 139,999$ & 39.5 \\
\hline & $\$ 140,000$ or more & 7.6 \\
\hline BMI Category & Underweight & 1.8 \\
\hline & Healthy Weight & 44.6 \\
\hline & Overweight & 32.7 \\
\hline & Obese & 20.9 \\
\hline
\end{tabular}


Table 4.2: Components of the Health Belief Model and Instruments Used for Measurement

\begin{tabular}{|l|l|l|l|l|}
\hline Component of HBM & Instrument/Measure & Scale & $\begin{array}{l}\text { Mean Score } \\
\text { (SD) }\end{array}$ & $\begin{array}{l}\text { Internal } \\
\text { consistency } \\
\text { reliability*** }\end{array}$ \\
\hline Dietary Behavior & Food Behavior Checklist & $0-48$ & $27.7(7.04)$ & .688 \\
\hline Physical Activity Behavior & BRFSS Moderate/Vigorous PA Items & $0-20,160^{*}$ & $17.2(9.00)^{\star *}$ & NA \\
\hline Perceived Risk of CHD & Perception of Risk of Heart Disease Scale & $20-80$ & $54.5(6.48)$ & .814 \\
\hline AUC Monetary Rewards & $\begin{array}{l}\text { Binary Choice Discounting Procedure using } \\
\text { Monetary Rewards }\end{array}$ & $0-1$ & $0.547(0.23)^{* *}$ & NA \\
\hline AUC Health Rewards & $\begin{array}{l}\text { Binary Choice Discounting Procedure using } \\
\text { Health Rewards }\end{array}$ & $0-1$ & $0.553(0.24)^{* *}$ & NA \\
\hline
\end{tabular}

*The maximum possible score for PA is based on 60 minutes per hour $\times 24$ hours per day $x 7$ days per week $\times 2$ (for time spent in vigorous PA)

${ }^{* *}$ Mean score and SD calculated using square root-transformed values

${ }^{* * *}$ Cronbach's alpha coefficients 
Table 4.3: Pearson Correlations

\begin{tabular}{|c|c|c|c|c|c|c|c|}
\hline & $\begin{array}{l}\text { Square } \\
\text { Root AUC } \\
\text { money }\end{array}$ & $\begin{array}{l}\text { Square } \\
\text { Root AUC } \\
\text { health }\end{array}$ & Diet & $\begin{array}{l}\text { Square } \\
\text { Root PA }\end{array}$ & $\begin{array}{l}\text { Perceived } \\
\text { Risk }\end{array}$ & Age & BMI \\
\hline Square Root AUC_money & 1 & & & & & & \\
\hline Square Root AUC_health & $.253^{* *}$ & 1 & & & & & \\
\hline Diet & .128 & .080 & 1 & & & & \\
\hline Square Root PA & .125 & .061 & $.271^{* *}$ & 1 & & & \\
\hline Perceived Risk & -.084 & -.080 & $-.303^{* *}$ & $-.296^{* *}$ & 1 & & \\
\hline Age & -.093 & $-.292^{* *}$ & $.157^{*}$ & $-.171^{*}$ & .120 & 1 & \\
\hline BMI & -.102 & -.081 & $-.220^{\star *}$ & $-.406^{\star *}$ & $.456^{* *}$ & $.211^{* *}$ & 1 \\
\hline
\end{tabular}

*Significant at the 0.05 level (two-tailed)

** Significant at the 0.01 level (two-tailed) 
Table 4.4: Hierarchical Regression - Association between Discounting of Monetary Rewards and Diet Score $(n=168)$

\begin{tabular}{|c|c|c|c|c|c|c|}
\hline & \multicolumn{2}{|l|}{ Step 1} & \multicolumn{2}{|l|}{ Step 2} & \multicolumn{2}{|l|}{ Step 3} \\
\hline Predictor & $\begin{array}{l}\text { Standardized Beta } \\
\text { (B) }\end{array}$ & $\mathbf{p}$ & $\begin{array}{l}\text { Standardized Beta } \\
\text { (B) }\end{array}$ & $\mathbf{p}$ & $\begin{array}{l}\text { Standardized Beta } \\
\text { (B) }\end{array}$ & $\mathbf{p}$ \\
\hline Female Dummy & $.223^{* *}$ & .003 & $.231^{* *}$ & .002 & $.199^{* *}$ & .006 \\
\hline Married Dummy & -.083 & .372 & -.078 & .404 & -.034 & .701 \\
\hline $\begin{array}{l}\text { Separated/Divorced/ Widowed } \\
\text { Dummy }\end{array}$ & -.158 & .073 & -.155 & .079 & -.134 & .112 \\
\hline$>$ High School Dummy & $.292^{* * *}$ & $<.001$ & $.272^{\star \star}$ & .001 & $.259^{* *}$ & .001 \\
\hline Income $\geq \$ 70 \mathrm{~K}$ Dummy & -.049 & .547 & -.056 & .491 & -.059 & .452 \\
\hline Age & $.221^{* *}$ & .007 & $.227^{* *}$ & .006 & $.246^{* *}$ & .002 \\
\hline $\begin{array}{l}\text { Square Root AUC Monetary } \\
\text { Rewards }\end{array}$ & & & .108 & .148 & .081 & .256 \\
\hline Perceived Risk & & & & & $-.283^{* * *}$ & $<.001$ \\
\hline
\end{tabular}

${ }^{*} \mathrm{p}<.05,{ }^{* *} \mathrm{p}<.01,{ }^{* * *} \mathrm{p}<.001$

Model Fit Statistics: Step 1: $R^{2}=.165$, Adj $R^{2}=.134, F(6,161)=5.29^{\star * *}, R^{2}$ change $=.165^{\star * *} ;$ Step 2: $R^{2}=.176$, Adj $R^{2}$

$=.140, F(7,160)=4.90^{* *}, R^{2}$ change $=.011$; Step 3: $R^{2}=.251$, Adj $R^{2}=.214, F(8,159)=6.67^{* * *}, R^{2}$ change $=.076^{\star * *}$ 
Table 4.5: Hierarchical Regression - Association between Discounting of Health Rewards and Diet Score ( $n=168)$

\begin{tabular}{|c|c|c|c|c|c|c|}
\hline & \multicolumn{2}{|l|}{ Step 1} & \multicolumn{2}{|l|}{ Step 2} & \multicolumn{2}{|l|}{ Step 3} \\
\hline Predictor & $\begin{array}{l}\text { Standardized } \\
\text { Beta (B) }\end{array}$ & $\mathbf{p}$ & $\begin{array}{l}\text { Standardized Beta } \\
\text { (B) }\end{array}$ & $\mathbf{p}$ & $\begin{array}{l}\text { Standardized Beta } \\
\text { (B) }\end{array}$ & $\mathbf{p}$ \\
\hline Female Dummy & $.223^{* *}$ & .003 & $.216^{* *}$ & .004 & $.186^{*}$ & .010 \\
\hline Married Dummy & -.083 & .372 & -.085 & .364 & -.039 & .664 \\
\hline $\begin{array}{l}\text { Separated/Divorced/ Widowed } \\
\text { Dummy }\end{array}$ & -.158 & .073 & -.151 & .089 & -.130 & .125 \\
\hline$>$ High School Dummy & $.292^{* * *}$ & $<.001$ & $288^{* * *}$ & $<.001$ & $.270^{* * *}$ & $<.001$ \\
\hline Income $\geq \$ 70 \mathrm{~K}$ Dummy & -.049 & .547 & -.050 & .538 & -.055 & .485 \\
\hline Age & $.221^{* *}$ & .007 & $.246^{* *}$ & .004 & $.264^{* *}$ & .001 \\
\hline $\begin{array}{l}\text { Square Root AUC Health } \\
\text { Rewards }\end{array}$ & & & .080 & .298 & .069 & .344 \\
\hline Perceived Risk & & & & & $-.288^{* * *}$ & $<.001$ \\
\hline
\end{tabular}

${ }^{*} \mathrm{p}<.05,{ }^{* *} \mathrm{p}<.01,{ }^{* * *} \mathrm{p}<.001$

Model Fit Statistics: Step 1: $R^{2}=.165$, Adj $R^{2}=.134, F(6,161)=5.29^{* * *}, R^{2}$ change $=.165^{* * *}$; Step 2: $R^{2}=.170$, Adj $R^{2}$

$=.134, F(7,160)=4.69^{\star \star \star}, R^{2}$ change $=.006$; Step 3: $R^{2}=.249$, Adj $R^{2}=.212, F(8,159)=6.61^{\star \star \star}, R^{2}$ change $=.079^{\star \star *}$ 
Table 4.6: Hierarchical Regression - Association between Discounting of Monetary Rewards and Physical Activity Score $(n=163)$

\begin{tabular}{|c|c|c|c|c|c|c|}
\hline & \multicolumn{2}{|l|}{ Step 1} & \multicolumn{2}{|l|}{ Step 2} & \multicolumn{2}{|l|}{ Step 3} \\
\hline Predictor & $\begin{array}{l}\text { Standardized } \\
\text { Beta (B) }\end{array}$ & $\mathbf{p}$ & $\begin{array}{l}\text { Standardized Beta } \\
\text { (B) }\end{array}$ & p & $\begin{array}{l}\text { Standardized Beta } \\
\text { (B) }\end{array}$ & p \\
\hline Female Dummy & -.068 & .396 & -.059 & .464 & -.092 & .238 \\
\hline Married Dummy & -.115 & .261 & -.111 & .276 & -.070 & .479 \\
\hline $\begin{array}{l}\text { Separated/Divorced/ Widowed } \\
\text { Dummy }\end{array}$ & -.025 & .794 & -.023 & .813 & -.003 & .972 \\
\hline > High School Dummy & .094 & .270 & .078 & .366 & .072 & .390 \\
\hline Income $\geq \$ 70 \mathrm{~K}$ Dummy & .081 & .364 & .077 & .388 & .069 & .425 \\
\hline Age & -.132 & .138 & -.126 & .155 & -.107 & .213 \\
\hline $\begin{array}{l}\text { Square Root AUC Monetary } \\
\text { Rewards }\end{array}$ & & & .085 & .295 & .058 & .457 \\
\hline Perceived Risk & & & & & $-.266^{\star *}$ & .001 \\
\hline
\end{tabular}

${ }^{*} \mathrm{p}<.05,{ }^{* *} \mathrm{p}<.01,{ }^{* * *} \mathrm{p}<.001$

Model Fit Statistics: Step 1: $R^{2}=.059$, Adj $R^{2}=.023, F(6,156)=1.64, R^{2}$ change $=.059$; Step 2: $R^{2}=.066$, Adj $R^{2}=$ $.024, F(7,155)=1.56, R^{2}$ change $=.007$; Step 3: $R^{2}=.133$, Adj $R^{2}=.088, F(8,154)=2.96^{* *}, R^{2}$ change $=.067^{* *}$ 
Table 4.7: Hierarchical Regression - Association between Discounting of Health Rewards and Physical Activity Score $(n=163)$

\begin{tabular}{|c|c|c|c|c|c|c|}
\hline & \multicolumn{2}{|l|}{ Step 1} & \multicolumn{2}{|l|}{ Step 2} & \multicolumn{2}{|l|}{ Step 3} \\
\hline Predictor & $\begin{array}{l}\text { Standardized } \\
\text { Beta (B) }\end{array}$ & $\mathbf{P}$ & $\begin{array}{l}\text { Standardized Beta } \\
\text { (B) }\end{array}$ & $\mathbf{p}$ & $\begin{array}{l}\text { Standardized Beta } \\
\text { (B) }\end{array}$ & $\mathbf{p}$ \\
\hline Female Dummy & -.068 & .396 & -.068 & .396 & -.098 & .206 \\
\hline Married Dummy & -.115 & .261 & -.115 & .262 & -.071 & .472 \\
\hline $\begin{array}{l}\text { Separated/Divorced/ Widowed } \\
\text { Dummy }\end{array}$ & -.025 & .794 & -.025 & .798 & -.005 & .957 \\
\hline > High School Dummy & .094 & .270 & .093 & .275 & .083 & .314 \\
\hline Income $\geq \$ 70 \mathrm{~K}$ Dummy & .081 & .364 & .081 & .366 & .071 & .409 \\
\hline Age & -.132 & .138 & -.130 & .160 & -.113 & .207 \\
\hline $\begin{array}{l}\text { Square Root AUC Health } \\
\text { Rewards }\end{array}$ & & & .005 & .951 & -.008 & .921 \\
\hline Perceived Risk & & & & & $-.272^{* \star}$ & .001 \\
\hline
\end{tabular}

${ }^{*} \mathrm{p}<.05,{ }^{* *} \mathrm{p}<.01,{ }^{* * *} \mathrm{p}<.001$

Model Fit Statistics: Step 1: $R^{2}=.059$, Adj $R^{2}=.023, F(6,156)=1.64, R^{2}$ change $=.059$; Step 2: $R^{2}=.059$, Adj $R^{2}=$ $.017, F(7,155)=1.40, R^{2}$ change $=.000$; Step $3: R^{2}=.130$, Adj $R^{2}=.085, F(8,154)=2.88^{* *}, R^{2}$ change $=.071^{* *}$ 
CHAPTER 5 


\section{CHAPTER 5:}

\section{GENERAL DISCUSSION}

\section{Rationale and Objective}

Although modifiable risk factors for coronary heart disease (CHD) can be favorably impacted by healthful diet and physical activity, health care providers face a population that generally exhibits unhealthy eating habits and sedentary lifestyles. Motivating patients to adopt heart healthy behaviors is a difficult task, and that task is even more challenging in populations with significant economic, environmental, and health disparities, such as those in Appalachia. ${ }^{1}$ Identifying strategies to improve the effectiveness of health care provider guidance is urgently needed to reduce CHD risk. The Health Belief Model (HBM) and behavioral economic theories have demonstrated that framing of future risk can impact intentions. Together these theories provide a promising new framework for the identification of strategies to improve provider communication. HBM research has shown that knowledge ${ }^{2-4}$ and perceived risk of $\mathrm{CHD}^{3,5}$ are correlated with diet and physical activity. These findings have not been consistent across populations, however, suggesting that factors such as age and health status may be influential. ${ }^{6-10}$ Similarly, behavioral economics research has found that the value individuals place on future health influences current health behaviors. Because CHD is generally asymptomatic and negative consequences may not be evident for years, the value placed on future health likely impacts the adoption of heart healthy behaviors. The degree to which future health is discounted has been 
associated with addictive behaviors, ${ }^{11-13}$ but has not been widely examined in preventive behaviors, such as diet and physical activity. ${ }^{14-18}$

The objective of this series of studies was to determine the association between CHD knowledge, perceived risk, and delay discounting and diet and physical activity levels in adults, in order to identify strategies to improve the effectiveness of health care provider communication. The research design was cross-sectional and the methods included an online survey to obtain information regarding CHD knowledge, perceived risk, and preventive behaviors and a binary choice discounting procedure to elicit degree of discounting for hypothetical monetary and health rewards in an Appalachian population. The specific aims of the studies were: (1) To determine the association between knowledge and perceived risk of CHD and diet and physical activity in Appalachians, and (2) To evaluate the association between the degree of discounting of future health and diet and physical activity.

\section{Summary of Findings}

CHD Knowledge, Perceived Risk of CHD, and Diet and Physical Activity (PA) Behaviors

In this cross-sectional study of CHD preventive behaviors in an Appalachian population, overall knowledge of CHD was positively correlated with both healthfulness of diet and PA levels, but these associations were no longer significant after controlling for demographic factors and other components of the HBM, including perceived risk of $\mathrm{CHD}$, perceived severity of $\mathrm{CHD}$, perceived benefits and barriers to preventive behaviors, self-efficacy, and cue to action. Contrary to the direction of association 
predicted by the HBM, perceived risk was negatively associated with diet and PA behaviors. Age, perceived barriers, self-efficacy and physician recommendations for lifestyle changes may also play a role based on their significance as predictors of dietary or PA behaviors. Self-efficacy was the strongest predictor of both healthfulness of diet and PA levels, after adjusting for demographic variables and the other components of the HBM.

Degree of Delay Discounting and Diet and PA Behaviors

Degree of delay discounting (a measure of how an individual values the future), assessed using a binary choice discounting procedure, was not associated with $\mathrm{CHD}$ preventive behaviors, specifically diet and PA. A positive association was found between AUC for monetary rewards and education level, with participants who reported $>$ high school education demonstrating greater value of the future compared to less educated participants. Age was negatively associated with value of the future assessed through discounting of health rewards, but no such association was found using discounting of monetary rewards. Perceived risk was negatively associated with preventive behaviors, but no association with degree of discounting was shown.

When associations between value of the future and preventive behaviors were explored by body mass index (BMI) category, a positive correlation was demonstrated between AUC and dietary behavior in underweight/healthy participants, but no association was found in overweight/obese participants. In addition, overweight/obese 
individuals discounted the future to a significantly greater degree than underweight/healthy weight individuals.

\section{Significance of the Studies}

These findings suggest that, while education to improve disease-related knowledge is an important tool for health promotion and chronic disease prevention, it may not be sufficient for a significant impact on health outcomes, a concept that is wellsupported by previous research. ${ }^{19}$ In a randomized, controlled trial in over 500 men and women hospitalized with cardiovascular disease, the effectiveness of patientcentered lifestyle counseling was compared to a control intervention consisting of a brief prevention message..$^{20}$ The study demonstrated a significant improvement in dietary and exercise behaviors, as well as increased HDL cholesterol levels in the group that received lifestyle counseling compared to the control group. A similar study showed fewer physician visits and decreased healthcare costs in the group that received lifestyle counseling compared to the one that received general health messages. ${ }^{21}$ In order to produce meaningful behavior change and improve clinical outcomes in patients at risk for $\mathrm{CHD}$, educational interventions should be designed to do more than simply provide disease-related knowledge.

While perception of risk of disease does seem to predict preventive dietary and PA behaviors, the temporal association is complex and evaluating the effect of risk perceptions can be difficult in cross-sectional research. ${ }^{22}$ It has been suggested that inaccurate perceptions of risk may not only discourage participation in preventive health 
behaviors, inappropriate risk perceptions may also lead to unnecessarily increased anxiety about chronic diseases, such as CHD. ${ }^{23,24}$ This emphasizes the importance of appropriate education regarding risk factors and lifestyle changes to decrease risk of $\mathrm{CHD}$, as well as conducting accurate risk assessments.

The construct that displayed the greatest influence on diet and PA behaviors in this series of studies was self-efficacy. Long recognized as an important component of individual behavior change theories, self-efficacy has been shown to be significantly positively associated with adoption of preventive health behaviors. ${ }^{25,26}$ Providing means of boosting self-efficacy for lifestyle changes for those at highest risk of CHD could positively impact morbidity and mortality, decreasing the societal burden of this disease. This would entail skill-building interventions on an individual level, as well as interventions to reduce perceived barriers on a population level, stressing the role of environment and policy change to encourage preventive behaviors. Individuals who live in environments that support healthful diet and PA would likely have higher self-efficacy for these behaviors. ${ }^{27,28}$ It has been suggested that interventions that impact the environment may be far more effective in reducing obesity, overeating and physical inactivity than those using educational efforts alone. ${ }^{29}$ Efforts are needed to increase access to healthful food and opportunities for PA, and reduce the financial and behavioral costs of such lifestyle changes, in conjunction with educational interventions.

Although the predicted relationships were not demonstrated when assessing degree of delay discounting, diet and PA behaviors, this research extends the literature in regard to time preference and preventive health behaviors. The lack of significant findings could be due to little diversity in the study sample in terms of gender, education, 
and participation in preventive behaviors. On the other hand, the association that exists between delay discounting and addictive behaviors ${ }^{11-13}$ may simply not exist with preventive health behaviors, or the magnitude of effect may be very small. This lack of direct relationship could be due to the complexity of factors that influence behaviors to prevent chronic diseases, including individual factors and environmental factors. The associations between degree of delay discounting and behavior in regard to BMI category were interesting and may point to differences in influence of self-controlled choice on behavior in overweight/obese, compared to underweight/healthy weight individuals.

The intent of these studies was to examine the concepts of CHD knowledge, perceived risk, delay discounting, and diet and physical activity levels in an Appalachian sample. Although Appalachia is defined by geography, and recruitment occurred within the Appalachian region, the resulting sample displayed greater levels of education, higher incomes, and more healthful lifestyle habits than are generally considered typical of Appalachians. This is likely due to recruitment activities, which took place in a university community whose residents tend to be of higher socioeconomic status, and the study methodology, which required computer skills and a visit to the research center. These requirements may have differentially encouraged individuals with greater levels of education to participate. 


\section{Strengths and Limitations}

Strengths of this series of studies include sound methodology using validated measures and a relatively large sample size for the questionnaire. The delay

discounting methodology used has been well-documented in the literature. ${ }^{30-32}$ The study is innovative because it is, to the best of the authors' knowledge, the first to address delay discounting of the future and its association with diet and physical activity in an Appalachian population at risk for CHD. Adaptation of a general health scenario to one more specific to CHD was a novel application of an established procedure for discounting the future using health rewards. ${ }^{31}$ Although the sample size for the delay discounting study was smaller than sample sizes for the other two studies, it still exceeded those for the large majority of research related to time preference and health behaviors, as reported in a review of this literature by Chapman. ${ }^{33}$

Despite many strengths of this series of studies, there were several limitations which should be recognized. First, the cross-sectional nature of the study design does not allow for establishment of causation. Prospective cohort studies would be needed to evaluate causal relationships between preventive behaviors and individual knowledge, perceptions, and value of the future. Second, all measures were based on self-report, introducing the potential for recall or social desirability bias. Third, the sample tended to be highly educated, physically active and mostly female, limiting generalizability to other populations or settings. Although the intent was to capture a sample that was representative of an Appalachian population, the resulting sample did 
not display the demographic characteristics most often associated with Appalachians. Recruitment for the study was community-wide, but many participants were university employees or students, potentially biasing the sample toward a greater level of education among participants. Also, advertisements for the study included the phrase "healthy heart study," which may have differentially encouraged individuals with healthier lifestyle habits to participate.

\section{Ideas for Future Study}

Given the strength of association between self-efficacy and diet and PA behaviors, more research is needed to examine the effect of self-efficacy boosting interventions on adoption and maintenance of preventive behaviors. This should entail both individual skill-building interventions, as well as environmental change interventions. Studies should be longitudinal and designed to assess effects of these interventions separately and track changes in behavior over time.

The current literature assessing the association between perception of $\mathrm{CHD}$ risk and preventive behaviors consists mostly of studies with cross-sectional designs. ${ }^{3,5-7,9}$ To better explain this association, a longitudinal study should be conducted, wherein perceived risk of CHD and diet and PA behaviors are measured at baseline and again at regular intervals over a multi-year period of time. This would better allow the assessment of change in behavior over time and the influence of risk perception on behavior change. 
In addition, delay discounting studies using similar methodology in larger, more behaviorally and demographically diverse populations are needed to determine if associations between degree of delay discounting and diet and PA behaviors truly exist. These studies should be powered to detect differences among individuals of various weight categories, using measured height, weight, and waist circumference to avoid self-report bias. Given that the current literature regarding delay discounting and obesity shows conflicting results, more studies are needed to examine what factors may modify the influence of time preference on obesity or vice versa. ${ }^{34-39}$

\section{Conclusion}

Self-efficacy, rather than knowledge or perceived risk, was found to be the strongest predictor of diet and PA behaviors. Value of the future was positively associated with healthfulness of diet in underweight/healthy weight individuals, but was not associated with diet or PA behaviors in the overall sample. A better understanding of the factors that are associated with healthfulness of diet and level of PA can inform patient education, as well as environment and policy change to encourage preventive behaviors. 


\section{References}

1. Barnett E, Elmes GA, Braham VE, Halverson JA, Lee JY, Loftus S. Heart Disease in Appalachia: An Atlas of County Economic Conditions, Mortality, and Medical Care Resources. Morgantown, WV: Prevention Research Center, West Virginia University; 1998.

2. Thanavaro JL, Moore SM, Anthony M, Narsavage G, Delicath T. Predictors of health promotion behavior in women without prior history of coronary heart disease. Appl Nurs Res. Aug 2006;19(3):149-155.

3. Ali NS. Prediction of coronary heart disease preventive behaviors in women: a test of the health belief model. Women Health. 2002;35(1):83-96.

4. Pace R, Dawkins N, Wang B, Person S, Shikany JM. Rural African Americans' dietary knowledge, perceptions, and behavior in relation to cardiovascular disease. Ethn Dis. Winter 2008;18(1):6-12.

5. O'Brien WH, VanEgeren L. Perceived susceptibility to heart disease and preventive health behavior among Type A and Type B individuals. Behav Med. Winter 1991;17(4):159-165.

6. Oliver-McNeil S, Artinian NT. Women's perceptions of personal cardiovascular risk and their risk-reducing behaviors. Am J Crit Care. May 2002;11(3):221-227.

7. Mosca L, Mochari H, Christian A, et al. National study of women's awareness, preventive action, and barriers to cardiovascular health. Circulation. Jan 31 2006;113(4):525-534. 
8. Haase A, Steptoe A, Sallis JF, Wardle J. Leisure-time physical activity in university students from 23 countries: associations with health beliefs, risk awareness, and national economic development. Prev Med. Jul 2004;39(1):182190.

9. Mirotznik J, Feldman L, Stein R. The health belief model and adherence with a community center-based, supervised coronary heart disease exercise program. $J$ Community Health. Jun 1995;20(3):233-247.

10. Lindsay-Reid E, Osborn RW. Readiness for exercise adoption. Soc Sci Med Med Psychol Med Sociol. Mar 1980;14A(2):139-146.

11. Bickel WK, Odum AL, Madden GJ. Impulsivity and cigarette smoking: delay discounting in current, never, and ex-smokers. Psychopharmacology (Berl). Oct 1999;146(4):447-454.

12. Vuchinich RE, Simpson CA. Hyperbolic temporal discounting in social drinkers and problem drinkers. Exp Clin Psychopharmacol. Aug 1998;6(3):292-305.

13. Madden GJ, Petry NM, Badger GJ, Bickel WK. Impulsive and self-control choices in opioid-dependent patients and non-drug-using control participants: drug and monetary rewards. Exp Clin Psychopharmacol. Aug 1997;5(3):256-262.

14. Chapman GB. Sooner or Later: The Psychology of Intertemporal choice. In: Medin DL, ed. The Psychology of Learning and Motivation. Vol 38. New York, NY: Academic Press; 1998:83-113.

15. Fuchs VR. Time preference and health: An exploratory study. NBER Working Paper No. W0539. Cambridge, MA: National Bureau of Economic Research; August 1980. 
16. Huston SJ, Finke MS. Diet choice and the role of time preference. J Consum Aff. 2003;37(1):143-160.

17. Axon RN, Bradford WD, Egan BM. The role of individual time preferences in health behaviors among hypertensive adults: a pilot study. J Am Soc Hypertens. Jan-Feb 2009;3(1):35-41.

18. Bradford WD. The association between individual time preferences and health maintenance habits. Med Decis Making. Jan-Feb 2010;30(1):99-112.

19. Mazzuca SA. Does patient education in chronic disease have therapeutic value? J Chronic Dis. 1982;35(7):521-529.

20. Mosca L, Mochari $\mathrm{H}$, Liao $\mathrm{M}$, et al. A novel family-based intervention trial to improve heart health: FIT Heart: results of a randomized controlled trial. Circ Cardiovasc Qual Outcomes. Nov 2008;1(2):98-106.

21. Nawathe AC, Glied SA, Weintraub WS, Mosca LJ. The effect of a cardiovascular educational intervention on healthcare utilization and costs. Am J Manag Care. May 2010;16(5):339-346.

22. Brewer NT, Weinstein ND, Cuite CL, Herrington JE. Risk perceptions and their relation to risk behavior. Ann Behav Med. Apr 2004;27(2):125-130.

23. van der Weijden $T$, van Steenkiste B, Stoffers HE, Timmermans DR, Grol R. Primary prevention of cardiovascular diseases in general practice: mismatch between cardiovascular risk and patients' risk perceptions. Med Decis Making. Nov-Dec 2007;27(6):754-761. 
24. Gramling R, Klein W, Roberts M, Waring ME, Gramling D, Eaton CB. Self-rated cardiovascular risk and 15-year cardiovascular mortality. Ann Fam Med. Jul-Aug 2008;6(4):302-306.

25. Bandura A. Self-efficacy: toward a unifying theory of behavioral change. Psychol Rev. Mar 1977;84(2):191-215.

26. Bandura A. Self-Efficacy: The Exercise of Control. New York: W. H. Freeman and Company; 1997.

27. Hermstad AK, Swan DW, Kegler MC, Barnette JK, Glanz K. Individual and environmental correlates of dietary fat intake in rural communities: a structural equation model analysis. Soc Sci Med. Jul 2010;71(1):93-101.

28. Motl RW, Dishman RK, Saunders RP, Dowda M, Pate RR. Perceptions of physical and social environment variables and self-efficacy as correlates of selfreported physical activity among adolescent girls. J Pediatr Psychol. Jan-Feb 2007;32(1):6-12.

29. Wing RR, Goldstein MG, Acton KJ, et al. Behavioral science research in diabetes: lifestyle changes related to obesity, eating behavior, and physical activity. Diabetes Care. Jan 2001;24(1):117-123.

30. Lagorio $\mathrm{CH}$, Madden GJ. Delay discounting of real and hypothetical rewards III: steady-state assessments, forced-choice trials, and all real rewards. Behav Processes. May 31 2005;69(2):173-187.

31. Chapman GB, Elstein AS. Valuing the future: temporal discounting of health and money. Med Decis Making. Oct-Dec 1995;15(4):373-386. 
32. Du W, Green L, Myerson J. Cross-cultural comparisons of discounting delayed and probabilistic rewards. Psychol Rec. 2002;52:479-492.

33. Chapman GB. Short-term cost for long-term benefit: time preference and cancer control. Health Psychol. Jul 2005;24(4 Suppl):S41-48.

34. Komlos J, Smith PK, Bogin B. Obesity and the rate of time preference: is there a connection? J Biosoc Sci. Mar 2004;36(2):209-219.

35. Borghans L, Golsteyn BH. Time discounting and the body mass index. Evidence from the Netherlands. Econ Hum Biol. Jan 2006;4(1):39-61.

36. Nederkoorn C, Smulders FT, Havermans RC, Roefs A, Jansen A. Impulsivity in obese women. Appetite. Sep 2006;47(2):253-256.

37. Smith PK, Bogin B, Bishai D. Are time preference and body mass index associated? Evidence from the National Longitudinal Survey of Youth. Econ Hum Biol. Jul 2005;3(2):259-270.

38. Weller RE, Cook EW, 3rd, Avsar KB, Cox JE. Obese women show greater delay discounting than healthy-weight women. Appetite. Nov 2008;51(3):563-569.

39. Zhang L, Rashad I. Obesity and time preference: the health consequences of discounting the future. J Biosoc Sci. Jan 2008;40(1):97-113. 
APPENDICES 
Appendix A: Online Questionnaire Conducted using Survey Monkey 


\section{Coronary Heart Disease, Diet and Physical Activity}

\section{Introduction and Informed Consent}

Researchers at the West Virginia University Health Sciences Center are conducting a study to test the association between knowledge of coronary heart disease, perceived risk of coronary heart disease, and diet and physical activity behaviors. The purpose of the study is to shed light on effective communication techniques that health care providers can use when talking to their patients about coronary heart disease prevention. The study is part of a PhD dissertation project.

We would appreciate your help in this study by answering the questions in this survey. Participation in this study is voluntary, and in no way will affect your class standing, grades, or status on an athletic team if you are a student at WVU, or job standing if you are an employee of WVU. Although there are no sensitive questions, or questions that are likely to cause discomfort, you may elect to quit at any time without penalty. Your name will not be used in publications or presentations that result from this survey. There are no known risks or direct benefits from participating in this study. The survey takes about 30 minutes to complete. If you have any questions about this study contact Kimberly Blake, PharmD, MBA, at 304-293-2306. If you complete the survey and provide your contact information, you will be entered in a drawing for one of ten $\$ 200$ gift cards to Giant Eagle.

Thanks for your help!

\section{By choosing "I accept" you acknowledge that you have read and understand the information given above, and agree to proceed with the questionnaire.}

I I accept

I do not wish to continue 


\section{Coronary Heart Disease, Diet and Physical Activity}

\section{Study Inclusion Criteria}

This survey is part of a study to test the association between knowledge of coronary heart disease, perceived risk of coronary heart disease, and diet and physical activity behaviors. Please answer the following two questions to determine your eligibility to participate in the study.

1. Are you 18 years of age or older?

Yes

No

2. Have you ever been told by your health care provider that you have coronary heart disease, angina, or have suffered a heart attack?

Yes

No

3. Have you ever had coronary bypass surgery, coronary stent placement, or angioplasty?

Yes

No 


\section{Confidentiality}

We know that information about your health is private. We are dedicated to protecting the privacy of that information. Because of this, we must get your authorization (permission) before we may use or disclose your protected health information or share it with others for research purposes.

You can decide whether or not to give your permission. However, if you choose not to permit the use or disclosure of this health information, you will not be able to take part in the research study. Whatever choice you make, it will not have an effect on your access to medical care.

Persons/Organizations receiving the information:

- WVU Health Research Center, the research site carrying out this study.

- The United States Department of Health and Human Services (which includes the National Institutes of Health, Food and Drug Administration (FDA)) and other groups that have the right to use the information as required by law.

- The members and staff of any Institutional Review Board (IRB) that oversee this research study.

- West Virginia University Office of Research Compliance and Office of Sponsored Programs.

The following information will be used:

Your height and weight, gender and date of birth.

The information is being disclosed for the following reasons:

- Review of your data for quality assurance purposes.

- Publication of study results (without identifying you).

- Other research purposes such as reviewing the effects of knowledge and perceived health risk.

You may cancel this authorization at any time by writing to the Principal Investigator:

Carole Harris, PhD, WVU Health Research Center, POB 9136, Morgantown, WV 26506-9136

- If you cancel this authorization, any information that was collected already for this study cannot be withdrawn. Once information is disclosed, according to this authorization the recipient may redisclose it and then the information may no longer be protected by federal privacy regulations.

- This authorization will not expire unless you cancel it.

\section{I have read this form and all of my questions about this form have been answered. By choosing "I accept", I acknowledge that I have read and accept all of the above.}

P accept 


\section{Coronary Heart Disease, Diet and Physical Activity}

\section{Contact Information}

1. I would like to receive a copy of the HIPPA information on the previous page.

$\bigcirc$ Yes

No

2. Please enter the following contact information. This information is necessary in order for us to enter your name in the lottery and to contact you in the event that you win. You may also be contacted in the next six months to participate in a follow-up study.

Name:

Address:

Address 2:

City/Town:

State:

ZIP/Postal Code:

Email Address:

Phone Number:

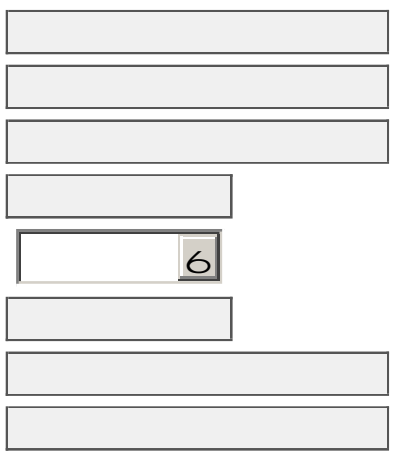




\section{Online Survey Instructions}

Thank you for participating in this survey addressing coronary heart disease prevention.

It should take you about thirty minutes to complete the survey.

Below are some items to keep in mind as you complete the survey:

- To move through the survey pages, use the "Next" and "Previous" buttons at the bottom of each page. Do not use your browser's "Back" button, as this may result in the loss of data.

- Once the "Next" button is clicked, the survey will advance to the next page unless there are error messages for questions on the current page. The error messages will appear in red above the questions that need to be addressed. You may need to scroll down on the page to locate the questions with error messages.

- All questions require an answer. This is to ensure we have complete data to evaluate the impact of knowledge and perceived risk on diet and physical activity behaviors.

- Please be assured that your responses will be confidential. Data from this survey will only be reported in summary form; individual responses will not be identified.

- The survey completion bar at the top of each page indicates the percentage of questions completed.

If you have any questions, please email us at kblake@hsc.wvu.edu or call 304-293-2306.

Thank you again for your participation in this survey! 


\section{Coronary Heart Disease, Diet and Physical Activity}

\section{Dietary Behavior}

UC Davis Food Behavior Checklist (Townsend et al, 2008)

These questions are about the ways you plan and fix foods. Think about how you usually do things. Choose one answer for each question.

\section{Do you eat fruits or vegetables as snacks?}

No

$\bigcirc$ Yes, sometimes

$\bigcirc$ Yes, often

$\bigcirc$ Yes, everyday

2. Do you drink fruit drinks, sport drinks, or punch?

No

Yes, sometimes

Yes, often

Yes, everyday

\section{Do you drink regular soda?}

No

Yes, sometimes

Yes, often

$\bigcirc$ Yes, everyday

\section{Do you drink milk?}

No

$\bigcirc$ Yes, sometimes

Yes, often

Yes, everyday

\section{Did you drink milk or use milk on cereal during the past week?}

Yes

No 


\section{Coronary Heart Disease, Diet and Physical Activity}

6. Did you have citrus fruit or citrus juice during the past week?

$\bigcirc$ Yes

$\bigcirc$ No

7. How many servings of fruit do you eat each day?

8. Do you eat more than one kind of fruit each day?

No

$\bigcirc$ Yes, sometimes

$\bigcirc$ Yes, often

Yes, always

9. Do you eat more than one kind of vegetable each day?

$\bigcirc$ No

Yes, sometimes

$\bigcirc$ Yes, often

$\bigcirc$ Yes, always

10. How many servings of vegetables do you eat each day?

11. Do you take the skin off chicken?

No

$\bigcirc$ Yes, sometimes

$\bigcirc$ Yes, often

$\bigcirc$ Yes, always

12. Did you have fish during the past week?

$\int$ Yes

$\bigcirc$ No 
13. Do you eat two or more vegetables at your main meal?

No

Yes, sometimes

$\bigcirc$ Yes, often

$\bigcirc$ Yes, everyday

14. When shopping, do you use the "Nutrition Facts" on the food label to choose food?

No

$\bigcirc$ Yes, sometimes

$\bigcirc$ Yes, often

$\bigcirc$ Yes, always

15. Do you run out of food before the end of the month?

No

$\bigcirc$ Yes, sometimes

Yes, often

Yes, always

16. How would you rate your eating habits?
1=Poor
$\bigcirc_{2}$
$\mathrm{O}_{3}$
4=Fair
$\bigcirc$
O
$7=$ Good
O
$\bigcirc 9$
$10=$ Excellent 


\section{Coronary Heart Disease, Diet and Physical Activity}

\section{Physical Activity Behaviors}

Behavioral Risk Factor Surveillance System Survey (CDC, 2009)

We are interested in two types of physical activity - vigorous and moderate. Vigorous activites cause large increases in breathing or heart rate while moderate activities cause small increases in breathing or heart rate.

1. Now, thinking about the moderate activities you do in a usual week, do you do moderate activities for at least $\mathbf{1 0}$ minutes at a time, such as brisk walking, bicycling, vacuuming, gardening, or anything else that causes some increase in breathing or heart rate?

$\bigodot_{\text {No }}$ Yes 


\section{8. "Yes" to Moderate Physical Activity}

1. How many days per week do you do these moderate activities for at least 10 minutes at a time?
O
$\mathrm{O}_{2}$
$\mathrm{O}_{3}$
4
$\bigcirc_{5}$
$\bigcirc_{6}$
$\bigcirc_{7}$
Don't know / Not sure

2. On days when you do moderate activities for at least $\mathbf{1 0}$ minutes at a time, how much total time per day (in minutes) do you spend doing these activities? 


\section{Coronary Heart Disease, Diet and Physical Activity}

\section{Physical Activity Behaviors - Vigorous Activity}

Behavioral Risk Factor Surveillance System Survey (CDC, 2009)

1. Now, thinking about the vigorous activities you do in a usual week, do you do vigorous activites for at least $\mathbf{1 0}$ minutes at a time, such as running, aerobics, heavy yard work, or anything else that causes large increases in breathing or heart rate?

Yes

No

Don't know / Not sure 


\section{0. "Yes" to Vigorous Physical Activity}

1. How many days per week do you do these vigorous activities for at least 10 minutes at a time?
$\bigcirc 1$
$\mathrm{O}_{2}$
$\mathrm{O}_{3}$
$\bigcirc^{4}$
$\bigcirc$
$\mathrm{O}^{6}$
$\bigcirc$
Don't know / Not sure

2. On days when you do vigorous activities for at least 10 minutes at a time, how much total time per day (in minutes) do you spend doing these activities? 


\section{Coronary Heart Disease, Diet and Physical Activity}

\section{Coronary Heart Disease Knowledge}

Modified Coronary Heart Disease Knowledge Test (Smith et al, 1991)

1. A risk factor of coronary heart disease that you cannot change is
Lack of exercise
Peredity
Obesity
Stress

2. The single most preventable cause of death and disease in the United States is

Drug abuse

Environmental pollution

Poor nutrition

Smoking

3. Which of the following blood fats is thought to lower risk of coronary heart disease?

High-density lipoprotein

Low-density lipoprotein

Cholesterol

Triglycerides

4. The major cigarette-smoke contributors to the development of coronary heart disease are carbon monoxide and

Carbon dioxide

Coal tar

$\bigcirc$ Nicotine

$\bigcirc$ Dioxin

5. Which of the following is a direct benefit of exercise?

Reduced work of heart for a given workload

$\bigcirc$ Reduction of fat cells

$\bigcirc$ Enlarged lungs

Increased resting heart rate 
6. The best type of physical activity to maintain cardiovascular fitness is exercise.

Anaerobic

$\bigcirc$ Aerobic

$\bigcirc$ Non-aerobic

Dynamic

\section{Warming up}

Allows the body to return to normal functioning

Assists in reducing strain on the heart

$\bigcirc$ Results from increased perspiration

$\bigcirc$ Allows muscles to become firmer

\section{Which of the following is a sign of overexertion?}

A perceived exertion rating of 14 on a 20 -point scale

A heart rate of 100 beats per minute upon finishing a workout

$\bigcirc$ Persistent tiredness the day following exercise

$\int$ Shortness of breath upon finishing an exercise routine

\section{The symptoms of angina pectoris after physical exertion include}

Numbness of the legs

$\bigcirc$ Prolonged, severe chest pain

$\bigcirc$ Pain in the right arm

$\bigcirc$ Temporary chest pain

\section{Most Americans could benefit from diets}

Lower in complex carbohydrates and higher in protein

Lower in complex carbohydrates and lower in fat

Higher in complex carbohydrates and higher in fat

Higher in complex carbohydrates and lower in fat 
11. The type of fat that is solid at room temperature is called

$\bigcirc$ Saturated

Monosaturated

Polyunsaturated

Unsaturated

\section{A reasonable weight-loss goal is}

O 1 pound a day

2 pounds a day

○ pounds a week

○ pounds a week

\section{Stress may be described as}

Abnormal responsive reactions to change

The pattern-specific response of the body to any disturbance

The non-specific response of the body to any demand

The responses of the body to an unpleasant situation

\section{What is the relationship between stress and atherosclerosis?}

Atherosclerosis is the major casue of stress

Elasticity of the arterial walls will increase with atherosclerosis

A single stress, by itself, is both necessary and sufficient to cause atherosclerosis

The stress response causes cholesterol to be circulated in the blood stream to aid in muscle activity

\section{The stress response begins with}

Adaptation to the stressor

Exposure to the stressor

Identification of the stressor

Physical symptoms of stress 
16. Which of the following is a physiologic response to stress?

Feeling hungry

Slower heart rate

Decreased metabolism

Increased blood pressure

\section{To successfully control a new stressful environment one must}

Seek assistance

Alleviate the cause

Adapt to the situation

Change to a pleasant environment

18. The condition in which the heart rate slows, blood pressure decreases and muscle tension reduces is known as

Stress

$\bigcirc$ Relaxation response

Concentration

Alpha activity

19. Which of the following is an element of relaxation?

Breathing slowly and rhythmically

Control of alpha waves

Concentrating on muscle tension

$\bigcirc$ Planned recreational activities

20. Meditation is used during

Transactional analysis

$\bigcirc$ Relaxation training

$\bigcirc$ Time management

General adaptation syndrome 


\section{Coronary Heart Disease, Diet and Physical Activity}

\section{Perception of Risk of Heart Disease}

Perception of Risk of Heart Disease Scale (Ammouri and Neuberger, 2008)

\section{Please indicate how much you agree or disagree with the following statements.}

There is a possibility that I have heart disease.
There is a good chance I will get heart disease during the next 10 years.
A person who gets heart disease has no chance of being cured.
I have a high chance of getting heart disease because of my past behaviors
I feel sure that I will get heart disease.
It is likely that I will get heart disease.
I am at risk for getting heart disease.
It is possible that I will get heart disease.
I am not doing anything now that is unhealthy to my heart.

\section{Please indicate how much you agree or disagree with the following statements.}

I am too young to have heart disease.

People like me do not get heart disease.

I am very healthy so my body can fight off heart disease.

I am not worried that I might get heart disease.

People my age are too young to get heart disease.

People my age do not get heart disease.

My lifestyle habits do not put me at risk for heart disease.

No matter what I do, if I am going to get heart disease, I will get it.

People who don't get heart disease are just plain lucky.

The causes of heart disease are unknown.

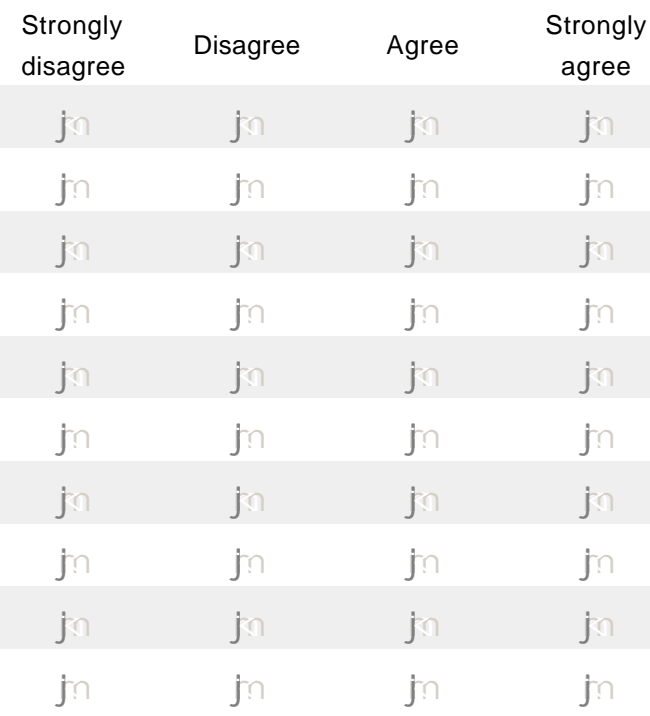




\section{Coronary Heart Disease, Diet and Physical Activity}

\section{Perceived Seriousness of CHD}

Perceived Seriousness of Coronary Heart Disease (Katz et al, 2009)

1. To what extent do you agree or disagree with the following statements:

The thought of having coronary heart disease scares me.
If I had coronary heart disease, I would be disabled or would die.
It would be very costly if I got coronary heart disease.
It would be very serious if I got coronary heart disease.




\section{Coronary Heart Disease, Diet and Physical Activity}

\section{Perceived Benefits}

Benefits Scale (Murdaugh and Verran, 1987)

Copyright 2002 C. Murdaugh

1. The following questions ask about your beliefs. Please indicate how strongly you agree or disagree to each statement. There are no right or wrong answers as the statements measure beliefs. Please answer according to your actual beliefs and not how you think you should believe or how you think others want you to answer.

Regular exercise may decrease my chances of a heart attack.
Even if I eat a low fat diet I will not reduce my chance of heart disease.
Regular exercise helps reduce tension and stress.
Regular exercise can help me maintain a normal weight.
Research now shows that it is probably okay to eat a high fat diet.
Regular exercise can make me feel I have more energy.
If I stopped smoking I will lower my chance of heart disease.
If I have smoked lessen my chance of high blood pressure.




\section{Coronary Heart Disease, Diet and Physical Activity}

\section{Perceived Barriers}

Barriers Scale (Murdaugh and Verran, 1987)

Copyright 2002 C. Murdaugh

1. The following questions ask about your beliefs. Please indicate how strongly you agree or disagree to each statement. There are no right or wrong answers as the statements measure beliefs. Please answer according to your actual beliefs and not how you think you should believe or how you think others want you to answer.

Family can often get in the way when I want to make healthy changes.
I enjoy eating too much to change my diet.
Even though it is a good idea, I don't take time to exercise.
A low fat diet takes too much time to prepare.
If I feel healthy there is no need to change my diet.
Iabits.
I do nom not not diets are too unappetizing to follow for long periods.
I am too busy with my family to exercise regularly.
If I stopped smoking I will gain weight, so I may as well smoke.
It will be too stressful for me to stop smoking.




\section{Coronary Heart Disease, Diet and Physical Activity}

\section{Self-Efficacy for Diet}

Eating Habits Confidence Survey (Sallis et al, 1998)

Below is a list of things people might do while trying to change their eating habits. We are mainly interested in salt and fat intake, rather than weight reduction. Whether you are trying to change your eating habits or not, please rate on a scale of 1 - 5 ( $1=$ I know I cannot and 5 = I know I can) how confident you are that you could really motivate yourself to do things like these consistently, for at least six months.

\section{Rate your confidence on a scale of 1 to 5 .} tense.

Stick to your low fat, low salt foods when there is high fat, high salt food readily available at a party.

Stick to your low fat, low salt foods when dining with friends or coworkers.

Stick to your low fat, low salt foods when the only snack close by is available from a vending machine.

Stick to your low fat, low salt foods when you are alone, and there is no one to watch you.

Eat smaller portions at dinner.

Cook smaller portions so there are no leftovers.

Eat lunch as your main meal of the day, rather than dinner.

Eat smaller portions of food at a party.

Eat salads for lunch.

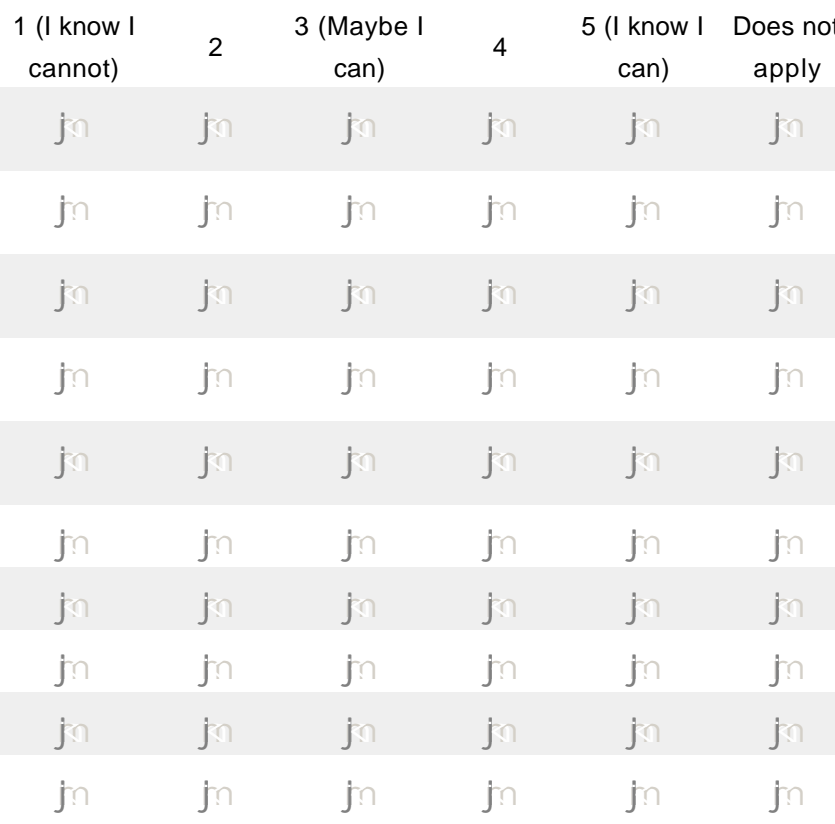

\section{Rate your confidence on a scale of 1 to 5 .}

Add less salt than the recipe calls for

Eat unsalted peanuts, chips, crackers, and pretzles.

Avoid adding salt at the table.

Eat unsalted, unbuttered popcorn.

Keep the salt shaker off the kitchen table.

Eat meatless (vegetarian) entrees for dinner.

Subsitute low or non-fat milk for whole milk at dinner.

Cut down on gravies and cream sauce.

Eat poultry and fish instead of red meat at dinner

Avoid ordering red meat (beef, pork, ham, lamb) at restaurants.

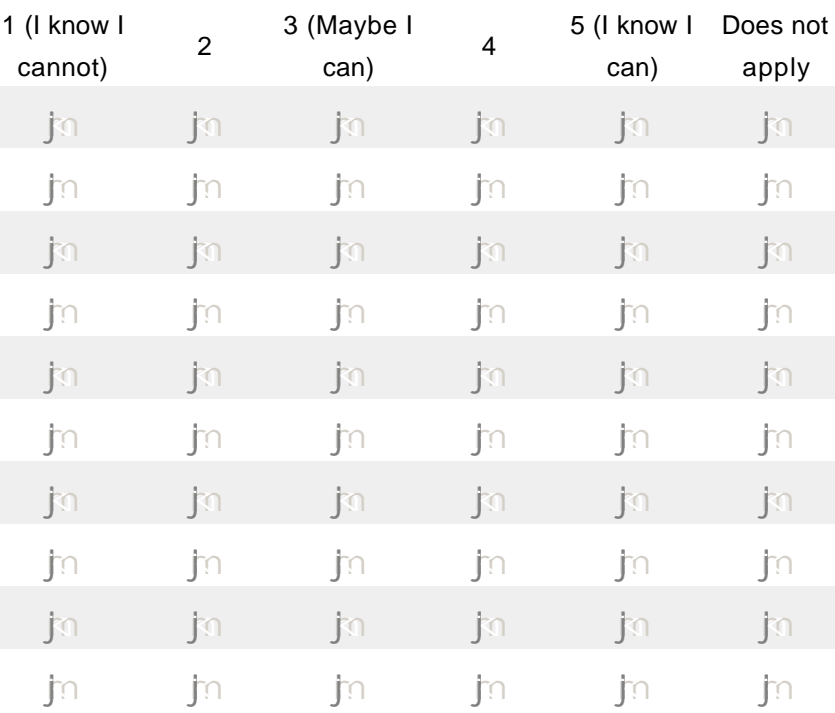




\section{Self-Efficacy for Exercise}

Exercise Confidence Survey (Sallis et al, 1998)

Below is a list of things people might do while trying to increase or continue regular exercise. We are interested in exercises like running, swimming, brisk walking, bicycle riding, or aerobics classes. Whether you exercise or not, please rate on a scale of 1 - 5 ( $1=1$ know I cannot and 5 = I know I can) how confident you are that you could really motivate yourself to do things like these consistently, for at least six months.

\section{Rate your confidence on a scale of 1 to 5 .}

Get up early, even on weekends, to exercise.

Stick to your exercise program after a long, tiring day at work.

Exercise even though you are feeling depressed.

Set aside time for a physical activity program; that is, walking, jogging, swimming, biking, or other continuous activities for at least 30 minutes, 3 times per week.

Continue to exercise with others even though they seem too fast or too slow for you.

Stick to your exercise program when undergoing a stressful life change (e.g., divorce, death in the family, moving).

Attend a party only after exercising.

Stick to your exercise program when your family is demanding more time from you.

Stick to your exercise program when you have household chores to attend to.

Stick to your exercise program even when you have excessive demands at work.

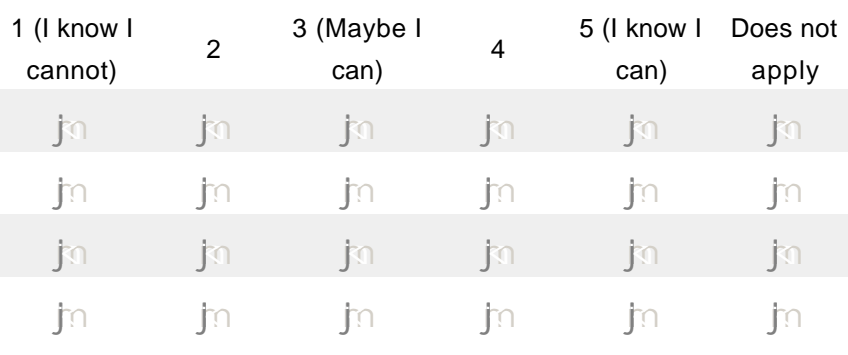

Stick to your exercise program when social obligations are very time consuming.

Read or study less in order to exercise more.

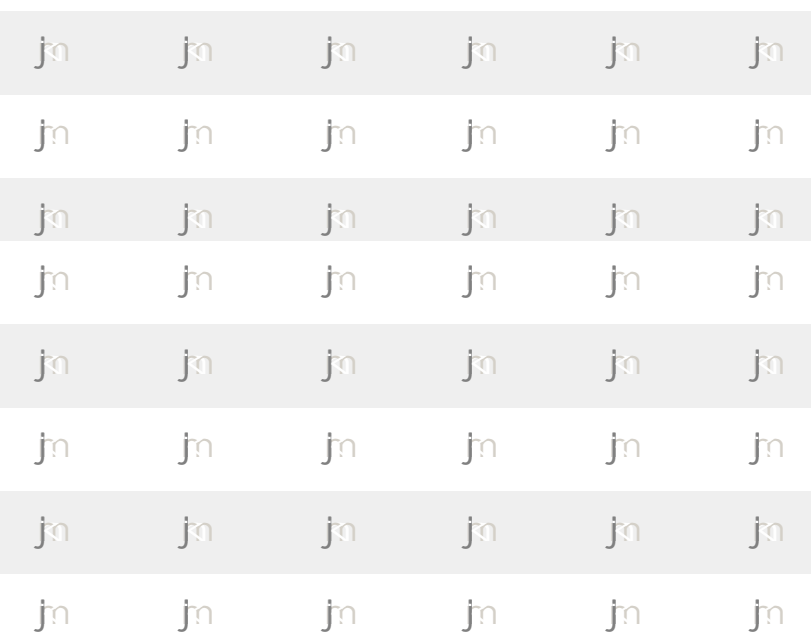




\section{Coronary Heart Disease, Diet and Physical Activity}

\section{Cues to Action}

1. Has your health care provider recommended that you change your diet to be healthier?
$\bigcirc$ Yes
$\bigcirc$ No

2. Has your health care provider recommended that you increase your level of physical activity to be healthier?
$\bigcirc$ Yes
$\bigcirc$ No 


\section{Demographics}

1. What is your gender?

$\bigcirc$ Male

Pemale

\section{What is your date of birth?}

$\begin{array}{lll} & M M \quad D D \quad \text { YYYY } \\ \text { Enter your date of birth in MM/DD/YYYY } \square / \square / \square\end{array}$

format

\section{What is your marital status?}

Single (never married)

Currently married

Separated, divorced or widowed

\section{What is your highest level of education?}

Less than high school

High school

Some college or college degree

5. What is your total annual household income?

Less than $\$ 20,000$ per year

$\$ 20,000$ to $\$ 69,999$ per year

$\$ 70,000$ to $\$ 139,999$ per year

$\$ 140,000$ or more per year

6. Approximately how much do you weigh without shoes (in pounds)?

7. Approximately how tall are you without shoes?

Feet

Inches 


\section{Coronary Heart Disease, Diet and Physical Activity}

\section{Request a Summary of Results}

1. Would you like to receive a summary of the results of the study after it is completed?

$\bigcirc$ Yes, please mail a summary to me

Yes, please e-mail a summary to me

No thanks 


\section{Coronary Heart Disease, Diet and Physical Activity}

\section{Exit the Survey}

Thank you for participating in our study! 


\section{Appendix B: Delay Discounting Procedure}

\section{Part 1 - Monetary Rewards}

Conducted using Labview

What follows are screen shots of the survey. The participant will read each box and click on the response option of his or her choice.

\section{Introduction:}

Thank you for agreeing to participate. This study involves making choices between two imaginary rewards. In the first exercise, the rewards are in terms of money received now or sometime in the future. In the second exercise, the rewards are in terms of a treatment that gives you full health, and may take effect right away, or may take effect sometime in the future.

You will choose the option you prefer.

\section{Money trial instructions:}

On the following screens, you will be given two choices. They will have different dollar values. One choice will be to receive a smaller dollar amount now; the other choice will be to receive a larger dollar amount in the future. Imagine that you are given the option to choose one or the other, and click on the box with the choice you would prefer. Keep in mind that the rewards are imaginary and you will not actually receive them.

Here are a few trial choices to familiarize you with the task. 


\section{Practice trials:}

Imagine that you have a choice between two dollar amounts: one you would receive now and one you would receive later.

Which of the following choices would you prefer?
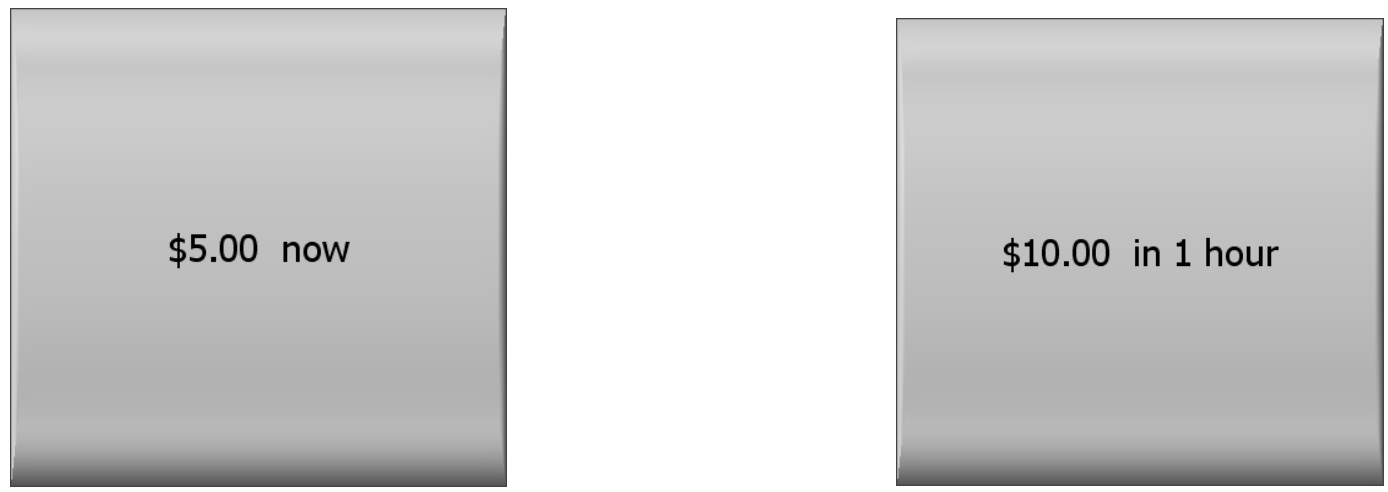

(Participant would be presented with two such practice trials) 
Be sure to read each choice very carefully. The "now" reward may be on the left OR the right side of the screen. The time you have to wait for the reward will also change.

You cannot change your choice after it has been clicked.

[next screen]

\section{Do you understand the task?}

If so, please click OK to continue. If you do not understand, please stop now and ask the researcher for further assistance.

\section{OK}


Imagine that you have a choice between two dollar amounts: one you would receive now and one you would receive later.

Which of the following choices would you prefer?
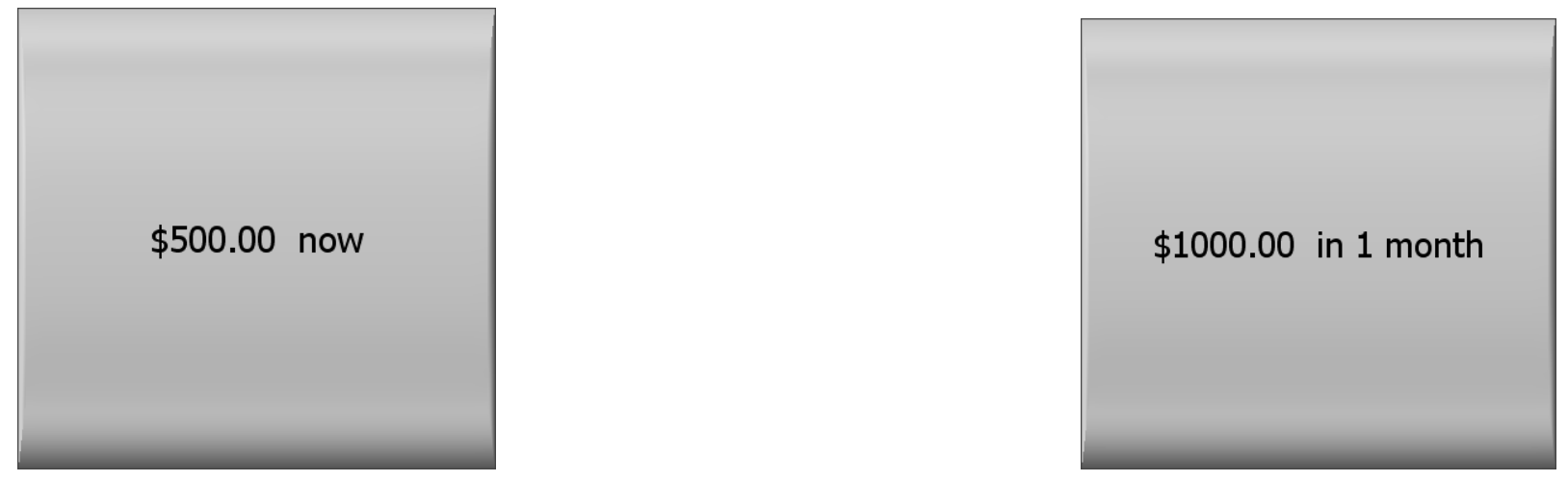

The participant will be presented with 6 different choices at each of 6 delays, for a total of 36 choices for monetary rewards. The amounts offered in each subsequent choice will vary based on the participant's answer to the preceding question. All rewards are hypothetical. The side of presentation of the button representing the immediate reward (right- or left-hand side) is chosen at random. An example interview might go as follows:

Practice Trial:

$\$ 5.00$ now or $\$ 10.00$ in 1 hour

$\$ 7.50$ now or $\$ 10.00$ in 1 hour

Delay $=1$ month

$\$ 500.00$ now or $\$ 1000.00$ in 1 month

$\$ 750.00$ now or $\$ 1000.00$ in 1 month

$\$ 625.00$ now or $\$ 1000.00$ in 1 month 
$\$ 687.50$ now or $\$ 1000.00$ in 1 month $\$ 718.75$ now or $\$ 1000.00$ in 1 month $\$ 703.12$ now or $\$ 1000.00$ in 1 month

Delay $=1$ year

$\$ 500.00$ now or $\$ 1000.00$ in 1 year $\$ 750.00$ now or $\$ 1000.00$ in 1 year $\$ 625.00$ now or $\$ 1000.00$ in 1 year $\$ 562.50$ now or $\$ 1000.00$ in 1 year $\$ 593.75$ now or $\$ 1000.00$ in 1 year $\$ 609.37$ now or $\$ 1000.00$ in 1 year

Delay $=2$ years

$\$ 500.00$ now or $\$ 1000.00$ in 2 years $\$ 250.00$ now or $\$ 1000.00$ in 2 years $\$ 375.00$ now or $\$ 1000.00$ in 2 years $\$ 437.50$ now or $\$ 1000.00$ in 2 years $\$ 468.75$ now or $\$ 1000.00$ in 2 years $\$ 484.37$ now or $\$ 1000.00$ in 2 years

Delay $=5$ years

$\$ 500.00$ now or $\$ 1000.00$ in 5 years $\$ 250.00$ now or $\$ 1000.00$ in 5 years $\$ 375.00$ now or $\$ 1000.00$ in 5 years $\$ 437.50$ now or $\$ 1000.00$ in 5 years 
$\$ 406.25$ now or $\$ 1000.00$ in 5 years $\$ 390.62$ now or $\$ 1000.00$ in 5 years

Delay $=10$ years

$\$ 500.00$ now or $\$ 1000.00$ in 10 years $\$ 250.00$ now or $\$ 1000.00$ in 10 years $\$ 125.00$ now or $\$ 1000.00$ in 10 years $\$ 62.50$ now or $\$ 1000.00$ in 10 years $\$ 31.25$ now or $\$ 1000.00$ in 10 years $\$ 15.62$ now or $\$ 1000.00$ in 10 years

Delay $=20$ years $\$ 500.00$ now or $\$ 1000.00$ in 20 years $\$ 750.00$ now or $\$ 1000.00$ in 20 years $\$ 875.00$ now or $\$ 1000.00$ in 20 years $\$ 812.50$ now or $\$ 1000.00$ in 20 years $\$ 781.25$ now or $\$ 1000.00$ in 20 years $\$ 765.62$ now or $\$ 1000.00$ in 20 years 


\section{Appendix C: Delay Discounting Procedure \\ Part 2 - Health Rewards}

\section{Health trial instructions:}

On the next screen, you will see a health scenario. Read the scenario and imagine yourself in that condition.

On the following screens, you will be given two choices of treatments for this imaginary health condition.

Both treatments return you to full health. One treatment will return you to full health starting now. The other treatment will return you to full health for a longer period of time - but will not take effect until sometime in the future.

Click on the box with the choice you would prefer.

[next screen]

Imagine that for the past two years your state of health has fit this description:

Because of your doctor's instructions, you need to take multiple medications each day. To monitor the effects of these medications, you must get blood drawn at your doctor's office at least once per month. You must also be very careful about what you eat and drink. You have to limit the amount of salt you eat and fluids you drink. You often have swollen ankles. You sometimes have chest pain, for which you must take nitroglycerin tablets. You have to visit the bathroom often to urinate. You often feel tired and cannot walk more than 20 feet without getting short of breath. You often do not have the energy for sexual activity. Sometimes, you feel depressed about your health. 


\section{Practice trials:}

Imagine that you have a choice between two treatments which return you to full health for different amounts of time and will take effect starting now or at some point in the future.

Which of the following choices would you prefer?
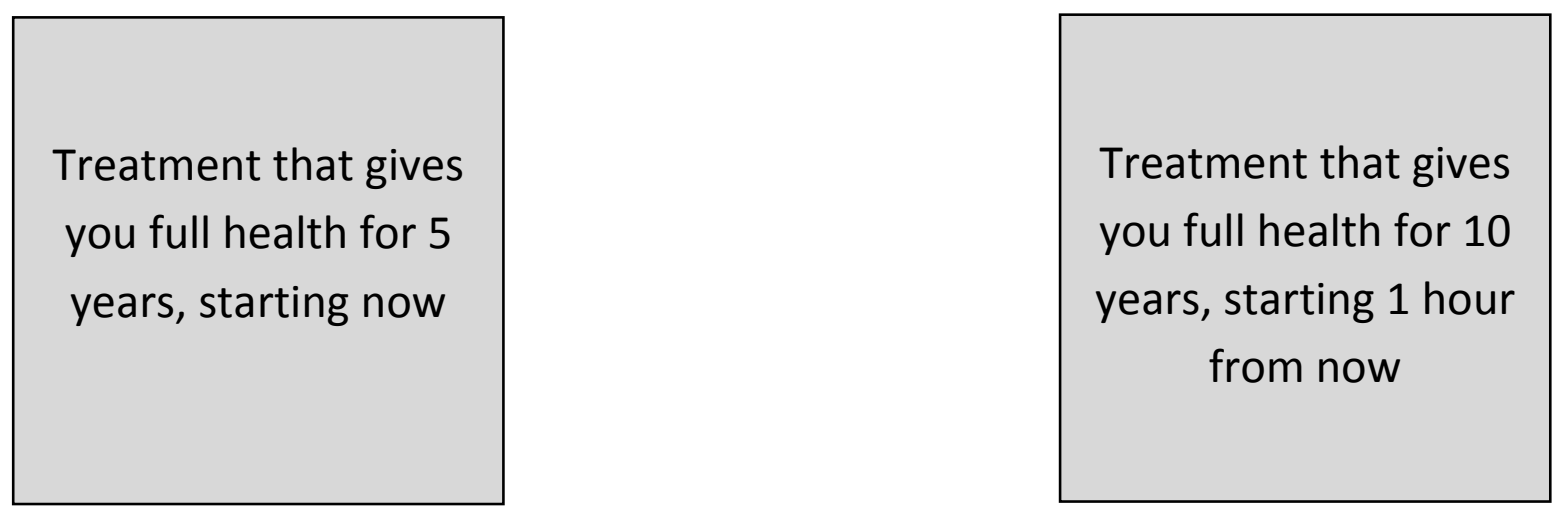

(Participant would be presented with two such practice trials)

Be sure to read each choice very carefully. The "now" treatment may be on the left OR the right side of the screen. The time you have to wait for the treatment to take effect will also change.

You cannot change your choice after it has been clicked. 
Do you understand the task?

If so, please click OK to continue. If you do not understand, please stop now and ask the researcher for further assistance.

\section{OK}


Imagine that you have a choice between two treatments which return you to full health for different amounts of time and will take effect starting now or at some point in the future.

Which of the following choices would you prefer?
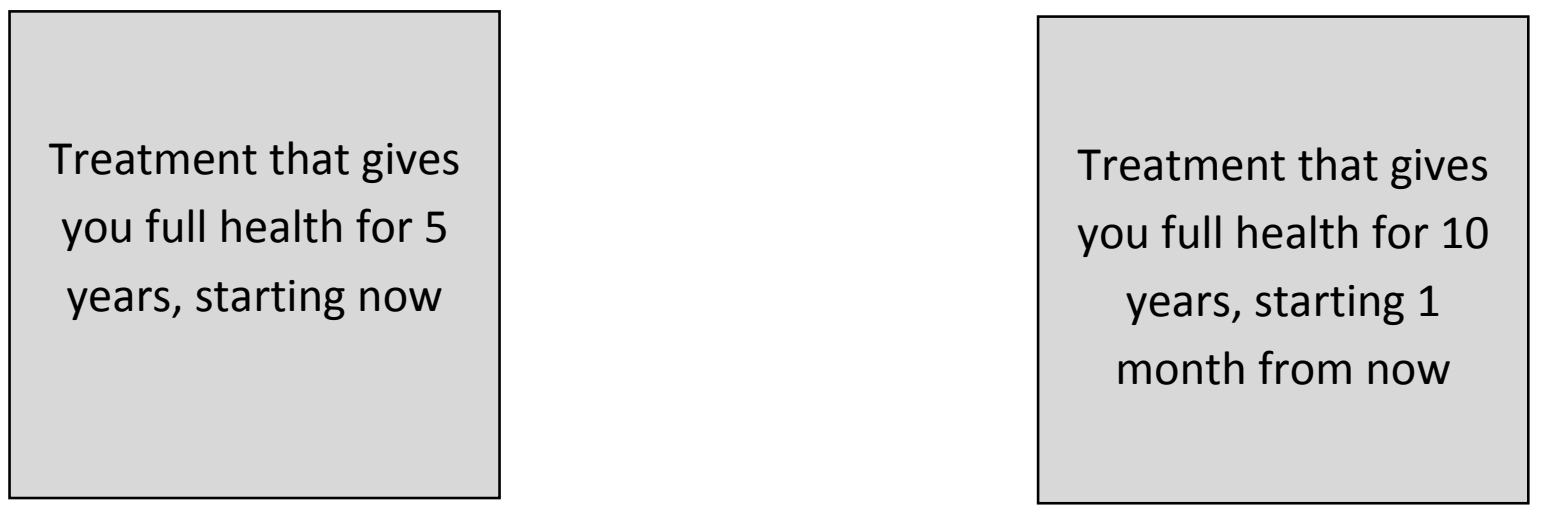

The participant would be presented with 6 different choices at each of 6 delays, for a total of 36 choices for health rewards. The amounts offered in each subsequent choice will vary based on the participant's answer to the preceding question. All rewards are hypothetical. The side of presentation of the button representing the immediate reward (right- or left-hand side) is chosen at random. An example interview might go as follows:

Practice Trial: (choices are in terms of length of time in full health)

5 years starting now or 10 years starting 1 hour from now

2 years and 6 months starting now or 10 years starting 1 hour from now

Delay $=1$ month (choices are in terms of length of time in full health) 
5 years starting now or 10 years starting 1 month from now 7 years and 6 months starting now or 10 years starting 1 month from now 8 years and 9 months starting now or 10 years starting 1 month from now 9 years and 4 months starting now or 10 years starting 1 month from now 9 years and 1 month starting now or 10 years starting 1 month from now 8 years and 11 months starting now or 10 years starting 1 month from now

Delay $=1$ year (choices are in terms of length of time in full health)

5 years starting now or 10 years starting 1 year from now

2 years and 6 months starting now or 10 years starting 1 year from now

1 year and 3 months starting now or 10 years starting 1 year from now 1 year and 10 months starting now or 10 years starting 1 year from now 2 years and 2 months starting now or 10 years starting 1 year from now 2 years and 4 months starting now or 10 years starting 1 year from now

Delay $=2$ years (choices are in terms of length of time in full health)

5 years starting now or 10 years starting 2 years from now 2 years and 6 months starting now or 10 years starting 2 years from now 3 years and 9 months starting now or 10 years starting 2 years from now 4 years and 4 months starting now or 10 years starting 2 years from now 4 years and 8 months starting now or 10 years starting 2 years from now 4 years and 10 months starting now or 10 years starting 2 years from now

Delay $=5$ years (choices are in terms of length of time in full health) 
5 years starting now or 10 years starting 5 years from now

2 years and 6 months starting now or 10 years starting 5 years from now 3 years and 9 months starting now or 10 years starting 5 years from now 4 years and 4 months starting now or 10 years starting 5 years from now 4 years and 8 months starting now or 10 years starting 5 years from now 4 years and 6 months starting now or 10 years starting 5 years from now

Delay $=10$ years (choices are in terms of length of time in full health)

5 years starting now or 10 years starting 10 years from now

7 years and 6 months starting now or 10 years starting 10 years from now 8 years and 9 months starting now or 10 years starting 10 years from now 9 years and 4 months starting now or 10 years starting 10 years from now 9 years and 8 months starting now or 10 years starting 10 years from now 9 years and 6 months starting now or 10 years starting 10 years from now

Delay $=20$ years (choices are in terms of length of time in full health)

5 years starting now or 10 years starting 20 years from now

7 years and 6 months starting now or 10 years starting 20 years from now 8 years and 9 months starting now or 10 years starting 20 years from now 8 years and 1 month starting now or 10 years starting 20 years from now 7 years and 10 months starting now or 10 years starting 20 years from now 8 years starting now or 10 years starting 20 years from now 